\title{
Metadados para reconciliação de transações em bancos de dados autônomos
}

Gustavo Luiz Duarte

\author{
DISSERTAÇÃO APRESENTADA \\ $\mathrm{AO}$ \\ Instituto DE MATEMÁtica E EstatísticA \\ DA \\ UNIVERSIDADE DE SÃO PAUlO \\ PARA \\ OBTENÇÃO DO TÍTULO \\ $\mathrm{DE}$ \\ Mestre EM Cî̂NCIAS
}

Programa: Ciência da Computação

Orientador: Prof. Dr. João Eduardo Ferreira

Durante o desenvolvimento deste trabalho o autor recebeu auxílio financeiro do Instituto Virtual Microsoft Research-FAPESP.

São Paulo, março de 2012 


\section{Metadados para reconciliação de transações em bancos de dados autônomos}

Esta versão da dissertação contém as correções e alterações sugeridas pela Comissão Julgadora durante a defesa da versão original do trabalho, realizada em 19/12/2011. Uma cópia da versão original está disponível no

Instituto de Matemática e Estatística da Universidade de São Paulo.

Comissão Julgadora:

- Prof. Dr. João Eduardo Ferreira (orientador) - IME-USP

- Prof. Dr. Fabio Kon - IME-USP

- Prof. Dr. Luiz Camolesi Junior - UNICAMP 


\section{Agradecimentos}

Agradeço à minha família por todo o apoio, sem os quais jamais chegaria tão longe em minha vida e onde encontrei meus exemplos de integridade e perseverança.

Agradeço aos Professores João Eduardo Ferreira e Fabio Kon pela orientação e pela paciência durante esses anos de trabalho.

Agradeço também aos profissionais do Centro de Saúde Escola do Butantã que foram bastante prestativos e possibilitaram o caráter prático deste trabalho.

Finalmente, agradeço também aos meus amigos de laboratório que estiveram presentes e tanto me ajudaram no decorrer do mestrado. Obrigado Alvaro Aliaga, Beraldo Leal, Carlos Eduardo dos Santos, Edwin Triana, Paulo Meirelles, Raphael Cóbe, Vinicius Pinheiro, Yanik Ngoko e tantos outros com quem interagi durante esses anos na USP. A sinergia criada por esse grupo teve papel fundamental na conclusão deste trabalho. 


\section{Resumo}

DUARTE, G. L. Metadados para reconciliação de transações em bancos de dados autônomos. 2012. 83 f. Dissertação (Mestrado) - Instituto de Matemática e Estatística, Universidade de São Paulo, São Paulo, 2012.

O uso de técnicas de replicação de dados em dispositivos móveis permite que uma aplicação móvel compartilhe dados com um servidor e possa atuar sobre tais dados durante períodos de desconexão. Embora essa característica seja fundamental em diversos domínios, a reconciliação das transações que foram aplicadas sobre a réplica móvel dos dados apresenta-se como um desafio a ser superado. O uso de bloqueios apresenta-se impraticável em determinados domínios de aplicação. Por outro lado, ao permitir a execução de operações de escrita em diversas réplicas sem uma sincronização a priori, o sistema se torna suscetível a conflitos de atualização, sendo necessário a implementação de um mecanismo de resolução de conflitos. Resolver conflitos é uma tarefa complexa e propensa a erros, em especial nos casos em que há a necessidade de intervenção humana. Diante desse cenário, foi desenvolvido um modelo para controle de transações em bancos de dados autônomos que faz uso de metadados e multiversão de banco de dados de forma a permitir a auditoria e retificação de resoluções de conflitos. Isso torna a resolução de conflitos uma operação não destrutiva, reduzindo, assim, o impacto de uma resolução de conflito incorreta. Neste trabalho é apresentado também um arcabouço para reconciliação de transações que implementa o modelo proposto. Como estudo de caso, o arcabouço desenvolvido foi utilizado para implementar a integração entre dois sistemas reais que possuem necessidades de replicação de dados e atualizações desconectadas.

Palavras-chave: reconciliação de transações, bancos de dados autônomos, bancos de dados móveis, replicação de dados, versionamento, conflitos. 


\section{Abstract}

DUARTE, G. L. Metadata for transaction reconciliation in autonomous databases. 2012. 83 f. Dissertação (Mestrado) - Instituto de Matemática e Estatística, Universidade de São Paulo, São Paulo, 2012.

The use of data replication techniques on mobile devices allows a mobile application to share data with a server and to work on such data while disconnected. While this feature is crucial in some application domains, the reconciliation of transactions applied to the mobile replica of data proves to be challenging. The use of locking is not feasible in some application domains. However, allowing write operations to be applied on several replicas without a priori synchronization makes the system susceptible to update conflicts, requiring a conflict resolution mechanism. Conflict resolution is a complex and error prone task, specially when human intervention is involved. Given this scenario, we developed a transactions control model for autonomous databases that uses metadata and database versioning to provide auditing and rectification of conflict resolutions. This turns the conflict resolution into a nondestructive operation, thus reducing the impact of an incorrect conflict resolution. This work presents also a framework for transaction reconciliation that implements the proposed model. As a case study, the developed framework was used to integrate two real systems that needed data replication and disconnected updates.

Keywords: transaction reconciliation, autonomous databases, mobile database, data replication, versioning, conflicts. 


\section{Sumário}

$\begin{array}{ll}\text { Lista de Figuras } & \text { ix }\end{array}$

Lista de Tabelas $\quad$ xi

1 Introdução $\quad 1$

1.1 Motivação . . . . . . . . . . . . . . . . . . . . . . . . 1

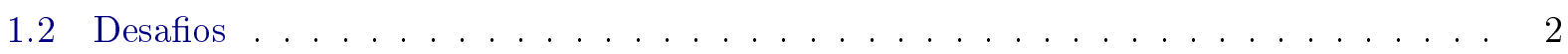

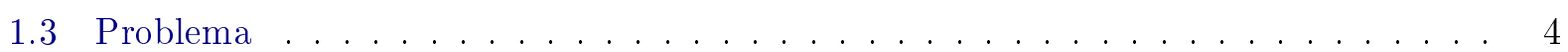

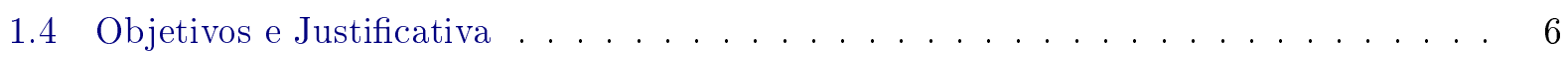

1.5 Estrutura do Trabalho . . . . . . . . . . . . . . . 7

2 Revisão bibliográfica $\quad 9$

2.1 Controle de concorrência e replicação de dados . . . . . . . . . . . . . . . 9

2.1.1 Controle de concorrência otimista . . . . . . . . . . . . . . . . . . . . 10

2.2 Resolução de Conflitos . . . . . . . . . . . . . . . . . . . . . . 10

2.2.1 Resolução de conflitos de forma manual . . . . . . . . . . . . . . . . . . 10

2.2.2 Resolução de conflitos por aborto . . . . . . . . . . . . . . . . . . . 11

2.2 .3 Resolução de conflitos incremental . . . . . . . . . . . . . . . . . . 11

2.2 .4 Resolução de conflitos por junção . . . . . . . . . . . . . . . . . . . 11

2.2.5 Resolução de conflitos por prioridade . . . . . . . . . . . . . . . . . 11

2.2.6 Resolução de conflitos por versionamento . . . . . . . . . . . . . . . . . . 12

2.3 Versionamento de dados em bancos de dados relacionais . . . . . . . . . . . . . . . 12

2.3 .1 Esquema único . . . . . . . . . . . . . . . . . . . . . . 12

2.3 .2 Espelhamento . . . . . . . . . . . . . . . . . . . . . 13

2.3 .3 Tabela polimórfica . . . . . . . . . . . . . . . . . 13

2.4 Sincronização de bancos de dados heterogêneos . . . . . . . . . . . . . . . . . . 14

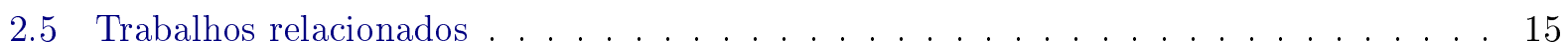

3 Mecanismo proposto para reconciliação de transações $\quad 19$

3.1 Processo de Separação . . . . . . . . . . . . . . . . . . . . . . . . 20

3.2 Processo de Integração . . . . . . . . . . . . . . . . . . . . . . 21

3.3 Auditoria e Retificação de Conflitos . . . . . . . . . . . . . . . . . . . . . 21

3.4 Arcabouço para Reconciliação de Transações . . . . . . . . . . . . . . . . . 22

3.4 .1 Implementação do processo de separação . . . . . . . . . . . . . . . . . . . . . . . . . . . . . . 23

3.4 .2 Implementação do processo de integração . . . . . . . . . . . . . . . . . . . 23 
4 Estudo de caso: Borboleta e SAGUISaúde $\quad 29$

4.1 Registro Eletrônico de Saúde . . . . . . . . . . . . . . . . . . . . . 29

4.2 O Sistema SAGUISaúde . . . . . . . . . . . . . . . . . . . . 30

4.3 O Sistema Borboleta . . . . . . . . . . . . . . . . . . . . 32

4.4 Compartilhamento de dados . . . . . . . . . . . . . . . . . . 34

4.4 .1 Necessidade de replicação de dados . . . . . . . . . . . . . . . . . . . . 34

4.5 Bancos de dados heterogêneos . . . . . . . . . . . . . . . . . 36

4.5.1 Banco de dados central . . . . . . . . . . . . . . 36

4.5.2 Banco de dados móvel . . . . . . . . . . . . . . . . . . 37

4.6 Implementação . . . . . . . . . . . . . . . . . . . . . . 38

4.6 .1 Transformação de dados . . . . . . . . . . . . . . . . . . 39

4.6 .2 Replicação. . . . . . . . . . . . . . . . . . . . 40

4.6 .3 Propagação de atualizações . . . . . . . . . . . . . . . . . . 48

5 Conclusões $\quad 49$

$\begin{array}{ll}\text { A Esquema de dados do SAGUISaúde } & 51\end{array}$

B Regras de transformação XSLT $\quad 69$

B.1 Regras de transformação do modelo do SAGUISaúde para o modelo do Borboleta . . 69

B.2 Regras de transformação do modelo do Borboleta para o modelo do SAGUISaúde . . 75

$\begin{array}{ll}\text { Referências Bibliográficas } & 81\end{array}$ 


\section{Lista de Figuras}

1.1 Compartilhamento de acesso aos dados . . . . . . . . . . . . . . . . . . . 2

1.2 Compartilhamento de dados por meio de replicação . . . . . . . . . . . . . . . . 3

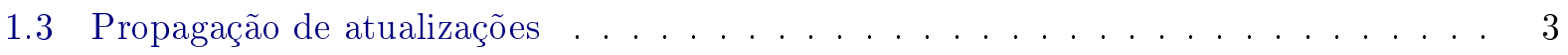

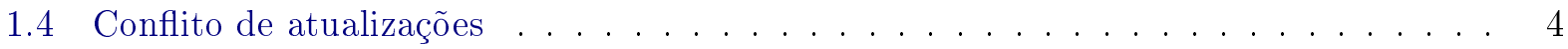

3.1 Topologia de replicação em estrela . . . . . . . . . . . . . . . . . . 20

4.1 Página inicial do SAGUISaúde . . . . . . . . . . . . . . . . 30

4.2 Modelo conceitual dos dados do SAGUISaúde . . . . . . . . . . . . . . . . . . 32

4.3 Telas do Borboleta . . . . . . . . . . . . . . . . . . . 34

4.4 Fluxo de dados entre os bancos de dados móvel e central . . . . . . . . . . . . . . . 38

4.5 Telas do Borboleta . . . . . . . . . . . . . . . . . . . . . . . 44 


\section{Lista de Tabelas}

4.1 Dados enviados como tabelas de apoio . . . . . . . . . . . . . . . 41 


\section{Capítulo 1}

\section{Introdução}

O uso de dispositivos móveis como celulares, smartphones e tablets tornou-se presente em diversas atividades, tanto para lazer quanto como ferramenta de produtividade. O uso de sistemas de informação em dispositivos móveis possui uma série de benefícios devido à mobilidade e praticidade no manuseio desses dispositivos. No entanto, a utilidade de sistemas móveis é bastante reduzida quando esses sistemas não possuem capacidade de integração com outros sistemas. Por exemplo, considere uma aplicação móvel de gerenciamento de uma lista de contatos. Essa lista de contatos armazena o nome, telefone, correio eletrônico e endereço dos contatos do usuário. Por um lado, essa aplicação é bastante útil uma vez que permite que o usuário organize e consulte seus contatos onde estiver. Por outro lado, a utilidade dessa aplicação seria bastante reduzida caso não fosse possível compartilhar essa lista de contatos com outros dispositivos e/ou aplicações. O usuário provavelmente possui uma lista de contatos na sua aplicação de correio eletrônico e ainda outra lista de contatos na sua aplicação de mensagem instantânea. Manter atualizadas todas essas listas de contatos independentemente seria penoso para o usuário. Além disso, quando o usuário adquirisse um novo dispositivo mais moderno seria obrigado a recriar todos os seus contatos um a um no novo dispositivo.

\subsection{Motivação}

Um modelo clássico de integração de sistemas é por meio do acesso compartilhado a um recurso centralizador. Nesse modelo, diversas aplicações, com objetivos semelhantes ou não, utilizam a mesma fonte de dados tanto para leitura quanto para atualização. Assim, as atualizações feitas por uma das aplicações ficam imediatamente visíveis para as demais. Esse é o modelo típico de sistemas gerenciadores de bancos de dados. Na Figura 1.1 é apresentado um esquema de como funciona o modelo de compartilhamento de acesso. Três sistemas diferentes compartilham os mesmos dados por meio de um servidor de banco de dados. Esse servidor de banco de dados é acessível por meio de uma rede (possivelmente a Internet) e responsável pelo controle do acesso concorrente aos dados. As operações de leitura e escrita são intermediadas pelo sistema gerenciador de banco de dados. Esse modelo se mostra efetivo para o compartilhamento de dados entre diversas aplicações. Alguns sistemas de informação para dispositivos móveis utilizam o modelo de acesso compartilhado [BANA06], [MKT ${ }^{+}$04]. Nesses sistemas, tanto o recurso compartilhado quanto o dispositivo móvel estão conectados a uma rede por meio da qual o sistema de informação móvel faz acesso aos dados.

No entanto, esse tipo de modelo de acesso compartilhado pressupõe que o recurso compartilhado 


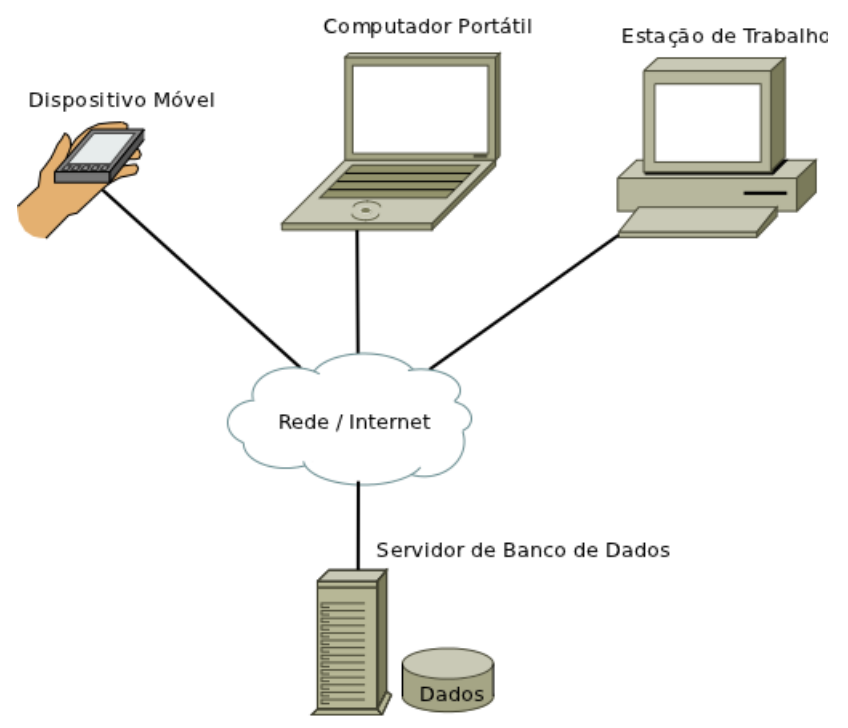

Figura 1.1: Compartilhamento de acesso aos dados: um celular, um computador portátil e uma estação de trabalho compartilhando o acesso a um banco de dados.

esteja sempre disponível para todos os sistemas que o utilizam. Assim, caso o recurso compartilhado esteja indisponível para um dos sistemas, esse sistema fica impossibilitado de acessar os dados compartilhados e consequentemente indisponível para o usuário. A exigência de conectividade durante todo o período em que se deseja operar o sistema móvel pode ser considerado impraticável em diversos domínios de aplicação devido ao alto custo do serviço de transferência de dados, instabilidade de sinal e indisponibilidade do serviço, em especial, em regiões remotas.

Uma alternativa ao modelo de acesso compartilhado que permite autonomia ao sistema durante desconexões é o uso de replicação dos dados. Nesse caso, os dados a serem compartilhados são replicados de forma que cada sistema de informação possui sua própria réplica dos dados localmente. Operações de leitura e escrita são então realizadas sobre a réplica local dos dados. As atualizações realizadas nessa réplica local não são propagadas para os demais sistemas de informação imediatamente, pois isso exigiria que o dispositivo estivesse conectado a uma rede. As atualizações são propagadas posteriormente, na ocasião em que o dispositivo tiver uma conexão de rede disponível. A Figura 1.2 apresenta o esquema de uma arquitetura de replicação de dados contendo três sistemas distintos, cada um com sua própria réplica dos dados. Cada sistema aplica as operações de leitura e escrita sobre sua própria réplica dos dados mesmo que não haja uma conexão com as demais réplicas no momento da submissão dessas operações. Posteriormente, quando a conexão com as demais réplicas for estabelecida, as operações de atualização são então propagadas para as demais réplicas. Essa abordagem aumenta a disponibilidade do sistema, uma vez que esse continua operando sobre a cópia local dos dados mesmo quando o dispositivo está desconectado da rede.

\subsection{Desafios}

Durante a propagação das atualizações realizadas por um dos dispositivos, para que haja convergência com relação ao resultado das atualizações dos diversos dispositivos envolvidos, é necessário que todos os sistemas que compartilham dados "entrem em um acordo" com relação à ordenação de tais atualizações. Esse "acordo" com relação à ordenação das atualizações é chamado de reconcilia- 


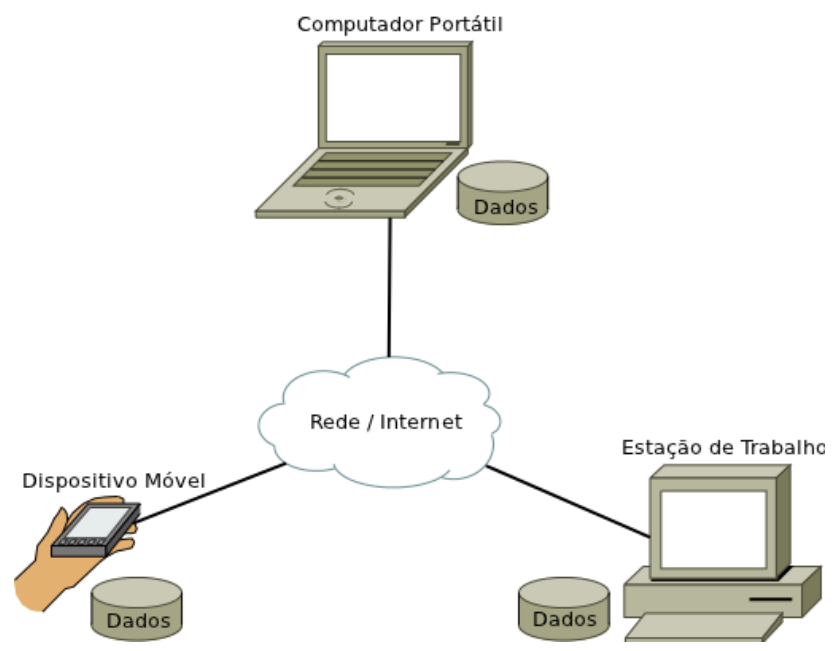

Figura 1.2: Compartilhamento de dados por meio de replicação: um celular, um computador portátil e uma estação de trabalho, cada qual com sua própria réplica dos dados compartilhados.

ção de dados e é um dos principais desafios no uso de replicação de dados. A Figura 1.3 apresenta os elementos presentes no uso de replicação de dados, o que inclui (a) a submissão de atualizações na réplica local; (b) a propagação dessas atualizações; (c) a reconciliação e, (d) a confirmação das transações submetidas nas diversas réplicas. Esses elementos em conjunto tornam as atualizações visíveis globalmente.
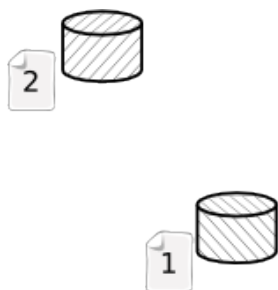

(a) Operações desconectadas: Cada um dos sistemas submete operações de escrita na réplica local dos dados.

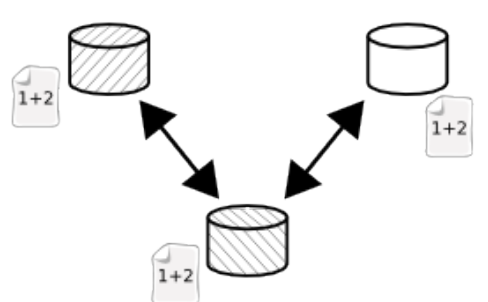

(c) Reconciliação: Dispositivos entram em acordo com relação à ordenação das atualizações propagadas.

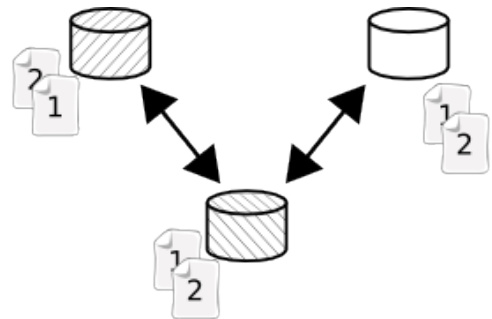

(b) Propagação: Os dispositivos se comunicam e propagam as atualizações locais aos demais sistemas.

Figura 1.3: Propagação de atualizações: Etapas pelas quais uma transação é submetida desde a aplicação na réplica local até a confirmação globalmente (em todas as réplicas). Os discos representam réplicas, páginas representam operações de atualização e setas representam comunicação entre as réplicas.

Uma das tarefas do processo de reconciliação é o tratamento de conflitos. Um conflito é caracterizado pela atualização concorrente de um mesmo dado em diferentes réplicas. Uma vez que um dado é atualizado concorrentemente em duas ou mais réplicas, o processo de reconciliação é res- 
ponsável por definir uma ordenação dessas atualizações que gere o resultado esperado pelo usuário. Porém, em alguns casos, não existe uma ordenação (ou escalonamento) que gere o resultado esperado. Como exemplo, considere o mesmo sistema de gerenciamento de lista de contatos mencionado anteriormente. O usuário possui sua lista de contatos replicada em sua estação de trabalho e em seu telefone celular. Um dos registros em sua lista de contatos é o de sua esposa, constando apenas o número do telefone dela (Figura 1.4a). Posteriormente, a esposa criou um correio eletrônico e, então, o usuário o adicionou na réplica de sua estação de trabalho. Além disso, a esposa também trocou seu número de telefone, e, assim, o usuário atualizou o número da esposa na réplica de seu telefone celular (Figura 1.4b). Considerando que um registro (nome, telefone e correio eletrônico) seja uma unidade atômica de atualização, quaisquer dos escalonamentos possíveis gerariam um resultado diferente do esperado pelo usuário (Figura 1.4c).

\begin{tabular}{|c|c|c|}
\hline Nome & Telefone & E-mail \\
\hline Luciana & $555-1212$ & \\
\hline \multicolumn{3}{|l|}{ Réplica 2: } \\
\hline Nome & Telefone & E-mail \\
\hline Luciana & 555-1212 & \\
\hline
\end{tabular}

(a) Estado original das réplicas.

Réplica 1:
\begin{tabular}{|l|l|l|}
\hline Nome & Telefone & E-mail \\
\hline Luciana & $555-1212$ & luciana@example.com \\
\hline Réplica 2: & & \\
\hline Nome & Telefone & E-mail \\
\hline Luciana & $555-8989$ & \\
\hline
\end{tabular}

(b) Estado das réplicas após a submissão de operações de escrita nas réplicas.

\begin{tabular}{|c|c|c|}
\hline Nome & Telefone & E-mail \\
\hline Luciana & $555-8989$ & \\
\hline \multicolumn{3}{|c|}{ Ordenaçào 2,1 : } \\
\hline Nome & Telefone & E-mail \\
\hline Luciana & $555-1212$ & Iuciana@example.com \\
\hline \multicolumn{3}{|c|}{ Resultado esperado: } \\
\hline Nome & Telefone & E-mail \\
\hline Luciana & $555-8989$ & Iuciana@example.com \\
\hline
\end{tabular}

(c) Ordenaçöes possíveis e resultado esperado pelo usuário.

Figura 1.4: Conflito de atualizações: Em (a) é apresentado o registro original presente em duas réplicas. Sobre as réplicas são realizadas concorrentemente operações de atualização, resultando em (b). Em (c) são apresentados os resultados dos dois escalonamentos possiveis para reconciliação e o resultado esperado pelo usuário.

A resolução automática de conflitos de maneira satisfatória é dificilmente alcançada sem conhecimento semântico dos dados e da aplicação que realizou as atualizações conflitantes. Por isso, tipicamente as aplicações abrem mão da generalidade e implementam mecanismos específicos de resolução de conflitos. Porém, mesmo ao abrir mão da generalidade e implementando mecanismos de resolução de conflitos específicos para cada aplicação, ainda assim é uma tarefa difícil determinar a correta resolução de alguns conflitos. Nesses casos, é necessário a intervenção humana para determinar o resultado correto da resolução desses conflitos ou até mesmo para coletar novas informações necessárias para determinar o resultado correto de tais conflitos.

\subsection{Problema}

Existem diversos mecanismos de reconciliação de transações para bancos de dados autônomos, porém tais mecanismos não fornecem a flexibilidade necessária ao desenvolvimento de aplicações móveis modernas. Para tal, faz-se necessário um modelo transacional que atenda os seguintes requisitos: 
- Disponibilidade: Os mecanismos que fazem uso de bloqueios de maneira a evitar a ocorrência de conflitos sofrem de baixa disponibilidade pois impedem o acesso a um registro que foi replicado;

- Transações interativas: Os mecanismos baseados em abortos e reexecuções de transações conflitantes não são apropriados para aplicações que possuem transações interativas, porque exigiriam retrabalho por parte do usuário.

- Resolução manual de conflitos: Os mecanismos que exigem a resolução automática de todos os conflitos por meio de rotinas pré-programadas são inapropriados para diversas aplicações para as quais a definição de tais rotinas é impossível ou possui um custo muito alto.

- Ferramentas de apoio à resolução manual de conflitos: Os mecanismos que admitem a resolução manual de conflitos dificultam o desenvolvimento de ferramentas adequadas de apoio à resolução manual de conflitos quando utilizados em ambientes de computação móvel. Isso ocorre porque tais mecanismos bloqueiam a propagação das atualizações conflitantes até que seja finalizada a resolução dos conflitos, exigindo que a resolução manual seja realizada no dispositivo móvel.

- Auditoria e retificação de resoluções de conflitos: Após determinar a resolução dos conflitos, os mecanismos existentes descartam a informação de que a transação em questão foi gerada a partir de uma transação conflitante. Os mecanismos existentes descartam também quais foram as atualizações originalmente realizadas pela transação conflitante pois tais atualizações são substituídas pelas atualizações da transação resultante da resolução dos conflitos. Ao descartar tais informações, esses mecanismos impedem que seja feita auditoria dos conflitos ocorridos e das resoluções desses conflitos. Isso impede também a recuperação de dados perdidos em decorrência de uma resolução incorreta de um conflito. Em decorrência da complexidade de se escrever rotinas de resolução de conflitos e da necessidade, em diversos casos, de resolução manual de conflitos, faz-se necessário prover mecanismos para auditoria e retificação das resoluções de conflitos.

- Semântica de conflitos: Ao descartar as informações relativas a transações conflitantes, perde-se também a possibilidade de uso dessas informações no apoio a reconciliações futuras. Considere o cenário no qual dois dispositivos móveis (M1 e M2) compartilham um registro na aplicação de lista de contatos mencionada anteriormente cuja cópia principal está armazenada em uma estação de trabalho (E). O registro compartilhado possui no campo Nome, denotado a partir daqui por X, o valor Gustavo. M1 e M2 estão inicialmente desconectados e então segue a sequência de eventos descrita a seguir:

1. $X_{m 1}=$ Gustavo Luis

2. $X_{m 2}=$ Gustavo Luiz

3. M1 se conecta à rede

4. M1 propaga suas transações para $\mathrm{E}$

5. M1 desconecta da rede

6. M2 se conecta à rede 
7. M2 propaga suas transações

Nesse momento, há um conflito entre as atualizações efetuadas por M1 e M2 e faz-se necessário a resolução do conflito. Mesmo que a resolução seja feita manualmente, o usuário pode não saber qual é o valor correto de X. Note que há uma diferença sutil entre os dois valores pois $X_{m 1}$ termina com a letra s e $X_{m 2}$ termina com a letra z. O usuário escolhe então o valor submetido por $X_{m 1}$, fazendo com que $\mathrm{X}=X_{m 1}=X_{m 2}=$ "Gustavo Luis". Segue então a sequência de eventos descrita a seguir:

8. M2 desconecta da rede

9. $X_{m 1}=$ Gustavo Luiz

10. M1 se conecta à rede

11. M1 propaga suas transações

Nesse momento há novamente um conflito entre a atualização efetuada por M1 e a atualização efetuada por M2 como resultado da resolução do conflito anterior. O usuário (potencialmente uma pessoa distinta da pessoa que resolveu o conflito anterior e mesmo da pessoa que submeteu a atualização conflitante) será novamente confrontada com dois possíveis valores para X, a saber "Gustavo Luis"e "Gustavo Luiz". A informação de que o dado presente no banco de dados ("Gustavo Luis") é resultado de uma resolução de conflito e as versões envolvidas em tal conflito podem ser decisivos na resolução do conflito atual.

\subsection{Objetivos e Justificativa}

Diante dos requisitos de flexibilidade mencionados acima (e das deficiências nos mecanismos de reconciliação de transações existentes ), este trabalho tem por objetivo desenvolver um mecanismo de reconciliação de transações que faça uso de metadados e versionamento de dados para prover a flexibilidade exigida no desenvolvimento de aplicações móveis.

Para obter os requisitos de disponibilidade e transações interativas, faz-se necessário abrir mão da seriabilidade e resolver os conflitos que ocorrerem. Resolver conflitos é uma tarefa complexa e propensa a erros. Em muitos casos, é necessário resolver os conflitos manualmente, ficando o sistema sujeito ao erro humano. Uma resolução de conflito incorreta pode levar o sistema a um estado irrecuperável.

Diversas informações são descartadas durante a resolução de conflitos, tais como quais foram as transações conflitantes, quais foram as atualizações realizadas por essas transações e qual foi o resultado da resolução dos conflitos. Ao armazenar essas informações como metadados que descrevam o histórico de resoluções de conflitos e fazendo uso de versionamento de dados, é possível auditar as resoluções de conflitos realizadas ao longo do tempo e recuperar o sistema de uma situação na qual um conflito foi resolvido incorretamente e que tenha levado o sistema a um estado inconsistente.

Dispositivos móveis possuem recursos limitados, como pouca memória e tamanho de tela reduzido. Tais limitações são especialmente restritivas à tarefa de resolver conflitos manualmente, pois essa tarefa envolve a análise e possível edição de diferentes versões de dados. Por permitir a retificação de resoluções de conflitos, ao armazenar metadados referentes ao histórico de resoluções de conflitos e utilizar versionamento de dados, é possível permitir ao dispositivo móvel realizar uma 
resolução de conflitos preliminar. O usuário é então encarregado de validar essa resolução preliminar ou submeter uma resolução de conflito retificadora. Entretanto, como as transações da aplicação móvel são propagadas após a resolução de conflitos preliminar, o usuário não é mais obrigado a utilizar o dispositivo móvel para realizar a resolução de conflitos retificadora. O usuário poderá utilizar um dispositivo com recursos mais adequados à realização dessa operação, como por exemplo uma estação de trabalho.

Em um ambiente de computação móvel, tipicamente, existem diversas réplicas de um mesmo dado e essas réplicas estão frequentemente desconectadas. Os dados replicados podem ser atualizados em qualquer uma das réplicas, potencialmente de maneira concorrente, gerando, assim, um conflito. Como essas atualizações podem ocorrer concorrentemente em diversas réplicas, conflitos de atualização podem envolver dois ou mais dispositivos. Para determinar a correta resolução desses conflitos é necessário levar em consideração todas as transações envolvidas no conflito. Não é possível exigir que todos os dispositivos com transações envolvidas no conflito em questão estejam todos conectados simultaneamente para determinar a resolução do conflito. Resolver o conflito localmente para cada transação conflitante gera resultados não ótimos. Ao armazenar os metadados referentes ao histórico de resoluções de conflitos é possível analisar todas as transações envolvidas no conflito e que já foram propagadas no momento da reconciliação de novas transações.

Para exemplificar a aplicação do mecanismo proposto neste trabalho, foi desenvolvido um arcabouço de reconciliação de transações. Esse arcabouço foi utilizado em uma aplicação móvel real que possui necessidades de compartilhamento de dados por replicação. Os requisitos de flexibilidade descritos na seção anterior são então verificados por meio de experimentos e protótipos de ferramentas de apoio à resolução de conflitos.

\subsection{Estrutura do Trabalho}

Para um melhor entendimento do modelo de reconciliação de transações desenvolvido nesta pesquisa de mestrado, este trabalho está divido em 5 capítulos. No Capítulo 2, são apresentados os conceitos fundamentais de controle de concorrência, replicação e versionamento de dados, bem como alguns trabalhos relacionados. No Capítulo 3 são apresentados os detalhes do mecanismo proposto e o arcabouço que implementa tal mecanismo. No capítulo 4 é descrito o estudo de caso no qual foi utilizado o arcabouço desenvolvido. Finalmente, no Capítulo 5 são apresentadas as conclusões obtidas ao final deste trabalho. 


\section{Capítulo 2}

\section{Revisão bibliográfica}

\subsection{Controle de concorrência e replicação de dados}

A maioria das aplicações móveis compartilham dados com outros dispositivos móveis ou com estações fixas. Porém o alto custo de transferência de dados, combinado com a banda estreita, alta latência e indisponibilidade de sinal fazem com que essas aplicações sejam obrigadas a replicar os dados compartilhados, mantendo uma cópia desses dados localmente.

Técnicas tradicionais de replicação sempre bloqueiam o acesso a uma réplica exceto quando essa réplica já esteja atualizada e, por isso, tais técnicas são chamadas de pessimistas [SS05]. Essas técnicas são fundamentadas na teoria clássica de controle transacional em banco de dados [FF00]. Tradicionalmente, sistemas de banco de dados asseguram a integridade dos dados armazenados mantendo as seguintes propriedades das transações, chamadas de propriedades ACID (Atomicidade, Consistência, Isolamento, Durabilidade):

- Atomicidade: ou todas as operações da transação são executadas e confirmadas ou nenhuma delas tem efeito sobre os dados.

- Consistência: uma transação, ao ser executada completamente, deve levar o banco de dados de um estado consistente para outro.

- Isolamento: embora seja possível que várias transações sejam executadas concorrentemente, a execução de uma transação não deve sofrer interferência de outra transação.

- Durabilidade: Após a confirmação de uma transação, as mudanças feitas por essa transação não podem ser desfeitas no banco de dados.

O componente do sistema de banco de dados que é responsável pela implementação do isolamento é o controle de concorrência. A consistência do banco de dados é assegurada, sob execução concorrente, garantindo que qualquer escalonamento de execução tenha o mesmo efeito de outra que tivesse sido executada sem qualquer concorrência. Isto é, um escalonamento de execução deve, de alguma forma, ser equivalente a um escalonamento sequencial [SKS06]. Isso é feito aplicando bloqueios e atrasando uma operação ou abortando a transação que emitiu essa operação. 


\subsubsection{Controle de concorrência otimista}

O uso de bloqueios é impraticável em um ambiente de computação móvel, no qual o período de desconexão é longo. Um dado em uso por uma transação longa atrasaria outras transações que utilizam aquele mesmo dado. Essas transações podem ser transações interativas e obrigariam o usuário a esperar o término da transação que bloqueou o dado. Quando temos transações que podem durar um período na ordem de dias, exigir que o usuário aguarde o término dessa transação para prosseguir com sua operação geraria um descontentamento do usuário com relação ao sistema.

Para fazer uso de replicação em um ambiente de computação móvel é necessário utilizar um controle de concorrência otimista, que não usa bloqueios para garantir isolamento entre as transações [BN09]. Ao invés de bloquear outras transações que acessam um dado que está sendo usado por uma transação em execução, os mecanismos de controle de concorrência otimistas permitem que esse dado seja acessado sem uma sincronização a priori baseados na suposição "otimista" de que problemas ocorrerão apenas raramente, se ocorrerem [SS05].

Em um ambiente de replicação que faça uso de controle de concorrência otimista, as operações de leitura e escrita são efetuadas na cópia local do banco de dados sem o uso de qualquer tipo de bloqueio entre os nós. Posteriormente, quando houver conexão, esse nó propagará essas operações para os demais nós. Nesse momento os nós que estão sendo sincronizados devem entrar em um acordo com relação à ordenação das suas transações. No entanto, como as transações dos nós sendo sincronizados efetuaram operações de leitura e escrita sem o conhecimento umas das outras, pode haver conflitos de atualização. Isso ocorre quando transações concorrentes efetuam escrita em cópias diferentes do mesmo dado [DPS ${ }^{+}$94].

\subsection{Resolução de Conflitos}

Existem diversas maneiras de tratar conflitos, uma maneira simples é simplesmente ignorar tal situação e escolher uma entre as ordenações possíveis. No entanto essa abordagem pode gerar a perda de atualizações. A perda de atualizações pode ser aceitável em alguns domínios, porém não é aceitável na maioria das aplicações. Para evitar que isso aconteça é necessário resolver tais conflitos de forma a preservar as atualizações de todas as transações sendo propagadas. Segundo Saito e Shapiro [SS05], a resolução de conflitos geralmente é bastante específica da aplicação e a maioria dos sistemas simplesmente sinaliza um conflito e deixa a cargo do usuário resolver o conflito. No entanto é possível identificar algumas soluções genéricas e alguns padrões utilizados em diversas aplicações como visto em [TFB97].

\subsubsection{Resolução de conflitos de forma manual}

Muitas aplicações utilizam uma abordagem manual na resolução de conflitos, ou seja, elas simplesmente sinalizam um conflito e deixam a cargo do usuário a resolução do conflito. O usuário pode escolher entre uma das versões geradas por cada uma das transações conflitantes ou submeter uma terceira versão. Em alguns casos pode ser possível que o usuário escolha por abortar uma das transações. Essa abordagem é bastante simples e de fácil implementação porém possui o inconveniente de exigir que o usuário esteja operando o sistema no momento da resolução do conflito e que ele resolva manualmente cada um dos conflitos identificados. Em um ambiente no qual acontecem muitos conflitos essa abordagem seria impraticável. Além disso em algumas aplicações é difícil 
apresentar de forma intuitiva ao usuário quais são as operações conflitantes e quais resultados serão obtidos ao escolher uma das transações conflitantes.

\subsubsection{Resolução de conflitos por aborto}

Uma outra maneira de tratar conflitos é abortar uma das transações conflitantes. No momento da sincronização entre duas réplicas, caso seja identificado um conflito entre duas transações, apenas uma das transações é propagada para as demais réplicas e a outra transação é abortada. Essa técnica possui o inconveniente de gerar abortos de transações que já foram confirmadas em uma das réplicas. Isso faz com que uma das réplicas fique em um estado diferente das demais réplicas mesmo após a sincronização, pois apenas essa réplica possui a transação que foi abortada durante a sincronização. Uma maneira de resolver esse problema é aplicando operações compensatórias que anulem os efeitos da transação que foi confirmada localmente mas abortada durante a sincronização. Porém, alguns tipos de operações não possuem uma operação compensatória correspondente. Isso é especialmente difícil em casos de transações interativas. Abortar uma transação que teve interação com o usuário pode gerar uma insatisfação por parte do usuário caso ele tenha que refazer a tarefa. Em alguns casos pode ser até mesmo impossível para o usuário refazer a tarefa referente à transação abortada.

\subsubsection{Resolução de conflitos incremental}

Em alguns casos, é possível utilizar uma abordagem incremental para o controle de conflitos de atualização. Isso ocorre em aplicações que possuem dados incrementais. Por exemplo, em um sistema de arquivos distribuído, uma operação conflitante pode conter a atualização de um diretório para a adição de um novo arquivo. Supondo-se que cada uma das réplicas adicionou um novo arquivo ao diretório, a resolução desse conflito seria a adição de ambos os arquivos ao diretório.

\subsubsection{Resolução de conflitos por junção}

Os esquemas de resolução de conflitos por junção possuem um procedimento, geralmente específico da aplicação, que recebe duas versões de um dado e gera uma terceira versão. As versões de entrada correspondem aos dados gerados pela aplicação de cada uma das transações conflitantes. A versão gerada pelo procedimento corresponde à junção das versões de entrada. Existem diversas maneiras de implementar a resolução de conflitos por junção. Alguns sistemas permitem que sejam configurados alguns procedimentos de junção que serão escolhidos de acordo com algum critério, por exemplo, num sistema de arquivos distribuído, o critério para escolha do procedimento pode ser o tipo de arquivo em conflito. Outros sistemas permitem que o programador forneça o procedimento de junção no momento da submissão da transação.

\subsubsection{Resolução de conflitos por prioridade}

Outra maneira de tratar conflitos é utilizar um esquema de prioridades. Essas prioridades podem ser definidas com base no usuário que submeteu a transação, o nó origem da transação, definido pelo programador no momento da submissão da transação ou até mesmo um critério específico da aplicação. Quando um conflito é identificado, a ordenação das operações é feita baseado nas prioridades de cada uma das transações conflitantes. 


\subsubsection{Resolução de conflitos por versionamento}

Nos esquemas de resolução de conflitos por versionamento, os dados passam a ser versionados e toda atualização de dados passa a ser uma inserção de uma nova versão daquele dado. Quando há um conflito entre duas transações que atualizam o mesmo dado utiliza-se um critério para ordenação das transações conflitantes e permite-se que tais transações efetuem suas atualizações. Diferentemente dos esquemas de resolução de conflitos por prioridade, onde também há uma escolha arbitrária da ordenação, nos esquemas de versionamento não há perda de atualizações. Isso porque armazena-se todas as versões do dado. Dessa forma é possível navegar no histórico de atualizações do dado e recuperar uma atualização que foi sobrescrita por outra transação conflitante ou até mesmo reordenar de forma definitiva essas transações.

\subsection{Versionamento de dados em bancos de dados relacionais}

Existem diferentes abordagens para versionamento de dados em bancos de dados relacionais. Com relação à camada de execução do versionamento de dados, existem abordagens que implementam o versionamento junto ao motor do banco de dados, abordagens que implementam o versionamento como procedimentos de usuários armazenados no banco de dados que interceptam as requisições de atualização, abordagens que implementam o versionamento em um middleware, tipicamente um arcabouço de mapeamento objeto-relacional, e abordagens em que a responsabilidade do versionamento fica a cargo do programador da aplicação.

As abordagens que implementam o versionamento junto ao motor do banco de dados possuem a vantagem de serem transparentes para o programador e não exigirem alteração no esquema do banco de dados [LBMS06] [Raj07]. Porém, as implementações existentes são produtos comerciais de código proprietário. Além disso, tais abordagens possuem pouca flexibilidade e não permitem versionamento seletivo, ou seja, versionar apenas algumas atualizações. Versionamento seletivo é necessário em alguns domínios de aplicação, em especial quando se usa versionamento de dados para resolução de conflitos de atualização. Em um ambiente de replicação otimista em que há a possibilidade de ocorrência de conflitos de atualização, pode-se usar versionamento de dados para resolver os eventuais conflitos. No entanto, nas demais ocasiões, nas quais não há conflitos, não é necessário fazer o versionamento dessas atualizações. Dessa forma é possível manter o número de versões de dados em um número gerenciável, não gerando assim uma grande sobrecarga no banco de dados.

Em oposição às abordagens que são implementadas junto ao motor do banco de dados, as demais abordagens exigem a adição de novas tabelas e/ou colunas ao esquema do banco de dados que armazenarão metadados referentes ao versionamento de dados. Com relação a essas mudanças no esquema original do banco de dados, é possível classificar as abordagens de versionamento de dados em 3 categorias: esquema único, espelhamento e tabela polimórfica.

\subsubsection{Esquema único}

Nas abordagens de esquema único as diferentes versões de um dado possuem o mesmo status do dado em si. Para isso é adicionada às tabelas que serão versionadas uma coluna que armazena a versão do dado. A partir disso, atualizações serão transformadas em inserções nessas tabelas utilizando uma cópia da última versão do respectivo registro contendo as alterações desejadas e 
com um incremento na versão. Dessa forma, é possível recuperar as diferentes versões de um dado. Para evitar duplicidade de chaves primárias durante a cópia do registro para inserção de uma nova versão, a coluna de versão passa a compor a chave primária da tabela, uma vez que durante essa cópia a versão é sempre incrementada. Nessas abordagens, não há diferenciação entre esquema de dados e esquema de versões ou metadados, uma vez que a única forma de diferenciar a versão "atual" das versões "antigas" de um dado é comparando os valores da coluna de versão.

\subsubsection{Espelhamento}

Nas abordagens de espelhamento, para cada tabela a ser versionada é criada uma tabela auxiliar, denominada tabela espelho, com o mesmo esquema da tabela original com a adição de uma coluna de versão, como na abordagem de esquema único. Essa tabela auxiliar é responsável por armazenar as diferentes versões dos dados armazenados na tabela original. Dessa forma, a versão corrente dos dados é recuperada da tabela original, enquanto que as versões antigas dos dados são recuperadas da tabela espelho. Atualizações na tabela original são interceptadas e então é feito uma cópia do registro a ser atualizado da tabela corrente para a tabela espelho, inserindo uma nova versão. Após essa cópia, a atualização pode ser efetuada na tabela original. Essa abordagem tem a vantagem de não impactar o desempenho de buscas na tabela original. As consultas à tabela original também não precisam ser reescritas nos casos em que se está interessado apenas na versão corrente dos dados. As desvantagens dessa abordagem são a necessidade de manutenção dos esquemas das tabelas espelho sincronizados com as tabelas originais e a duplicação do número de tabelas no esquema original do banco de dados.

\subsubsection{Tabela polimórfica}

Nas abordagens de tabela polimórfica apenas uma nova tabela é criada no esquema original. Essa tabela é denominada tabela de versões. A cada atualização nas tabelas sendo versionadas é criada uma nova entrada na tabela de versões. Dessa forma, as tabelas do esquema original do banco de dados não são modificadas e contêm apenas os dados correntes do banco. As versões antigas dos dados de todas as tabelas sendo versionadas são todas armazenadas em uma única tabela. Sendo assim, essa tabela deve ser capaz de armazenar diferentes tipos de dados e armazenar também a qual tabela cada registro se refere, além da versão do dado.

O desafio nesse tipo de abordagem está em como armazenar, em uma única tabela, diferentes tipos de dados. Uma alternativa, utilizada pelo arcabouço PaperTrail ${ }^{1}$, consiste em serializar os dados da tabela a ser versionada em um formato texto de uma maneira reversível, por exemplo utilizando XML ou JSON. Dessa forma, a tabela de versões passa a conter apenas uma coluna do tipo texto para armazenar os dados do registro serializados, sendo as demais colunas responsáveis por armazenar metadados, como o nome da tabela de origem do respectivo registro e a versão do dado.

Esse tipo de abordagem possui a desvantagem de dificultar a busca na tabela de versões, uma vez que os dados passam a ser armazenados nessa tabela de maneira semi-estruturada e os sistemas gerenciadores de bancos de dados existentes não fornecem mecanismos eficientes para busca em dados semi-estruturados. Diante disso, para recuperar as diferentes versões de um dado específico

\footnotetext{
${ }^{1}$ http://github.com/airblade/paper_trail
} 
é necessário recuperar todas as entradas oriundas da tabela em questão e, na aplicação, filtrar apenas as versões referentes ao registro em que se está interessado. Uma maneira de amenizar esse efeito colateral é adicionar mais informação na tabela de versões referente aos dados armazenados de forma semi-estruturada. Geralmente se está interessado em todas as versões anteriores de um dado específico armazenado na tabela original, portanto uma opção interessante seria armazenar na tabela de versões, além da versão, do nome da tabela de origem e dos dados serializados, armazenar também, de forma estruturada, o valor da chave primária do respectivo registro. Dessa forma seria possível escrever uma consulta que retornasse apenas as versões de um dado específico, sem a necessidade de filtrar os resultados da busca na aplicação. No entanto, para isso é necessário que todas as tabelas sendo versionadas possuam o mesmo tipo de dado para a chave primária.

\subsection{Sincronização de bancos de dados heterogêneos}

Em um ambiente com bancos de dados homogêneos, o processo de separação e integração pode ser dividido em três fases: separação, evolução e reintegração [FF00]. A fase de separação consiste na extração de dados da base central e replicação na base móvel. Nesta fase, o sistema central é responsável por aplicar os bloqueios necessários para o controle de acessos concorrentes e armazenar metadados de controle a serem utilizados na fase de reintegração. Na fase de evolução, o sistema móvel executa operações de leitura e escrita sobre seus dados locais normalmente. A fase de reintegração é responsável por integrar a base móvel com a base central, levando em consideração as alterações ocorridas em cada uma delas. Neste ponto, o sistema central é responsável por identificar conflitos de dados e resolvê-los, seja automaticamente, seja com o auxílio de intervenção humana [KS95]. Para evitar conflitos, o sistema central pode aplicar bloqueios de acesso exclusivo aos dados que foram replicados na base móvel. Porém, em um sistema no qual os conflitos de dados são pouco prováveis, pode valer a pena abrir mão de bloqueios e utilizar um esquema de resolução de conflitos quando estes ocorrerem [SS05].

Para um ambiente com bancos de dados heterogêneos, é necessário um processo adicional: transformação dos dados [BL07]. A transformação se dá ao final da fase de separação e no início da fase de reintegração. A necessidade de um processo de transformação ocorre no momento da integração de dados semelhantes com diferentes representações. De acordo com [Suj01], diferenças de representação podem ser agrupadas em:

1. Diferenças estruturais: podem ser diferenças na composição das tabelas, diferenças na representação como dados ou metadados ou diferenças no armazenamento estruturado ou na codificação em texto. Por exemplo, há pelo menos duas formas diferentes de modelar um telefone para recados a um usuário. A primeira, utilizando duas colunas da tabela Pessoa: telefone e nome-para-recado. A segunda, utilizando uma tabela chamada Telefone, com as colunas número e nome-para-recado;

2. Diferenças de nomenclatura: são caracterizadas por termos distintos denotando os mesmos objetos semânticos em diferentes bases de dados. Podem manifestar-se como diferenças na nomenclatura de metadados ou dos próprios dados. Por exemplo, um banco de dados pode se referir a um exame como "Velocidade de hemossedimentação" enquanto o outro se refere ao mesmo exame como " $V H S$ "; 
3. Diferenças semânticas: acontecem quando o significado dos nomes das tabelas, das colunas ou os valores dos dados, entre os bancos de dados, são parecidos mas não equivalentes. Esse problema é particularmente traiçoeiro quando os nomes das tabelas e colunas e os valores dos dados são idênticos em ambos os bancos de dados, mas possuem significados diferentes. Por exemplo, para representar o resultado de um exame da cultura do sangue, um banco de dados pode armazenar, em uma coluna chamada crescimento-cultura-sangue, os valores: "nenhum crescimento", "crescimento baixo ou moderado" e "crescimento significativo"; um outro banco de dados pode possuir a mesma coluna da tabela, porém com os valores: "nenhum ou baixo crescimento" e "crescimento moderado ou significativo";

4. Diferenças de conteúdo: ocorrem quando os dados representados em um banco de dados não são diretamente representados no outro banco de dados. O dado pode ser implícito, dedutível ou simplesmente não estar presente no banco de dados. Por exemplo, em um registro municipal de enfermeiros, cada registro pode estar associado à unidade de saúde onde esse enfermeiro atua; já no cadastro de enfermeiros do centro de saúde, este dado pode não estar presente, pois está implícito que todos os enfermeiros cadastrados atuam naquela unidade.

Existem diversas abordagens para solucionar o problema de interoperabilidade entre bancos de dados heterogêneos. Tais abordagens podem ser agrupadas em duas categorias: reescrita de transaçôes e transformação de modelo de dados. A reescrita de transações consiste em (1) interceptação das operações realizadas em um banco, (2) reescrita dessas operações de forma que possam ser aplicadas sobre um outro modelo de dados e, opcionalmente, uma outra linguagem de operação e (3) a efetiva aplicação dessas operações no segundo banco de dados. A transformação de modelo de dados consiste na extração dos dados do banco, seguida de um processo de transformação dos dados em um formato específico. Os dados nesse novo formato devem ser diretamente mapeáveis para um segundo banco de dados, o qual possui um modelo diferente da fonte dos dados. Benguria e Larrucea descrevem algumas abordagens utilizando transformação de modelos de dados [BL07] enquanto que Arens et al. apresentam abordagens utilizando reescrita de transações [ACK93].

\subsection{Trabalhos relacionados}

Existe uma infinidade de aplicações para as técnicas de replicação de dados. Além disso, os diferentes ambientes de computação móvel e seus requisitos variados refletem em uma grande variedade de abordagens existentes na literatura. Muitas dessas abordagens apresentam-se muito diferentes entre si em decorrência de terem focado em diferentes requisitos e ambientes da aplicação.

Alguns autores adotam um ambiente de computação móvel híbrido, sendo parte dos nós móveis e parte dos nós fixos. Por outro lado, alguns autores abordam problemas nos quais todos os nós da rede são móveis e estão sujeitos a desconexões. Com relação ao grau de conectividade dos nós móveis, alguns autores consideram que tais nós possuem pequenos intervalos de desconexão e passam a maior parte do tempo conectados. Em oposição, existem autores consideram que o tempo com que os nós móveis passam conectados é muito inferior ao tempo com que tais nós passam desconectados.

A pesquisa em replicação de dados data da década de 70 . Um dos trabalho pioneiros é o de David Gifford [Gif79], no qual ele descreve uma técnica de replicação conhecida como "votação ponderada". Essa técnica utiliza quóruns de votação para leitura e escrita de forma que a interseção 
entre todos os quóruns seja não vazia. Dessa forma, é possível garantir transações seriáveis. Posteriormente, surgiram diversas variações utilizando a técnica de votação [Her86] [Pâr86] [AT89]. Uma característica dessas abordagens é o uso de estratégias pessimistas de replicação, ou seja, visavam garantir a consistência dos dados por meio de transações seriáveis ao custo de negar o acesso a certos dados na ocorrência de particionamentos da rede.

O Coda [Sat02] é um dos trabalhos pioneiros no uso de replicação de dados em ambientes de computação móvel. Tem como objetivo prover um ambiente de sistema de arquivos distribuído tolerante a falhas e desconexões. Embora não fizesse parte de seus objetivos iniciais, o Coda se mostrou prático para uso em ambientes de computação móvel. Para garantir disponibilidade na presença de particionamentos da rede, o Coda utiliza replicação otimista dos dados em diversos servidores. Dessa forma, caso haja uma falha na conexão entre o cliente e o servidor que provê um arquivo, o cliente pode utilizar um outro servidor que tenha replicado esse arquivo e que esteja em sua partição de rede. Outra técnica utilizada pelo Coda para aumentar a disponibilidade do sistema é o uso de operações desconectadas. Isso permite aos clientes executar operações de leitura e escrita mesmo na presença de um particionamento que isole o cliente de todos os servidores da rede. Uma consequência do uso de replicação otimista e operações desconectadas é a presença de conflitos. O Coda utiliza um mecanismos que permite aplicações externas executarem a resolução de conflitos envolvendo determinados tipos de arquivos. Nos casos em que a resolução do conflito falha ou não existe uma aplicação externa para resolução do conflito em questão, o usuário é então notificado para resolução manual.

Inicialmente, o Coda identificava apenas conflitos do tipo escrita/escrita. Os conflitos do tipo leitura/escrita eram ignorados. Posteriormente, o Coda foi estendido com um mecanismo denominado Isolation-Only Transaction (IOT). Esse mecanismo garante o isolamento entre as transações que são executadas concorrentemente. Para isso, o mecanismo permite a sinalização de início e fim de uma transação. Os resultados de uma transação não são visíveis ao servidor até que a transação seja finalizada. No momento da finalização da transação, é verificado se os resultados da transação são consistentes com o estado do servidor. No caso afirmativo, os resultados da transação se tornam disponíveis no servidor. Caso contrário é possível reexecutar automaticamente a transação, abortar, invocar uma ferramenta externa ou resolver manualmente.

O uso de versionamento de dados na reconciliação de transações foi explorado por Phatak e Badrinath [PB99]. Nessa abordagem, o servidor armazena não apenas o estado atual do banco de dados, mas um conjunto de estados. Esses estados do banco de dados são denominados snapshots. A cada transação efetivada, um novo snapshot é cridado e armazenado junto ao banco de dados. Os clientes (dispositivos móveis) replicam um subconjunto dos dados de um snapshot. Os clientes podem então executar transações locais sobre essa réplica dos dados e posteriormente propagar para o servidor as atualizações realizadas por essas transações.

Para tentar reduzir a ocorrência de conflitos, o algoritmo de reconciliação utiliza o histórico de snapshots para encontrar um escalonamento que matenha o isolamento de snapshots [BBG $\left.{ }^{+} 95\right]$. O histórico de snapshots permite que a transação seja reconciliada "no passado", ou seja, anteriormente a uma trasação que já foi confirmada. Isso aumenta a probabilidade de reconciliação da transação.

As deficiências da abordagem de Phatak e Badrinath residem justamente na tentativa de garantia de isolamento de snapshots. Durante a reconciliação de uma transação, caso seja identificado um conflito, ou seja, caso não seja possível garantir o isolamento de snapshots, a transação deve 
ser abortada. Além disso, o algoritmo de reconciliação pressupõe que apenas serão confirmadas as transações que mantenham a consistência do banco de dados. Isso impossibilita a discriminação de transações conflitantes e transações não conflitantes e, consequentemente, impossibilita a auditoria de resoluções de conflitos.

Os sistemas móveis de saúde existentes não atendem as necessidades do atendimento domiciliar em saúde pública. Um exemplo de aplicação médica para dispositivos móveis é o MobMed $\left[\mathrm{MKT}^{+}\right.$04]. O MobMed possui um sistema móvel de prontuário eletrônico que tem por objetivo atender as necessidades de mobilidade dos profissionais de saúde em um ambiente hospitalar. O MobMed envia requisições a um sistema de prontuário eletrônico web e faz a tradução das páginas HTML para uma interface compatível com o dispositivo móvel. Isso permite agilidade no desenvolvimento do sistema móvel, porém exige que o dispositivo móvel esteja conectado à rede para ser operado.

Outros autores que abordaram o problema de integração entre bancos de dados heterogêneos, tendo como principal motivação a integração de bancos de dados federados [SL90]. O trabalho de Sujansky [Suj01] ilustra os desafios existentes na integração de bancos de dados heterogêneos e algumas das soluções existentes. O trabalho de Benguria e Larrucea [BL07] apresenta um comparativo de diferentes técnicas utilizadas na integração de bancos de dados heterogêneos. 


\section{Capítulo 3}

\section{Mecanismo proposto para reconciliação de transações}

Neste capítulo é apresentado como os metadados referentes ao histórico de conflitos podem ser usados de forma a prover flexibilidade no desenvolvimento de aplicações móveis. Em seguida, é descrita a implementação de um arcabouço para reconcilicação de transações que faz uso de metadados e versionamento de dados.

Para reduzir a complexidade envolvida no protocolo de compartilhamento e manter o foco do trabalho na reconciliação das transações, utiliza-se uma topologia em estrela, na qual diversos dispositivos móveis se comunicam com um servidor, que é responsável pela centralização da comunicação, como mostra a Figura 3.1. Dessa forma, os dispositivos móveis não se comunicam diretamente entre si, eles propagam suas atualizações locais e recebem as atualizações realizadas pelos demais dispositivos por meio do servidor central, que é responsável por realizar a reconciliação e propagação de todas as transações originadas nos dispositivos móveis.

O servidor central armazena a cópia primária de todos os dados e está conectado a uma infraestrutura fixa. Dessa forma considera-se que não há desconexão do servidor central. Além disso, assume-se que o servidor central possui recursos abundantes, tanto em poder de processamento quanto em armazenamento e memória, para armazenar todos os dados sendo compartilhados pelos diversos dispositivos móveis. Além dos dados compartilhados, o servidor central armazena uma série de metadados que são utilizados no controle dos dispositivos móveis e no apoio à reconciliação das transações.

Os dispositivos móveis podem possuir recursos muito mais limitados que os recursos do servidor central. Por tal motivo, deve-se poupar ao máximo o uso de recursos dos dispositivos móveis. Dessa forma, esses dispositivos armazenam um subconjunto dos dados armazenados no servidor central. Além disso, assume-se que os dispositivos móveis possuem conectividade intermitente e o custo de conexão e transmissão de dados no dispositivo móvel é variável. Portanto, é de responsabilidade do dispositivo a decisão de quando deve ser feita a comunicação com o servidor central. Por exemplo, caso a única rede disponível seja a rede de telefonia móvel, o dispositivo pode escolher utilizar essa rede para comunicação com o servidor central ou aguardar a presença de uma rede sem fio local, que tenha um baixo custo de transmissão de dados. Os dispositivos móveis armazenam apenas réplicas secundárias, sendo que tais réplicas podem possuir atualizações locais.

Como mencionado anteriormente, toda comunicação é feita entre um dispositivo móvel e o 


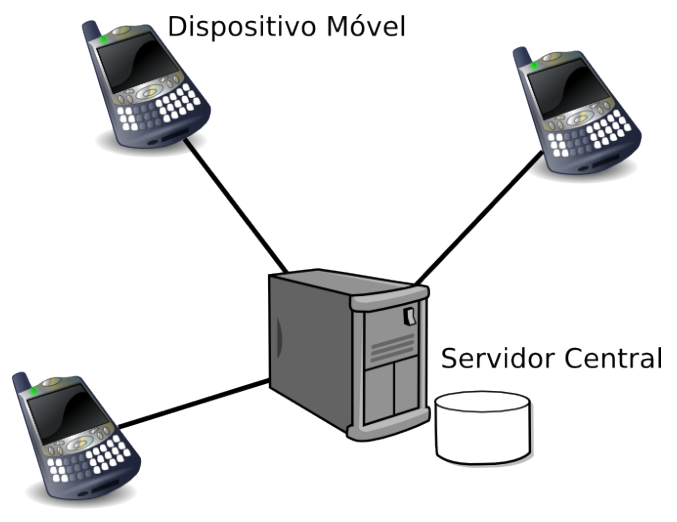

Figura 3.1: Topologia de replicação em estrela: o servidor central mantém a cópia primária de todos os dados que são compartilhados entre os sistemas.

servidor central e é iniciada pelo dispositivo móvel. O servidor central fornece aos dispositivos móveis apenas duas operações: recebe e envia. Os dispositivos móveis requisitam a operação recebe para receber novas réplicas e atualizações para suas réplicas locais. Para propagar suas atualizações realizadas localmente, os dispositivos móveis utilizam a operação envia. A operação recebe dispara, junto ao servidor central, o processo de separação. Já a operação envia dispara o processo de integração.

\subsection{Processo de Separação}

Ao requisitar a operação recebe, o dispositivo móvel solicita ao servidor central a última versão de um determinado dado ou conjunto de dados. O dispositivo móvel requisita essa operação para receber uma réplica de um dado que ele não possui em seu banco de dados local ou, caso o dado solicitado já esteja replicado, para receber as atualizações que foram realizadas por outros dispositivos desde a última vez que o dispositivo requisitou a operação recebe para o dado em questão. O dispositivo móvel não deve requisitar a operação recebe de um dado que possui atualizações locais. Caso o dado possua atualizações locais, o dispositivo móvel deve primeiramente requisitar a operação envia para propagar suas atualizações locais para o servidor central. Só então o dispositivo móvel pode requisitar a operação recebe.

Uma transação móvel é iniciada no momento em que um dispositivo móvel requisita a operação recebe. O dispositivo móvel pode então realizar diversas operações de leitura e escrita sobre a sua réplica parcial dos dados recebidos. Uma transação móvel que possui atualizações é finalizada no momento em que o dispositivo móvel requisita a operação envia e a transação é reconciliada com sucesso. Já as transações somente de leitura são finalizadas de maneira diferente das transações que possuem atualizações. Uma transação somente de leitura é finalizada por meio da operação recebe. A requisição da operação recebe possui dupla função. A primeira é a de solicitar as atualizações realizadas por outros dispositivos móveis no período em que o dispositivo esteve desconectado. A segunda função diz respeito à finalização das transações móveis somente de leitura ativas para o dispositivo móvel requisitante.

O servidor central deve manter em seu banco de metadados a lista de transações móveis ativas. Essa lista corresponde às transações que estão em execução nos diversos dispositivos móveis. Cada entrada na lista de transações móveis ativas deve conter um identificador do dispositivo móvel 
executando a transação, quais dados estão envolvidos na transação móvel e a marca de tempo de quando foi iniciada a transação. Esses dados são utilizados durante a reconciliação da transação pelo servidor central de modo a identificar a ocorrência de conflitos.

\subsection{Processo de Integração}

A operação envia é a operação utilizada pelos dispositivos móveis para propagar suas atualizações realizadas na cópia local dos dados. Essa operação também é utilizada nos casos em que novos dados são criados pelo dispositivo móvel como, por exemplo, a inserção de um novo registro no banco de dados. Nesse caso, os dados propagados não são atualizações de um dado existente no servidor central, mas sim a solicitação de inserção de novos dados no servidor central. Caso a operação envia, requisitada pelo dispositivo móvel e contendo dados a serem inseridos no banco de dados do servidor central, seja finalizada com sucesso, os dados enviados na requisição passam a estar disponíveis para replicação em outros dispositivos móveis.

A reconciliação de transações conflitantes é realizada pelo servidor central de forma automática. Dessa forma, o servidor central deve manter o histórico de reconciliações realizadas e marcar as transações conflitantes, o que permitirá a auditoria e retificação dessa reconciliação. Então, o servidor central informará ao dispositivo móvel a ocorrência de conflitos durante a reconciliação. Assim, o dispositivo móvel informará ao usuário o conflito ocorrido.

A propagação das atualizações é feita por meio de transferência de estado, ou seja, o dispositivo móvel deve enviar ao servidor central o estado resultante das atualizações realizadas sobre sua réplica local. Isso simplifica a implementação das aplicações móveis, uma vez que não será necessário que o dispositivo armazene o histórico de atualizações. O dispositivo móvel não deve manter o histórico de atualizações e dados que foram atualizados. O servidor central deve ser capaz de identificar as atualizações realizadas pelo dispositivo comparando os dados propagados pelo dispositivo aos dados enviados anteriormente ao dispositivo (armazenados juntamente com a lista de transações móveis ativas).

O Algoritmo 1 descreve esse processo de integração de dados. Note que o esse processo é idependente do mecanismo de resolução de conflitos. Isso permite que diferentes aplicações utilizem diferentes mecanismos de resolução de conflitos ou que uma aplicação utilize mecanismos diferentes para diferentes tipos de dados.

\subsection{Auditoria e Retificação de Conflitos}

A auditoria e retificação de conflitos é realizada junto ao servidor central. O servidor central pode fornecer aos dispositivos móveis uma interface de acesso ao módulo de auditoria e retificação de conflitos. E essa tarefa deve ser feita de forma síncrona, ou seja, o dispositivo móvel deve estar conectado à rede para realizar tal operação. O módulo de auditoria e retificação deve fornecer o histórico de reconciliações de transações conflitantes e, para cada reconciliação de transações conflitantes, as diferentes versões conflitantes, a versão resultante da resolução do conflito e o algoritmo utilizado na resolução do conflito. O módulo de auditoria e retificação de conflitos deve também fornecer uma operação de retificação das reconciliações.

É responsabilidade do servidor central o controle de quais dispositivos possuem réplicas secun- 


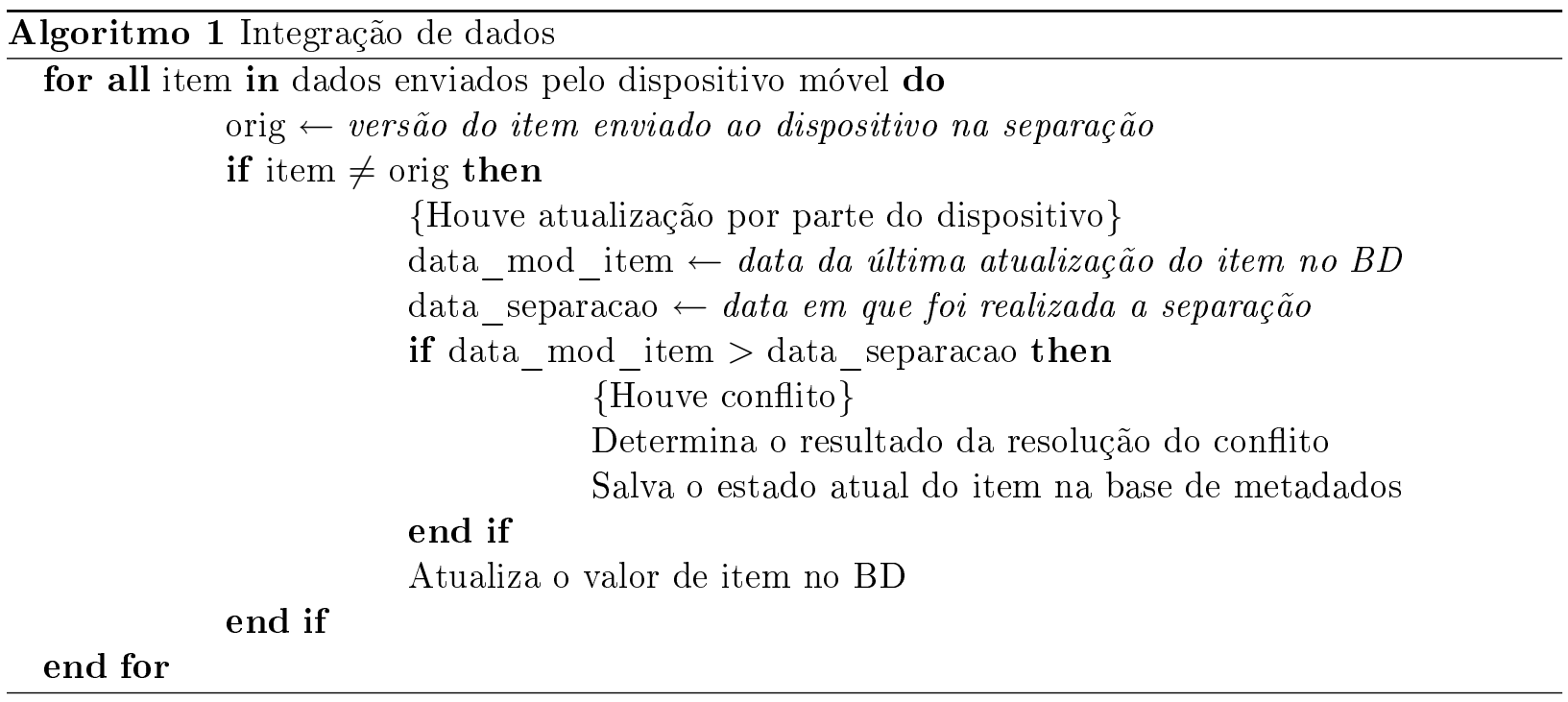

dárias e o estado dessas réplicas. Dessa forma, ao requisitar a operação recebe, o dispositivo móvel deve identificar-se e, em seguida, informar quais os dados que ele deseja receber. Um efeito colateral da operação recebe é a atualização do estado do dispositivo móvel requisitante junto ao servidor central. Em outras palavras, é por meio da operação recebe que o servidor central é informado de quais dados estão replicados em cada um dos dispositivos móveis e qual o estado desses dados. Por esse motivo, o dispositivo móvel deve ter um mecanismo de descarte de quaisquer réplicas secundárias nele armazenadas que não tenham sido solicitadas na última requisição da operação recebe. É considerado um erro o envio de atualizações, por meio da operação envia, sobre dados que não constavam da última operação recebe requisitada pelo dispositivo móvel em questão. O servidor central deve rejeitar uma requisição como essa.

\subsection{Arcabouço para Reconciliação de Transações}

Um arcabouço para reconciliação de transações foi desenvolvido para exemplificar a implementação do modelo de transações proposto. Esse arcabouço foi desenvolvido como uma extensão do arcabouço de mapeamento objeto-relacional Active Record ${ }^{1}$.

O arcabouço desenvolvido cria, de maneira automática, a infraestrutura necessária para armazenamento dos metadados e para o versionamento de dados. Além disso, uma interface de programação é fornecida de forma a permitir que a aplicação tenha acesso a esses metadados de maneira simplificada.

A criação dos metadados durante o processamento de uma transação móvel ocorre em dois momentos: o primeiro durante o processo de separação e o segundo durante o processo de integração. Durante o processo de separação, uma nova transação móvel é criada e alguns metadados que descrevem essa transação são armazenados. Durante o processo de integração, os metadados armazenados na etapa anterior são utilizados para identificar e resolver possíveis conflitos. Os metadados criados durante o processo de integração registram a ocorrência e resolução dos conflitos e o versionamento de dados.

\footnotetext{
${ }^{1}$ http://api.rubyonrails.org/classes/ActiveRecord/Base.html
} 


\subsubsection{Implementação do processo de separação}

Durante o processo de separação, são gerados e armazenados os metadados que auxiliarão na reconciliação das transações executadas no dispositivo móvel. Os metadados gerados durante o processo de separação são armazenados junto ao banco de dados do servidor central em uma tabela denominada sincronizacaos. Essa tabela é acessada pelo módulo de sincronização por meio do arcabouço Active Record. O nome da tabela foi escolhido de maneira a seguir as convenções utilizadas pelo arcabouço, de maneira que o objeto do arcabouço utilizado para acessar a tabela é denominado Sincronizacao. A seguir são descritos os metadados que são armazenados em cada uma das colunas da tabela sincronizacaos:

- id: número inteiro identificador único para cada requisição de separação de dados. Esse identificador é utilizado como o identificador de sessão que é enviado ao dispositivo móvel. O dispositivo móvel deve informar o identificador de sessão durante processo de integração para que o módulo de sincronização possa relacionar a requisição em questão com os metadados que foram armazenados durante o processo de separação.

- separacao: texto contendo o XML gerado durante o processo de separação para envio ao dispositivo móvel.

- integracao: texto contendo o XML enviado pelo dispositivo móvel durante o processo de integração.

- usuario_separacao: identificador do usuário que autenticou no sistema durante o processo de separação.

- usuario_integracao: identificador do usuário que autenticou no sistema durante o processo de integração. Essa coluna será populada durante o processo de integração.

- conflito: valor booleano que indica se houve conflito durante o processo de integração.

- created_at: data em que a entrada foi criada na tabela. Essa coluna é atualizada automaticamente pelo arcabouço de persistência e corresponde à data em que foi realizado o processo de separação, com uma granularidade na ordem de microssegundos.

- updated_at: data da última atualização da entrada. Essa coluna é atualizada automaticamente pelo arcabouço de persistência.

\subsubsection{Implementação do processo de integração}

Durante o processo de integração é realizado a identificação e resolução de conflitos e versionamento de dados. Para implementação desse processo fez-se extenso reúso do arcabouço de Active Record utilizando-se da técnica de mixin para estender suas funcionalidades. Isso permitiu uma rápida prototipação de um esquema genérico de identificação e resolução de conflitos. Esse esquema genérico de identificação e resolução de conflitos permite a evolução do modelo de dados sem a necessidade de alteração do módulo de sincronização, além de permitir a inclusão de novas entidades à sincronização de maneira bastante simples. 


\section{O arcabouço de persistência ActiveRecord}

O arcabouço de persistência fornecido pelo Ruby on Rails é denominado Active Record ${ }^{2}$. Sua interface de programação inclui um procedimento de atualização em massa. Esse procedimento recebe como parâmetro de entrada os dados de uma entidade do banco de dados e atualiza esses dados no banco de dados. Seguindo a política de convention over configuration [Che06], o procedimento de atualização em massa pressupõe que a entidade possui uma chave primária denominada id. Caso o valor para esse atributo seja fornecido junto com os demais dados, o procedimento gerará uma requisição de atualização no banco de dados; caso não seja fornecido um valor para esse atributo, o procedimento gerará uma requisição de inserção no banco de dados.

Há duas características do procedimento de atualização fornecido pelo Active Record que o tornam especialmente útil para a implementação da identificação e resolução de conflitos: (1) a possibilidade de aninhamento de entidades (o que caracteriza a atualização em massa) e (2) a execução de validações das entidades sendo atualizadas.

Os dados de entrada do procedimento de atualização em massa são passados no formato de um emphhashmap, uma estrutura de dados da linguagem ruby do tipo chave/valor. Cada item do emphhashmap deve corresponder ao nome de um atributo da entidade e o valor a ser armazenado nesse atributo. Um emphhashmap pode armazenar tanto valores com tipos primitivos, como inteiros e strings, quanto valores com tipos complexos, como vetores ou mesmo outros emphhashmaps.

Utilizando uma única chamada do procedimento de atualização em massa é possível atualizar, além da entidade em questão, também outras entidades relacionadas, daí o nome de atualização em massa. Para fazer uso dessa funcionalidade basta passar um outro emphhashmap como valor de um dos items, criando, assim, entidades aninhadas. A chave de uma entidade aninhada deve corresponder ao nome do atributo que identifica o relacionamento da entidade principal com a entidade aninhada. Para exemplificar, considere uma entidade Pessoa que possui um relacionamento um para um com a entidade Endereco. Dessa forma, o código para atualizar ambas as entidades utilizando uma única chamada é mostrado na Listagem 3.1:

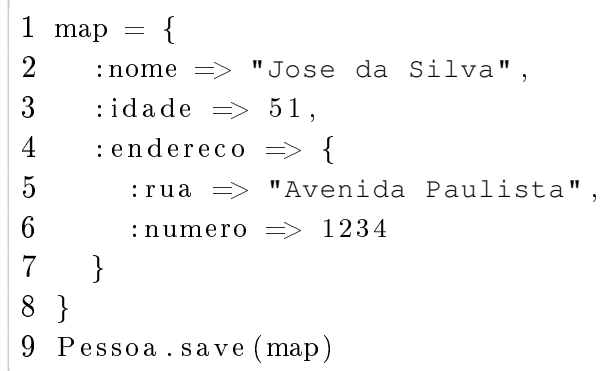

Listing 3.1: Exemplo de XML com tabelas de apoio

A segunda característica que torna o uso do Active Record especialmente interessante para a implementação da identificação e resolução de conflitos é a execução de validações das entidades sendo atualizadas. O arcabouço Active Record fornece uma interface de programação que permite a definição de entidades, que tipicamente correspondem a uma tabela do banco de dados. Na definição da entidade é possível definir regras de integridade dos dados por meio de procedimentos que são implementados na linguagem Ruby.

No momento da atualização de uma entidade, o Active Record executa cada um dos métodos

\footnotetext{
${ }^{2}$ http://ar.rubyonrails.org
} 
de validação daquela entidade, passando para os métodos os valores sendo atualizados. Os métodos de validação são responsáveis então por validar os dados e informar o Active Record caso os dados não sejam válidos. Ao final da execução de todos os métodos de validação da entidade, caso algum dos métodos tenha sinalizado que os dados são inválidos, o Active Record aborta a execução da atualização informando quais dados são inválidos e uma mensagem informativa gerada pelo método de validação. No caso de atualizações em massa, em que várias entidades são atualizadas em uma única chamada, as validações de todas as entidades envolvidas são executadas e a atualização de todas as entidades envolvidas é abortada caso um dos métodos de validação sinalize a atualização com dados inválidos.

Outra funcionalidade fornecida pelo Active Record é a manutenção automática das datas de criação e última atualização de todos os registros do banco de dados mantidos pelo arcabouço. Isso é feito adicionando automaticamente a todas as tabelas as colunas created_at e updated_at. Essas colunas armazenas, respectivamente, a data de criação do registro e a data da última atualização do registro. Os valores armazenados nessas colunas possuem uma granularidade na ordem de microssegundos e são gerados automaticamente pelo Active Record. Essa funcionalidade foi utilizada para identificar conflitos de atualização durante o processo de integração.

\section{Identificação e resolução de conflitos}

O processo de separação envia ao dispositivo móvel o estado do banco de dados do servidor central no instante da requisição. Além disso, como visto anteriormente, o processo de separação armazena, junto com outros metadados, a marca de tempo em que foi executada a requisição de separação de dados. Dessa forma, é possível identificar conflitos de atualização verificando, para cada dado que foi atualizado pelo dispositivo móvel, se houve uma atualização desde a data da requisição de separação. Em outras palavras, um conflito é identificado caso o dispositivo móvel tenha atualizado (em seu banco de dados local) um dado X, e a data da última atualização (valor da coluna updated_at) desse mesmo dado X no banco de dados do servidor central seja posterior à data em que o dispositivo móvel realizou a leitura desse dado, ou seja, posterior à data do processo de separação.

Essa verificação foi implementada adicionando-se um método de validação às entidades que podem ser sincronizadas. Esse método pressupõe que as entidades possuem o atributo updated_at e compara esse valor com a data de execução do processo de separação. Caso seja identificado um conflito, o método acusa uma falha na validação e indica que essa falha foi devido a um conflito de atualizações. Isso faz com que a atualização seja abortada. Um detalhe importante é que essa validação não faz sentido para atualizações não relacionadas à sincronização, assim deve ser possível habilitar e desabilitar essa validação. Dessa forma, o método de validação que realiza a identificação de conflitos apenas será executado durante uma atualização iniciada pelo processo de integração.

Uma vez identificado um conflito é necessário realizar a resolução desse conflito. O módulo de sincronização possui as informações necessárias para a resolução dos conflitos: a versão do dado gerado pelo dispositivo móvel, a versão gerada pela transação concorrente (versão presente no banco de dados do servidor central), e a versão anterior a ambas as atualizações. A aplicação pode fornecer uma função de resolução de conflitos, que recebe como parâmetros de entrada as três versões do dado mencionadas (as duas versões com atualizações conflitantes mais a versão original, sem tais atualizações) e devolve como resultado o valor a ser armazenado (resultado da resolução do conflito). 
Caso a aplicação não forneça uma função de resolução de conflitos, uma função padrão é executada. A função de resolução de conflitos padrão que foi implementada utiliza um algoritmo de resolução de conflitos por ordenação, sendo a data da requisição de integração utilizada como critério de ordenação

\section{Versionamento de dados}

Dentre os metadados armazenados gerados que possibilitarão a auditoria e retificação de conflitos, o mais importante é o versionamento dos dados. Para implementação do versionamento de dados utilizou-se um plugin para o Ruby on Rails denominado PaperTrail ${ }^{3}$. Esse plugin provê uma interface de programação para versionamento de dados de fácil utilização.

$\mathrm{O}$ versionamento de entidades pode ser habilitado ou desabilitado a qualquer momento. Quando habilitado, ao atualizar uma entidade o estado anterior à atualização é armazenado em uma tabela separada. Isso permite a recuperação de versões históricas da entidade. Além disso, ao armazenar em uma tabela específica para versionamento, as tabelas das entidades versionadas não precisam ser modificadas com esse propósito. As consultas que não estão interessadas em versões históricas dos dados também não precisam ser modificadas. Dessa forma, o versionamento é transparente para o servidor central, sendo o módulo de sincronização o único ciente do comportamento de versionamento das entidades.

A Listagem 3.2 apresenta um exemplo de como o plugin PaperTrail pode ser utilizado para versionar uma entidade e recuperar as diversas versões dessa entidade. As linhas 1 a 3 definem uma entidade Pessoa e habilitam o versionamento dessa entidade. O ActiveRecord não exige a definição dos atributos da entidade pois ele recupera essas informações diretamente do esquema do banco de dados. Na linha 5, é recuperado um registro por meio de sua chave primária e armazenado em uma variável. Essa variável é do tipo Pessoa e possui o método versions, que foi adicionado pelo PaperTrail. O método versions (linha 6) retorna um conjunto de objetos do tipo Version. Cada objeto do tipo Version encapsula uma versão do registro, além de alguns metadados relacionados a essa versão, como por exemplo a data em que foi executada a atualização que gerou a versão. Vale ressaltar que todos os objetos retornados pelo método versions correspondem a versões históricas. Assim, na linha 7 atribui-se à variável v a versão anterior à última atualização do registro. Para exemplificar alguns dos metadados que são fornecidos pelos objetos do tipo Version, na linha 8 é recuperada a operação que gerou a versão em questão. O valor retornado pode ser "update", "create" ou "destroy", que correspondem, respectivamente, às operações do banco de dados de update, insert e delete. A linha 9 recupera o identificador do usuário que realizou a operação de atualização. A linha 10 recupera a data em que foi realizada a operação de atualização. A linha 11 recupera o estado do registro antes da operação de atualização. Caso o evento que tenha gerado essa versão tenha sido um create, a linha 11 retorna o valor nil. É importante ressaltar que nenhuma das operações apresentadas na Listagem 3.2 realiza atualizações em qualquer tabela do banco de dados, ou seja, são operações somente de leitura. Mesmo após a execução da linha 11, nenhuma alteração é feita no banco de dados. Para que haja um reflexo no banco de dados é necessário realizar essa operação explicitamente, nesse caso executando pessoa.save após a linha 11.

1 class Pessoa < ActiveRecord : : Base

2 has_paper_trail

\footnotetext{
${ }^{3}$ http://airbladesoftware.com/tags/papertrail
} 


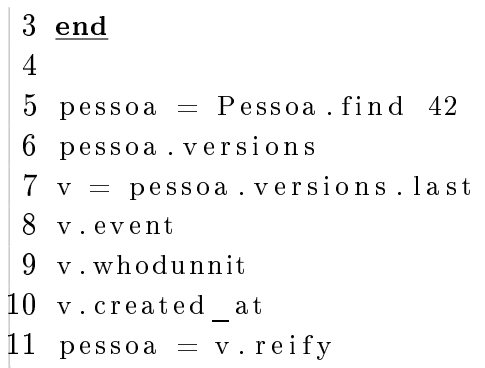

Listing 3.2: Exemplo de XML com tabelas de apoio

A infraestrutura de versionamento criada pelo PaperTrail se restringe a uma única tabela onde são armazenadas as versões históricas de todas as entidades junto aos demais metadados necessários para o versionamento. Cada entrada da tabela armazena uma versão de uma entidade. Essa tabela é denominada versions e possui as seguintes colunas:

- id: identificador único para cada entrada da tabela.

- item_type: entidade a que se refere a versão armazenada.

- item_id: identificador da versão armazenada.

- event: evento que gerou a versão armazenada (create, update ou destroy).

- whodunnit: identificador do usuário que executou a atualização que gerou a entrada.

- object: XML que corresponde aos dados da versão.

- created_at: data de criação da entrada.

Além dessas colunas, que são geradas automaticamente pelo PaperTrail, é possível adicionar novas colunas que armazenarão metadados adicionais. Para que o PaperTrail possa preencher as colunas adicionais é necessário fornecer um procedimento que será executado pelo PaperTrail automaticamente no momento da criação de uma nova entrada na tabela versions. Para facilitar a busca das diversas versões geradas por uma sincronização, adicionou-se à tabela versions a coluna sincronizacao, que armazena o identificador da entrada na tabela sincronizacaos responsável pela versão. 


\section{Capítulo 4}

\section{Estudo de caso: Borboleta e SAGUISaúde}

Este capítulo tem por objetivo apresentar a aplicação do modelo proposto em sistemas reais. Para isso implementou-se o compartilhamento de dados por replicação em uma aplicação utilizando metadados no apoio à reconciliação de transações como proposto no Capítulo 3. A aplicação utilizada como estudo de caso é o SAGUISaúde, um sistema de prontuário eletrônico voltado a centros de saúde. O SAGUISaúde é um sistema web que integra-se com o Borboleta, um sistema de prontuário eletrônico desenvolvido para dispositivos móveis. De modo a esclarecer os requisitos desses dois sistemas no que tange a integração de dados, a seguir é abordado brevemente o contexto no qual esses sistemas são utilizados e em seguida apresenta-se uma descrição dos sistemas e dos dados envolvidos. Em seguida é descrito a implementação do modelo proposto no Capítulo 3 para integração dos sistemas SAGUISaúde e Borboleta.

Os Centros de Saúde, também denominados de Unidades Básicas de Saúde (UBSs), têm o papel de órgãos provedores da atenção primária à saúde, conforme definido pelo SUS (Sistema Único de Saúde) brasileiro. Para atender uma cidade, existem várias UBSs, sendo que cada uma é responsável pelos cuidados à população de um território definido. Entre as principais atribuições das UBSs estão as ações de promoção da saúde, prevenção de agravos e atenção aos principais problemas de saúde da população.

Visando promover a saúde preventiva de maneira mais eficaz, além do atendimento no Centro de Saúde, os profissionais de saúde atuam proativamente em sua região, deslocando-se até residências ou locais públicos. Nesses eventos, ou encontros, o profissional de saúde realiza uma série de observações com relação à situação da pessoa atendida, suas atividades e o ambiente em que vive.

\subsection{Registro Eletrônico de Saúde}

Um dos sistemas de informação mais importantes para uma UBS é o Prontuário Eletrônico ou Registro Eletrônico de Saúde (RES), que é um sistema que armazena os registros médicos (prontuários) dos pacientes em meios digitais [BEG $\left.{ }^{+} 03\right]$. Um RES melhora a qualidade dos serviços de saúde devido à facilidade de guardar e posteriormente fornecer informações de forma clara, organizada e rápida aos seus usuários. O SAGUISaúde [DCK $\left.{ }^{+} 08\right]$ é um sistema de prontuário eletrônico de código aberto desenvolvido pelo Centro de Competência em Software Livre (CCSL) 
da USP em conjunto com o Centro de Saúde Escola do Butantã (CSEB) da Faculdade de Medicina da USP. O sistema se propõe a atender às necessidades específicas dos centros de saúde, gerenciando informações como: cadastro de usuários, histórico de encontros, cadastro de medicamentos, consultas e exames.

Um ponto importante no desenvolvimento de um RES para Centros de Saúde é que o sistema deve ser capaz de atender tanto suas atividades internas como as externas. Nesse sentido, para dar apoio ao atendimento domiciliar, foi desenvolvido pelo CCSL, com a colaboração do CSEB, o Borboleta [CKK08], um sistema móvel de prontuário eletrônico integrado ao SAGUISaúde. Com a proposta de ser uma extensão móvel do SAGUISaúde, o Borboleta permite sua instalação em celulares inteligentes, permitindo que os profissionais de saúde possam registrar as informações do encontro diretamente em meios digitais, mesmo quando atuando fora da UBS.

\subsection{O Sistema SAGUISaúde}

O sistema SAGUISaúde utiliza a tecnologia Ruby on Rails ${ }^{1}$ e é formado por três módulos principais: cadastro de usuários, administração do sistema e histórico e agendamento de encontros. A página inicial do SAGUISaúde, pode ser visualizada na Figura 4.1.

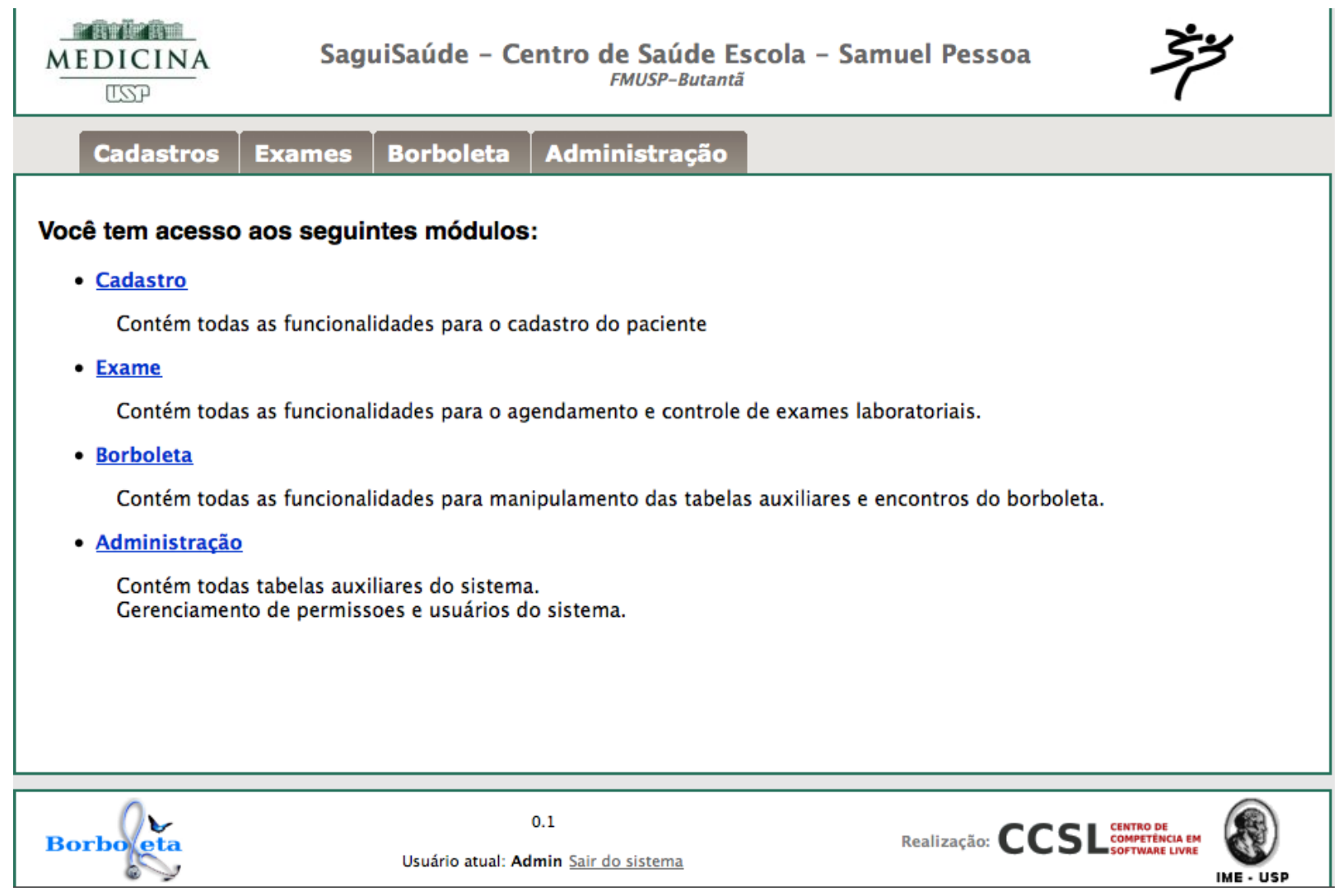

Figura 4.1: Página inicial do SAGUISaúde

O cadastro de usuários possui dados pessoais e socioeconômicos dos usuários. Usuários incluem pacientes, médicos, enfermeiros e demais funcionários do centro de saúde, sendo que a caracterização dos diversos usuários se dá pela definição de tipos de usuários. Os tipos de usuários definem a semântica de interpretação do relacionamento entre usuários.

\footnotetext{
${ }^{1}$ http://rubyonrails.org
} 
O módulo de histórico e agendamento de encontros gerencia os encontros realizados com os diversos pacientes e os agendamentos de futuros encontros. Um encontro é caracterizado pela interação entre paciente e profissional de saúde em um dado momento. $O$ encontro possui informações em formato estruturado, texto, e voz, que englobam o estado de saúde do paciente, suas atividades diárias, o ambiente em que vive, o tratamento médico ao qual o paciente é submetido e a evolução da saúde desse paciente. Um encontro pode ser realizado por meio de uma visita do profissional de saúde ao domicílio do paciente, uma visita do paciente ao centro de saúde ou mesmo por meio de ações comunitárias em espaços públicos na região de atendimento do centro de saúde, como escolas e praças. Durante um encontro, o profissional de saúde coleta uma série de informações referentes à saúde do paciente e o ambiente no qual ele vive e, com base nas informações coletadas e em sua experiência profissional, realiza uma série de ações no sentido de orientar e promover a saúde do paciente sendo atendido. Tanto as informações coletadas durante o encontro quanto as ações tomadas pelo profissional de saúde devem ser registradas de maneira a prover um histórico da evolução da saúde do paciente. Essas informações serão posteriormente utilizadas para instrumentar o profissional de saúde em futuros encontros com o paciente, permitindo que o profissional de saúde estabeleça um plano de promoção da saúde do paciente.

O modelo de dados conceitual do sistema SAGUISaúde pode ser visto na Figura 4.2. O encontro é a entidade central do modelo de dados, relacionando o paciente, o profissional de saúde, as informações coletadas e as ações tomadas pelo profissional de saúde. Uma coleta de informação pode ser especializada em aplicação de questionários, levantamento de antecedentes de saúde do paciente, medições, levantamento de sintomas, levantamento do uso de medicamentos por parte do paciente ou resultados de exames realizados pelo paciente. Uma ação pode ser especializada em procedimento de saúde, prescrição médica, atividade, encaminhamento médico ou um diagnóstico. Observe que, embora paciente e profissional de saúde apareçam na Figura 4.2 como classes de entidades separadas, eles são representados de fato como diferentes papéis de uma mesma classe de entidade usuário. O modelo lógico do SAGUISaúde pode ser visto no Apêndice A.

O módulo de administração pode ser dividido em duas partes: tabelas de apoio e controle de acesso. As tabelas de apoio correspondem à configuração de dados estáticos utilizados pelo sistema, incluindo listas de doenças, medicamentos, ruas, religiões, tipos de documentos, níveis de educação, etc. O SAGUISaúde evita acoplar esses dados ao código de forma a possibilitar a evolução do sistema apenas reconfigurando o mesmo. Não existe ainda um consenso na comunidade médica com relação à terminologia a ser utilizada em sistemas de prontuário eletrônico. Dessa forma, acoplar esses dados ao código de maneira estática impossibilitaria a adaptação do sistema a centros de saúde em contextos diversos, como por exemplo centros de saúde em diversos estados da federação.

O controle de acesso engloba a administração dos usuários do sistema e as permissões desses usuários para executar as diversas funções do sistema. Uma preocupação presente durante todas as etapas do desenvolvimento de um sistema de prontuário eletrônico diz respeito à segurança do sistema e privacidade dos dados. Dados armazenados em um sistema de prontuário eletrônico são sigilosos, e é necessário garantir que apenas pessoas autorizadas terão acesso a esses dados. Para isso, o sistema possui um módulo de controle de acesso baseado em papéis que permite ao administrador do sistema gerenciar os usuários do sistema, a que dados cada usuário possui acesso, e os serviços que podem executar.

O código do SAGUISaúde é distribuído livremente como software aberto e pode ser baixado a 


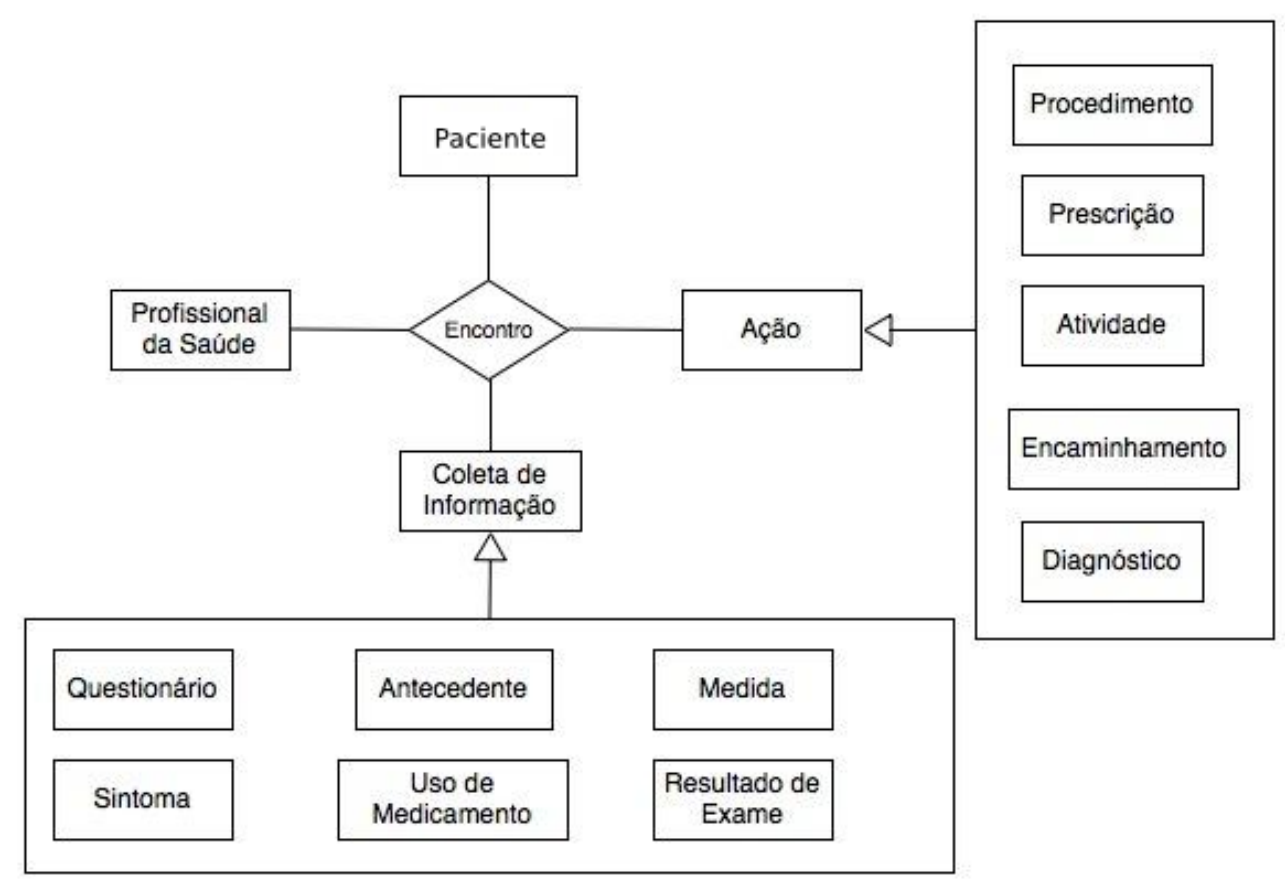

Figura 4.2: Modelo conceitual dos dados do SAGUISaúde. Um encontro relaciona paciente, profissional de saúde, informações coletadas e ações tomadas pelo profissional. Uma coleta de informação pode ser especializada em aplicação de questionários, levantamento de antecedentes de saúde do paciente, medições, levantamento de sintomas, levantamento do uso de medicamentos por parte do paciente ou resultados de exames realizados pelo paciente. Uma ação pode ser especializada em procedimento de saúde, prescrição médica, atividade, encaminhamento médico ou um diagnóstico.

partir do site do projeto: http://ccsl.ime.usp.br/borboleta.

\subsection{O Sistema Borboleta}

O sistema Borboleta tem por objetivo prover um sistema de prontuário eletrônico móvel para smartphones e PDAs, de modo a substituir os formulários de papel que são utilizados em atendimentos domiciliares. Dessa forma, é possível recuperar mais facilmente todo o histórico do paciente durante um atendimento domiciliar, melhorando, assim, a qualidade do atendimento. Ao eliminar a necessidade de redigitação das informações que estão em formulários de papel, reduz-se a carga de trabalho dos profissionais de saúde, além de reduzir também o risco de erros durante essas redigitações. O sistema foi desenvolvido de maneira a minimizar a necessidade de digitação durante a entrada de dados.

Assim como o SAGUISaúde, o Borboleta tem como usuários os profissionais de um centro de saúde. Por esse motivo também possui como entidade central o encontro. As seguintes funcionalidades são fornecidas pelo Borboleta [Cor11]:

- Cadastro de pacientes: armazena os dados pessoais do paciente, incluindo nome, número de matrícula no centro de saúde, data de nascimento, nome da mãe e endereço de residência do paciente.

- Dados socioeconômicos: armazena informações relativas à situação financeira e social do paciente, tais como profissão, escolaridade, nacionalidade e religião. 
- Cuidador: o registro do cuidador refere-se à pessoa que auxiliará o paciente no seu tratamento na ausência do profissional de saúde.

- Registro de encontros: entrada de dados e armazenamento das informações coletadas pelo profissional de saúde durante um encontro.

- Agendamento de futuros encontros: permite que o profissional de saúde agende novos encontros de modo a dar prosseguimento no tratamento do paciente.

- Histórico de encontros: permite ao profissional de saúde consultar o histórico de encontros realizados com o paciente, incluindo as informações coletadas e anotações realizadas durante esses encontros.

- Catálogo de doenças: permite a consulta a um extenso catálogo de doenças padronizado pela Organização Mundial de Saúde, denominado CID (Catálogo Internacional de Doenças). Esse catálogo é utilizado no diagnóstico do paciente.

- Catálogo de medicamentos: fornece uma lista de medicamentos disponíveis na farmácia do centro de saúde, bem como informações adicionais sobre esses medicamentos. Esse catálogo é utilizado no registro de prescrições médicas durante um encontro.

A Figura 4.3 apresenta três telas do Borboleta: da esquerda para a direita, Cadastro de Pacientes, Registro de Encontros e Motivos do Encontro. A tela da esquerda, Cadastro de Paciente, é a tela que permite ao profissional de saúde consultar e atualizar os dados pessoais de um paciente. A tela do centro, Registro de Encontros, é a tela inicial de registro de encontros. Essa tela dá acesso às demais seções que constituem um encontro, a saber Caracterização Geral, Dados Específicos, Problemas/Necessidades e Programação Final. A tela da direita, Motivos do Encontros, é uma das telas que constituem a seção de Dados Específicos do encontro.

As tecnologias utilizadas no desenvolvimento do Borboleta incluem a plataforma Java $\mathrm{ME}^{2}$, e a biblioteca de interfaces LWUIT $^{3}$. O Borboleta não dispõe de um sistema gerenciador de banco de dados tradicional para persistência de dados. Isso porque tal recurso não está presente nas plataformas utilizadas para desenvolvimento do Borboleta. Assim, a tecnologia utilizada pelo Borboleta para persistência de dados é o RecordStore ${ }^{4}$, um mecanismo de persistência independente de plataforma, baseado em registros, fornecido pela plataforma Java ME. As operações fornecidas por essa tecnologia correspondem ao armazenamento de registros de forma linear e a recuperação de registros por índice. As operações de armazenamento de um registro e de recuperação de um registro são atômicas, fornecendo, assim, garantias mínimas de integridade dos dados. No entanto não há qualquer recurso para implementação de transações ou manutenção de relacionamentos entre registros e integridade referencial, ficando a cargo do programador implementar tais funcionalidades.

O código do Borboleta é distribuído livremente como software aberto e pode ser baixado a partir do site do projeto: http://ccsl.ime.usp.br/borboleta.

\footnotetext{
${ }^{2}$ http://www.oracle.com/technetwork/java/javame

${ }^{3}$ http://lwuit.java.net

${ }^{4}$ http://java.sun.com/javame/reference/apis/jsr118/javax/microedition/rms/RecordStore.html
} 

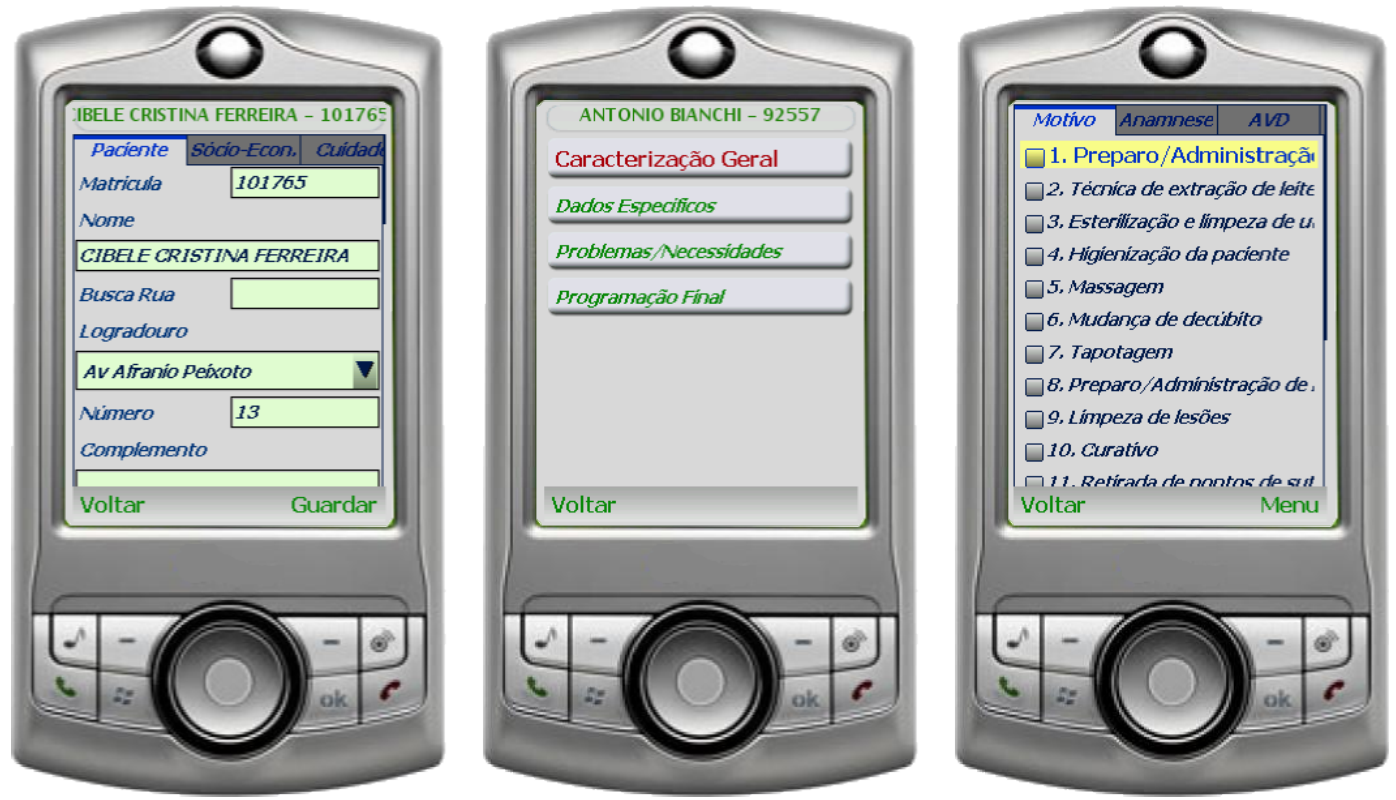

Figura 4.3: Telas do Borboleta: à esquerda apresenta-se a tela de cadastro de pacientes, que permite a consulta e atualização dos dados pessoais de um paciente. Ao centro apresenta-se a tela inicial de registro de encontros, que fornece acesso às seções de Caracterização Geral, Dados Específicos, Problemas/Necessidades e Programação Final. À direita apresenta-se a tela de Motivos do Encontro, que pertence à seção de Dados Especificos do encontro.

\subsection{Compartilhamento de dados}

O desenvolvimento de um sistema de informação móvel como o Borboleta integrado a um sistema de informação central como o SAGUISaúde apresenta uma série de desafios a serem superados. O primeiro deles diz respeito ao acesso aos dados. Os sistemas móvel e central compartilham dados que podem ser estáticos ou dinâmicos. Um exemplo de dados estáticos compartilhados é a lista dos estados da federação e suas respectivas siglas. Ambos os sistemas central e móvel fazem uso desses dados de forma paralela e cooperativa mas não realizam operações de escrita sobre eles. Dados compartilhados de forma dinâmica são dados que sofrem alterações por parte do sistema central, do sistema móvel, ou de ambos. Um RES para um Centro de Saúde deve permitir que os sistemas central e móvel compartilhem dados de forma dinâmica, realizem operações de leitura e atualização sobre esses dados sem atrasos e tenham acesso aos dados atualizados. Esses requisitos tornam-se desafiadores em um ambiente de computação móvel devido a atrasos na comunicação, períodos de indisponibilidade e a escassez de recursos em dispositivos móveis. Um exemplo de dados compartilhados de forma dinâmica é o cadastro de medicamentos. O Borboleta realiza operações de leitura sobre o cadastro de medicamentos enquanto o SAGUISaúde realiza operações de leitura e escrita. Um outro exemplo é o cadastro de pacientes, sobre o qual tanto o Borboleta quanto o SAGUISaúde realizam operações de leitura e escrita.

\subsubsection{Necessidade de replicação de dados}

Em um sistema de informação móvel existem duas formas para acesso aos dados: (1) remoto, por meio de uma conexão com os servidores do Centro de Saúde - denominado acesso online, ou (2) local, utilizando uma réplica parcial desses dados. O acesso online aos dados é impraticável, no contexto de atendimento público de saúde domiciliar, devido ao alto custo do serviço de transferência 
de dados, instabilidade de sinal e indisponibilidade do serviço em regiões remotas.

A alternativa viável que não exige o acesso online ao banco de dados do centro de saúde é a replicação parcial dos dados nos dispositivos móveis. Ainda na UBS, o profissional de saúde efetua um processo de separação de dados, no qual os registros das pessoas a serem visitadas, que estão armazenados no banco de dados da UBS, são replicados no dispositivo móvel utilizando-se da infraestrutura disponível na UBS, como por exemplo uma rede WiFi. Com essa réplica dos dados, os profissionais de saúde podem se deslocar até as residências e realizar seu trabalho. Nesse momento, operações de leitura e escrita são efetuadas sobre os dados da réplica. Posteriormente, quando o profissional voltar ao centro de saúde, será necessário um processo de integração dos dados do dispositivo móvel com o banco de dados central para que as atualizações efetuadas durante a visita fiquem disponíveis no sistema central.

Replicação de dados tem sido bastante utilizada para se obter maior disponibilidade em sistemas móveis. Técnicas tradicionais de replicação sempre bloqueiam o acesso a uma réplica exceto quando essa réplica já esteja atualizada e, por isso, tais técnicas são chamadas de pessimistas [SS05]. Ao utilizar esse tipo de técnica em um ambiente de sistemas móveis como o Borboleta, replicar um registro em um dos dispositivos móveis implica em bloquear o acesso a esse registro em todos os demais nós, incluindo o banco de dados central. Esse bloqueio ficaria ativo durante todo o período de uma visita, durante o qual o dispositivo móvel estaria desconectado.

Em oposição às técnicas pessimistas existem as técnica chamadas de otimistas. Segundo Saito e Shapiro [SS05], a principal característica que separa os algoritmos de replicação otimistas dos algoritmos de replicação pessimistas é a abordagem com relação ao controle de concorrência. Algoritmos pessimistas coordenam as réplicas sincronamente durante o acesso e bloqueiam outros usuários durante uma atualização. Algoritmos otimistas permitem que dados sejam acessados sem sincronização a priori baseados na suposição "otimista" de que problemas ocorrerão apenas raramente, se acontecer. As atualizações são propagadas assincronamente e eventuais conflitos são resolvidos depois que já aconteceram.

O uso de técnicas tradicionais de replicação no Borboleta/SAGUISaúde causaria muitos inconvenientes, pois manteria bloqueado um registro no banco de dados central durante todo o período em que o dispositivo móvel, armazenando uma cópia desse registro, estivesse fora do centro de saúde ou desligado. Diante disso, este trabalho propõe o uso de técnicas de replicação otimistas para controle de concorrência no Borboleta/SAGUISaúde, permitindo assim que atualizações sejam feitas tanto no banco de dados central quanto no dispositivo móvel, independente da configuração de replicação corrente dos dados. Porém, para implementar essa solução, três desafios devem ser superados: (1) O sistema móvel não permite um controle rígido de atualizações, por isso o sistema central deve ser capaz de identificar, no momento da integração, quais dados foram atualizados pelo dispositivo móvel. (2) O processo de integração deve também ser capaz de identificar conflitos quando eles ocorrerem. (3) O sistema central deve ser capaz de resolver os conflitos, preferencialmente de maneira automática.

Este trabalho propõe o compartilhamento de dados entre os sistemas SAGUISaúde e Borboleta por meio de replicação assíncrona e controle de concorrência otimista. O SAGUISaúde é responsável pela centralização dos dados de pacientes e encontros. Ele tem acesso de leitura e escrita aos registros de todos os pacientes do Centro de Saúde e deve estar disponível para uso dos profissionais de saúde situados no Centro de Saúde. 
Apenas um subconjunto dos registros de pacientes e encontros é replicado no Borboleta. Existem diversas instâncias do Borboleta instaladas em vários dispositivos móveis, no entanto a replicação de dados acontece sempre entre uma instância do Borboleta e o SAGUISaúde, formando assim uma configuração em estrela. Não há nenhuma troca de dados entre os dispositivos móveis.

A replicação é semi-automática, sendo necessário que um operador selecione quais registros serão replicados do SAGUISaúde para o Borboleta e em seguida dispare o processo de replicação. Esse processo ocorre enquanto o Borboleta possui conectividade, tipicamente dentro do Centro de Saúde utilizando uma rede sem fio.

\subsection{Bancos de dados heterogêneos}

Uma questão que merece atenção pelo seu impacto no compartilhamento de dados diz respeito ao modelo de dados utilizado nos sistemas Borboleta e SAGUISaúde.

Os sistemas móvel e central atendem a profissionais de saúde distintos. O sistema central é abrangente e oferece uma gama de serviços que vai desde uma simples consulta do histórico de um usuário do centro de saúde ou de uma família até a mineração de dados para a descoberta de focos de doenças. O profissional que utiliza o sistema central trabalha no centro de saúde. Já o sistema móvel atende ao profissional de saúde que realiza seu trabalho nas residências dos usuários.

Tanto o sistema central quanto o sistema móvel atuam sobre os mesmos dados. Por tal motivo, uma solução intuitiva seria unificar os modelos de dados dos dois sistemas. Porém, consideramos essa abordagem inadequada por não admitir que os modelos possuem necessidades distintas, o que dificulta e enrijece as evoluções e definições dos dois modelos, gerando restrições ao poder do banco de dados central e à flexibilidade do banco de dados móvel.

A melhor abordagem é permitir que os dois bancos de dados evoluam de forma independente, cada um atendendo às necessidades impostas pelo sistema a que serve. Por outro lado, nessa abordagem teremos dois modelos distintos representando os mesmos dados, o que implica na necessidade de um processo de separação e integração [TFB97] que deve levar em conta que estamos tratando de modelos heterogêneos. Essa heterogeneidade exige um processo de transformação dos dados tanto na separação quanto na integração. Para esse trabalhado adicional, existem várias soluções que viabilizam o uso de banco de dados heterogêneos.

Nas próximas seções apresentamos as características de cada um dos bancos de dados, justificando a abordagem de mantê-los heterogêneos. Em seguida, descrevemos como é tratada a transformação de dados entre os bancos de dados central e móvel.

\subsubsection{Banco de dados central}

O banco de dados central possui normalmente uma modelagem complexa devido às características das informações de saúde. Existem vários padrões e especificações que tratam dessa complexidade e fornecem diretrizes e regras para implementar um sistema de informação na área de saúde. Um exemplo é o padrão HL7 [Bee98], que, na sua terceira versão, é considerado bastante complexo, tanto em suas abstrações quanto na quantidade de código necessário para implementá-lo. Outro exemplo é a especificação OpenEHR [BH07], na qual é definida uma ontologia para tratar com informações de saúde. 
A evolução e as alterações no modelo de dados do banco de dados central são frequentes. $\mathrm{O}$ modelo de dados, devido à sua complexidade, trata de informações clínicas dos usuários do centro de saúde, mas também deve se preocupar com o estoque de medicamentos, vacinas e manter as informações dos funcionários - as suas especialidades, agendas, etc. Essas informações são bastante dinâmicas e é muito comum a necessidade de mudar alguma regra de funcionamento ou acrescentar algum serviço novo devido a mudanças na legislação ou a mudanças definidas por órgãos governamentais, que possuem sistemas nacionais, estaduais e municipais que interagem com o centro de saúde.

A quantidade de acessos ao banco de dados central é expressiva, pois o número de acessos é proporcional à quantidade de usuários do centro de saúde e à quantidade de profissionais de saúde que utilizam esse banco de dados. Quanto maior a quantidade de usuários que um centro de saúde atende em um certo dia, maior é o acesso ao banco de dados central para gravar e consultar as informações desses usuários. Por outro lado, independentemente da quantidade de atendimentos em um certo dia, os profissionais de saúde utilizam o banco de dados para realizar pesquisas, cruzando dados para gerar estatísticas que podem ajudar os trabalhos de prevenção. Esses acessos têm características diferentes. O primeiro tipo, que está relacionado com os atendimentos, é chamado de transacional e o segundo, usado para cruzar os dados e gerar estatísticas, é denominado de analítico. O banco de dados central deve responder rapidamente e corretamente aos acessos transacionais e analíticos.

\subsubsection{Banco de dados móvel}

Os profissionais de saúde deslocam-se, munidos de dispositivos móveis contendo o sistema móvel de informação, até locais públicos ou até as residências dos usuários para realizar o trabalho de atendimento e coleta de dados. Nesses locais, em sua maioria situados fora do alcance da rede WiFi do centro de saúde, frequentemente não existe serviço de conexão de dados ou, quando existe, é de alto custo.

Nessa situação, o sistema móvel exige um banco de dados local para realizar as operações de leitura e escrita de dados. No entanto, embora opere sobre as mesmas informações que o sistema central, o sistema móvel possui restrições e necessidades específicas em relação ao banco de dados. Em oposição ao sistema central, o sistema móvel atende a um trabalho bem definido: o atendimento domiciliar a um grupo restrito de usuários.

Durante um encontro, o profissional de saúde deve ter toda sua atenção voltada para o usuário. Essa atenção não pode ser desviada para a utilização do software de apoio. Desta forma, o sistema móvel tem como objetivo a praticidade e a agilidade na entrada dos dados, bem como oferecer ao profissional de saúde uma interface simples e com apenas as opções relevantes.

Considerando as características apresentadas, conclui-se que os requisitos de dados para o sistema móvel são bem mais simples que para o sistema central. Exigir a homogeneidade entre os modelos central e móvel é um requisito artificial e apenas contribuiria para aumentar o acoplamento entre os dois sistemas. Por tal motivo consideramos necessária a representação heterogênea dos modelos de banco de dados móvel e central.

Neste trabalho foi escolhida a opção de transformação de modelos de dados ao invés de reescrita de transações. Essa abordagem provê independência das tecnologias utilizadas no sistema móvel. Isso é especialmente importante dado que os recursos disponíveis nos dispositivos móveis são bastante 
restritos.

\subsection{Implementação}

O Borboleta, para começar a funcionar, precisa solicitar ao SAGUISaúde uma lista de usuários e suas informações de saúde e várias tabelas de parâmetros, tais como a lista de CIDs (código internacional de doenças) e a lista de medicamentos. Essa solicitação é feita por meio de uma rede sem fio e é atendida pelo processo de separação. Esse processo faz uma consulta na base de dados central, gera um documento XML no formato que o sistema móvel espera e devolve o resultado da solicitação para o dispositivo.

Após a carga inicial das tabelas de parâmetros, o profissional de saúde pode iniciar o trabalho de coleta e atualização dos dados dos usuários. Normalmente, esse trabalho é realizado em um local distante do centro de saúde, onde não está disponível a rede sem fio.

Em um momento oportuno, depois que o profissional volta para o centro de saúde, é possível realizar a transmissão dos dados armazenados no dispositivo para o sistema central. Para isso, é feita uma solicitação para o processo de integração, contendo os dados coletados. O mecanismo de integração processa os dados dessa solicitação, codificados em XML, realizando o processo de transformação e inclusão dos dados na base central. A Figura 4.4 mostra esse fluxo de dados.

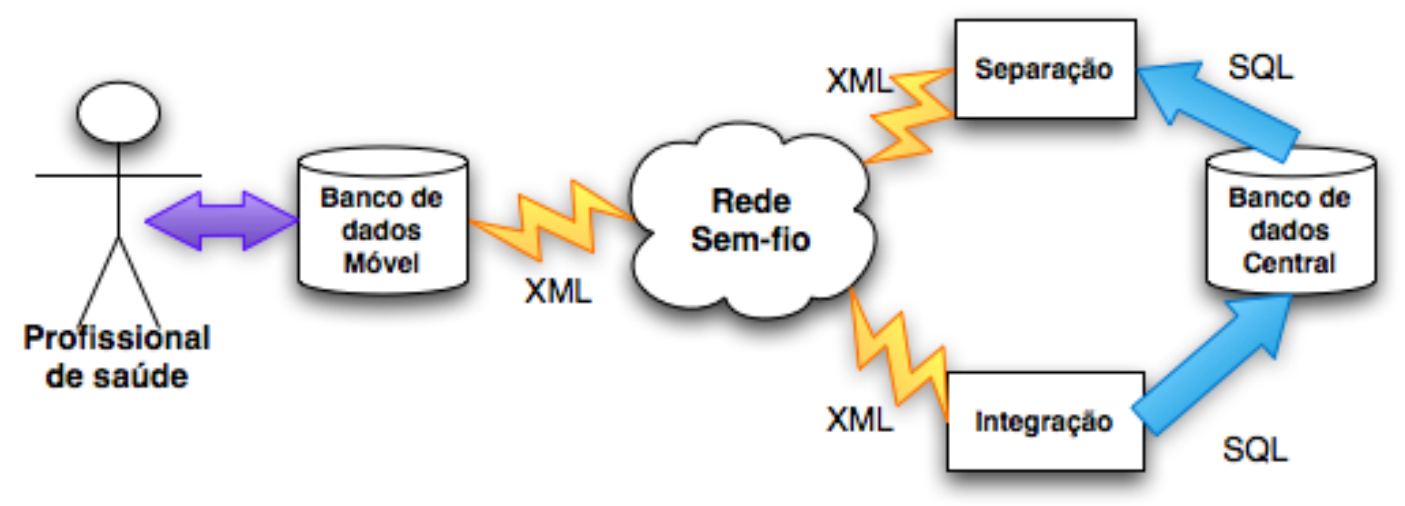

Figura 4.4: Fluxo de dados entre os bancos de dados móvel e central

O módulo de sincronização foi implementado utilizando a linguagem Ruby ${ }^{5}$ e o arcabouço Ruby on Rails ${ }^{6}$, também utilizados pelo SAGUISaúde. Para garantir que todas as regras de integridade implementadas pelo SAGUISaúde tivessem efeito no momento da sincronização com o Borboleta, o módulo de sincronização não faz acesso direto ao banco de dados, fazendo uso do arcabouço de persistência do SAGUISaúde para isso. O SAGUISaúde utiliza o arcabouço de mapeamento objetorelacional Active Record ${ }^{7}$, disponibilizado pelo Ruby on Rails, como mecanismo de persistência.

O módulo de sincronização é implementado junto ao SAGUISaúde e segue o modelo REST (Representational State Transfer) [Fie00]. Toda a comunicação é feita por meio de requisições HTTP ${ }^{8}$ transmitindo dados no formato XML. Na fase de separação, o dispositivo móvel realiza uma opera-

\footnotetext{
${ }^{5}$ http://ruby-lang.org

${ }^{6} \mathrm{http}: / /$ rubyonrails.org

${ }^{7}$ http://api.rubyonrails.org/classes/ActiveRecord/Base.html

${ }^{8}$ Hypertext Transfer Protocol
} 
ção GET ${ }^{9}$ em uma URL específica para acesso aos dados de usuário. O dispositivo móvel solicita sempre uma lista de usuários que foram previamente selecionados no SAGUISaúde. Embora o modelo REST recomende disponibilizar os dados gradualmente, decidimos enviar todos os dados referentes ao usuário e seu histórico de encontros em um único documento XML. Essa decisão foi tomada para simplificar a implementação do sistema móvel, devido ao baixo volume de dados (o XML de um usuário típico tem menos de $1 \mathrm{MB}$ e um dispositivo móvel armazena poucas dezenas de usuários) e a alta velocidade de transferência desses dados, devido à infraestrutura de rede do centro de saúde.

No momento em que o dispositivo móvel solicita os dados dos usuários, o sistema central gera um XML com os dados do usuário e seu histórico de encontros, porém esse XML representa o modelo do banco de dados central e precisa passar por uma transformação antes de ser enviado ao dispositivo móvel. Nesse ponto, entra em ação o processo de separação, que é responsável pela transformação do XML.

Após realizar operações sobre os dados, o sistema móvel deve enviar para o sistema central suas alterações por meio do protocolo HTTP. Para isso, o dispositivo móvel realiza uma operação POST ${ }^{9}$ sobre a URL de acesso aos dados dos pacientes. Junto ao POST, é enviado um documento XML contendo os dados dos pacientes alterados e os seus respectivos históricos de encontros. Nesse momento, entra em ação o processo de integração que, como na separação, realiza uma transformação no documento XML. O resultado dessa transformação é um segundo XML que é diretamente mapeável para o modelo do banco de dados central. Nessa fase, o processo de integração é responsável por identificar e resolver eventuais conflitos.

\subsubsection{Transformação de dados}

A transformação é feita utilizando XSLT (Extensible Stylesheet Language Transformations) [Cla99], uma linguagem de transformação de documentos XML. O processo de separação transforma o XML gerado pelo sistema central em um segundo XML que tem uma estrutura diretamente mapeável para o modelo do banco de dados móvel. Após essa transformação, o XML resultante é enviado ao dispositivo móvel. Nesse momento, o processo de separação é responsável por armazenar meta-dados que serão utilizados no processo de integração.

Utilizamos a biblioteca ruby-xslt ${ }^{10}$ como processador XSLT. As transformações são definidas em um arquivo no formato XSL. A Listagem 4.1 apresenta um trecho de XML no formato exportado do banco de dados central. A Listagem 4.2, um trecho de um XML no formato do banco de dados móvel. Por último, a Listagem 4.3 apresenta um trecho do XSLT que transforma o XML do sistema central no XML do sistema móvel.

O uso de XSLT se mostrou bastante flexível e permitiu com que mantivéssemos o código do módulo de sincronização bastante claro e conciso, separando a descrição do mapeamento entre os modelos separada do código de sincronização. Embora não tenhamos encontrado uma ferramenta que se adequasse às nossas necessidades, existem iniciativas de desenvolvimento de ferramentas para geração de código XSLT com base em uma descrição gráfica. As desvantagens do uso de XSLT para a transformação dos dados incluem a sintaxe, que é bastante prolixa, e o fato de a transformação ser de via única, ou seja, é necessário escrever uma transformação central-móvel e outra móvel-central.

\footnotetext{
${ }^{9}$ Operação definida no protocolo HTTP

${ }^{10}$ http://raa.ruby-lang.org/project/ruby-xslt
} 


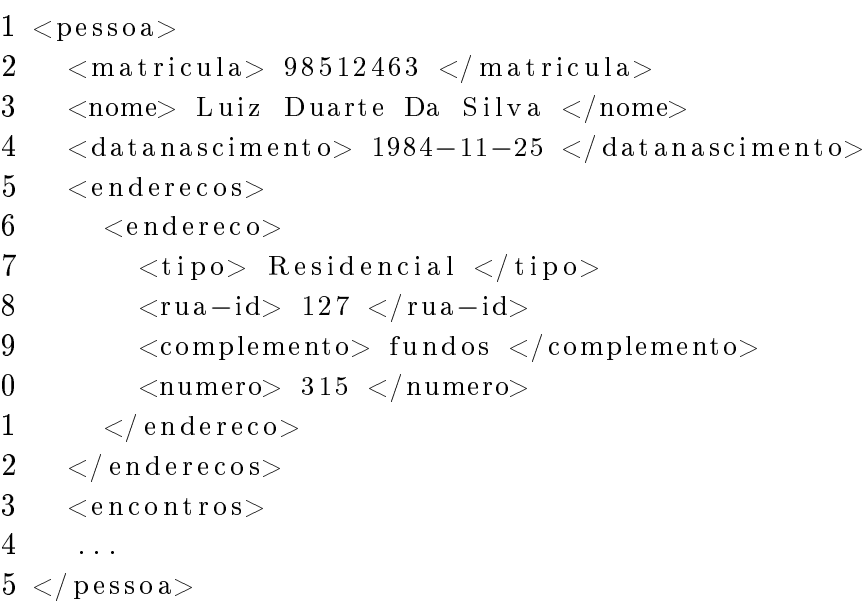

Listagem 4.1: XML representando modelo do banco de dados central

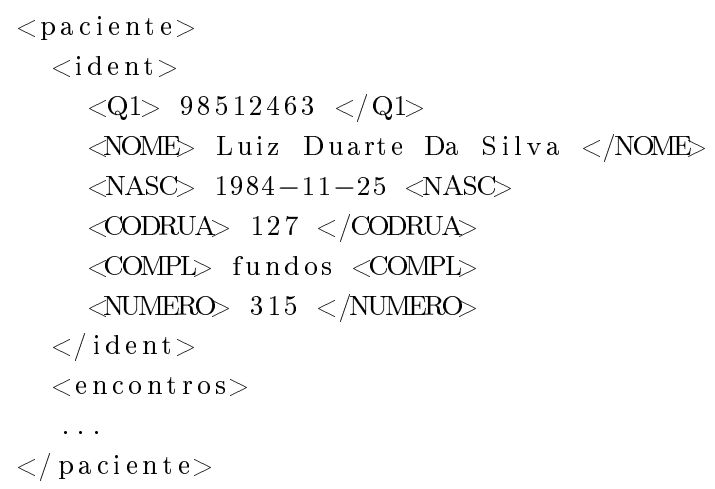

Listagem 4.2: XML representando modelo do banco de dados móvel

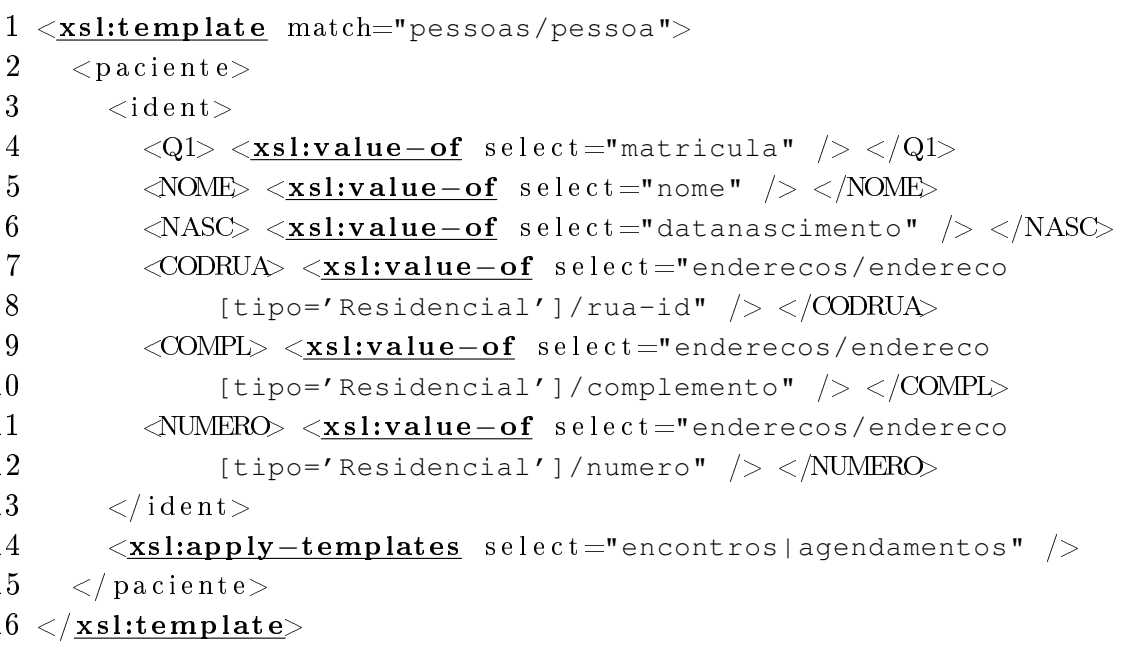

Listagem 4.3: Exemplo de transformação em XSL

\subsubsection{Replicação}

A replicação de dados compreende o envio de registros do banco de dados do SAGUISaúde para um dispositivo móvel. Esse processo é disparado pelo usuário utilizando o Borboleta, que oferece ao usuário as operações "Importar Pacientes" e "Importar Tabelas de Apoio". Cada uma 


\begin{tabular}{|l|l|}
\hline Marca no XML & Descrição \\
\hline \hline motivoencontros & $\begin{array}{l}\text { Opções que o profissional de saúde poderá escolher para preenchi- } \\
\text { mento do campo "Motivo do encontro" na tela de encontro. }\end{array}$ \\
\hline medidas \\
Tipos de medidas que poderão ser realizadas pelo profissional de \\
medicamentos & Lista de medicamentos disponíveis na farmácia do centro de saúde. \\
\hline dificuldades & $\begin{array}{l}\text { Lista de dados a serem coletados durante um encontro referentes } \\
\text { à dificuldade enfrentada pelo paciente na execução de atividades } \\
\text { cotidianas. }\end{array}$ \\
\hline tipoCuidados & $\begin{array}{l}\text { Lista de cuidados e atividades que podem ser indicados ao paciente } \\
\text { pelo profissional de saúde durante o encontro, bem como possíveis } \\
\text { caracterizações para cada um desses tipos de cuidados. }\end{array}$ \\
\hline tipoExames & $\begin{array}{l}\text { Lista de exames que podem ser indicados ao paciente durante um } \\
\text { encontro. }\end{array}$ \\
\hline dietas & $\begin{array}{l}\text { Lista de dietas que podem ser indicadas ao paciente durante um } \\
\text { encontro. }\end{array}$ \\
\hline tipoVidasCotidianas & $\begin{array}{l}\text { Lista de aspectos relevantes da vida cotidiana do paciente que po- } \\
\text { dem ser observados e documentados pelo profissional de saúde du- } \\
\text { rante um encontro. }\end{array}$ \\
\hline profissionais & $\begin{array}{l}\text { Lista contendo nome e matrícula dos profissionais do centro de } \\
\text { saúde. }\end{array}$ \\
\hline categoriascid & $\begin{array}{l}\text { Lista de capítulos da Classificação Internacional de Doenças (CID). } \\
\text { nacional de Doenças (CID). }\end{array}$ \\
\hline subcategoriascid de acordo com a Classificação Inter- \\
\hline cidReduzidos \\
Lista reduzida de categorias de doenças mais comumente diagnos- \\
ricadas durante os encontros. \\
$\begin{array}{l}\text { Lista de ruas que compõem a região de atendimento do centro de } \\
\text { saúde. }\end{array}$ \\
\hline
\end{tabular}

Tabela 4.1: Dados enviados como tabelas de apoio

dessas operações dispara uma requisição HTTP no SAGUISaúde, que é responsável por transmitir os dados solicitados em formato XML.

As tabelas de apoio são dados estáticos que são necessários para o funcionamento do Borboleta mas que não sofrem atualizações por parte do dispositivo móvel. As tabelas de apoio podem ser atualizadas apenas pelo SAGUISaúde, no entanto, essas atualizações são pouco frequentes. Os dados enviados na requisição de tabelas de apoio incluem a lista de ruas que compõem a região de atendimento do centro de saúde, lista de medicamentos que podem ser indicados ao paciente, lista de doenças e seus respectivos códigos de acordo com o Cadastro Internacional de Doenças (CID), entre outros. A Tabela 4.1 apresenta a relação dos dados que são enviados ao dispositivo móvel durante uma requisição de tabelas de apoio. A coluna da esquerda apresenta a marca do XML que compreende um tipo de elemento e a coluna da direita apresenta uma breve descrição de tal elemento. A Listagem 4.4 apresenta um exemplo reduzido de XML contendo tabelas de apoio. Nesse exemplo é apresentado um item para cada tipo de elemento contido em uma requisição de tabelas de apoio. 


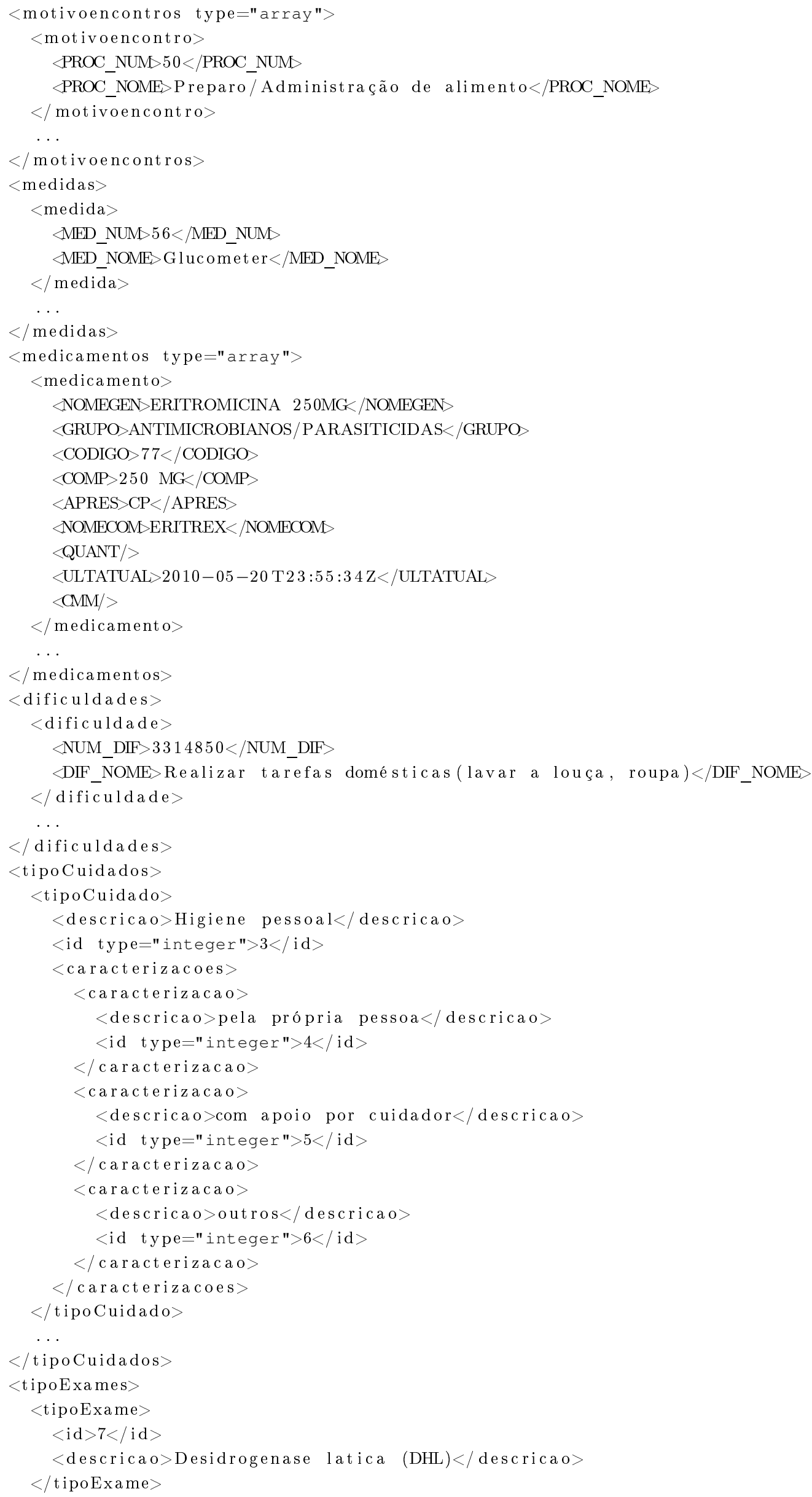




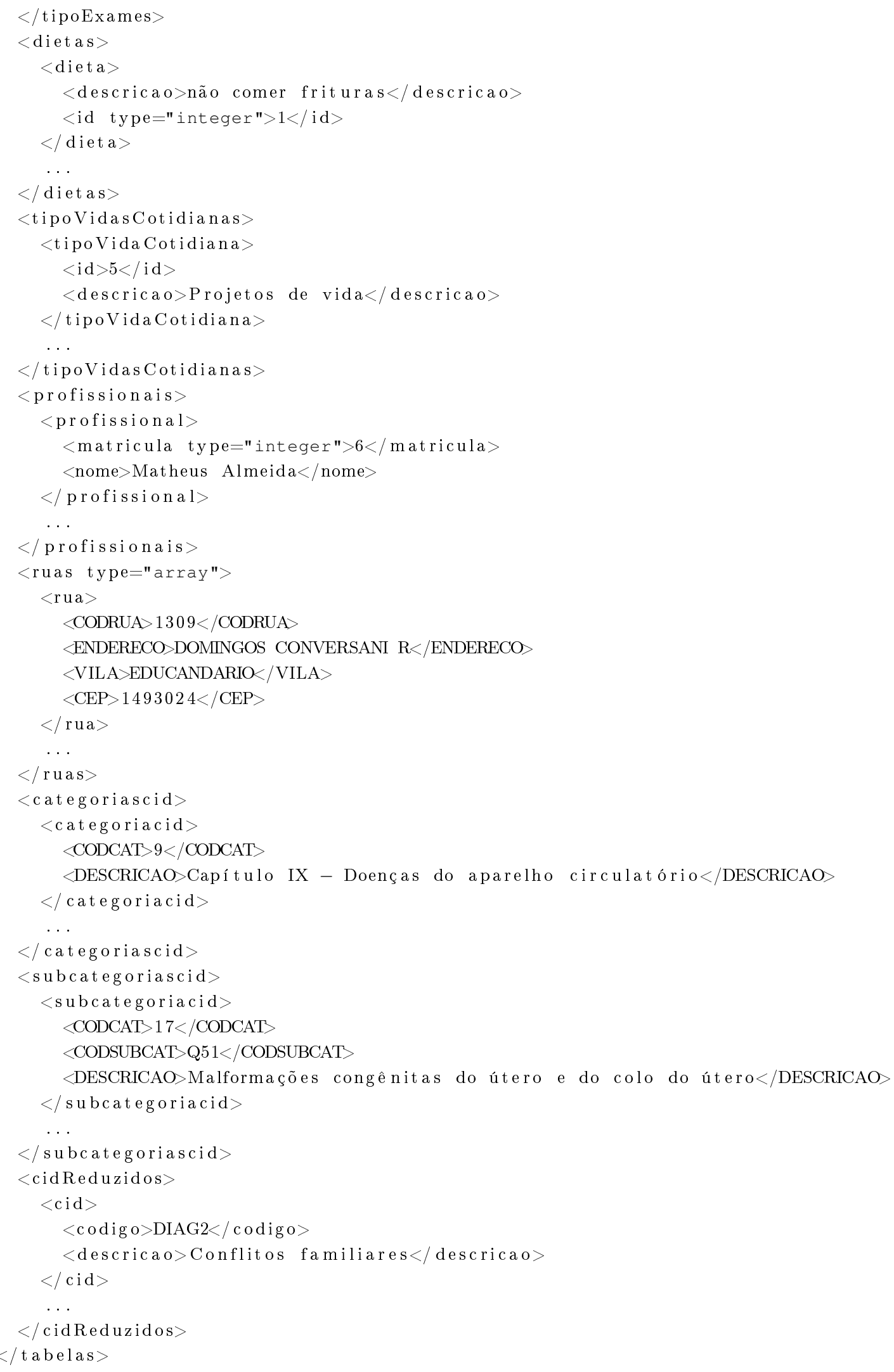

Listagem 4.4: Exemplo de XML com tabelas de apoio

Além da função "Importar Tabelas de Apoio", o Borboleta oferece também ao usuário a função "Importar Pacientes". Essa função dispara uma requisição HTTP no SAGUISaúde e transfere registros de pacientes do banco de dados do SAGUISaúde para o dispositivo móvel. No entanto, antes de disparar essa função, o usuário deve selecionar quais registros devem ser transferidos. 
O SAGUISaúde armazena o registro de todos os pacientes atendidos pelo centro de saúde. Porém, o dispositivo móvel não possui recursos de armazenamento suficientes para suportar todos os registros de pacientes. Por isso, apenas alguns registros são replicados. Além disso, em um contexto de atendimento domiciliar, que é o objetivo principal do Borboleta, sabe-se a priori quais pacientes serão atendidos durante um ciclo de separação e integração, por exemplo os pacientes que possuem agendamento de encontro no dia corrente ou na semana corrente.

A escolha dos registros que serão enviados ao dispositivo móvel é realizada junto ao SAGUISaúde, que oferece uma interface apropriada para essa tarefa. A Figura 4.5 apresenta a tela do SAGUISaúde onde são selecionados os registros a serem enviados ao dispositivo móvel. É possível realizar buscas de registros pelo nome do paciente, número de matrícula ou data de nascimento do paciente. É possível também buscar pelos pacientes que foram selecionados para envio ao dispositivo móvel.

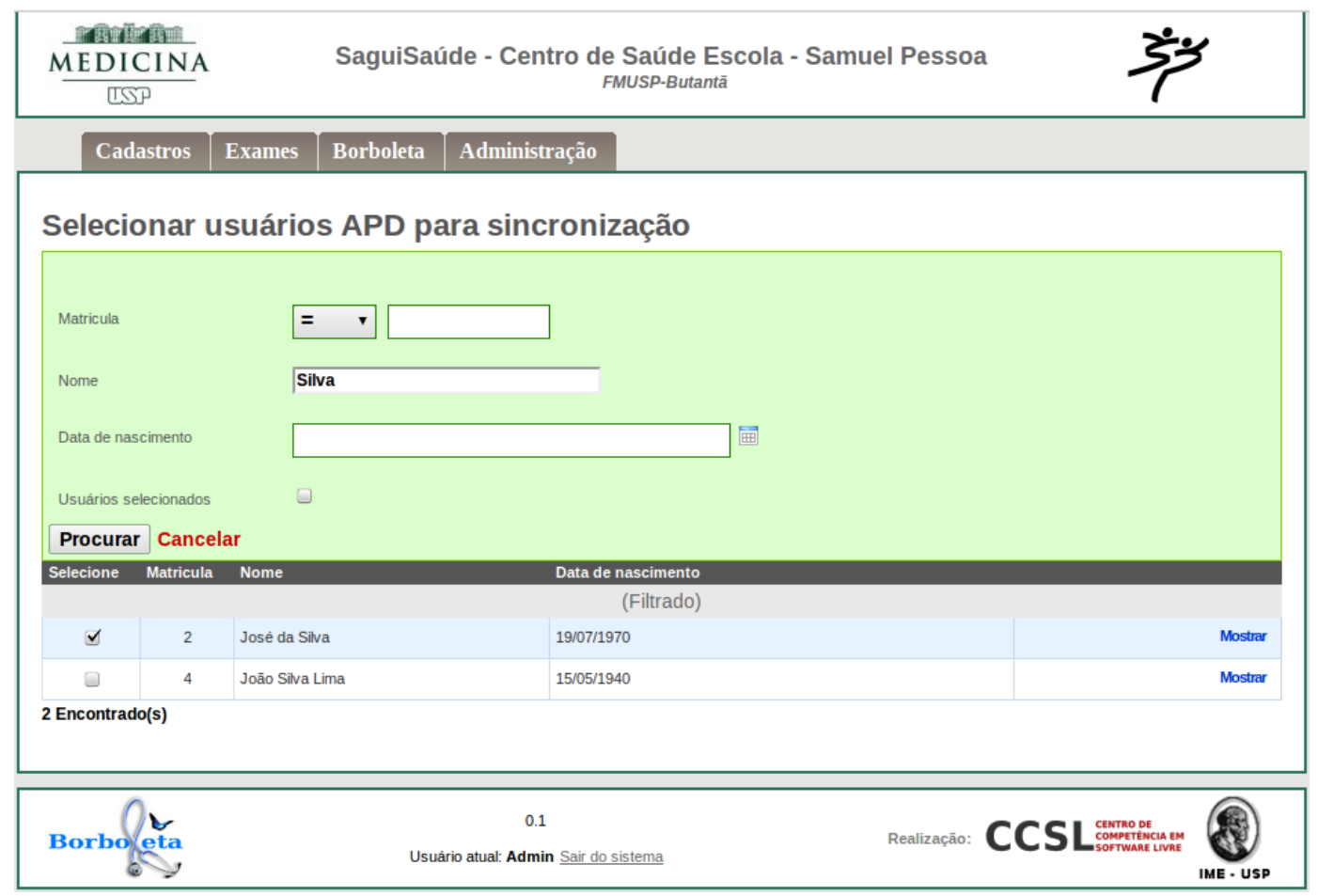

Figura 4.5: Telas do Borboleta: à esquerda apresenta-se a tela de cadastro de pacientes, que permite a consulta e atualização dos dados pessoais de um paciente. Ao centro apresenta-se a tela inicial de registro de encontros, que fornece acesso às seções de Caracterização Geral, Dados Específicos, Problemas/Necessidades e Programação Final. À direita apresenta-se a tela de Motivos do Encontro, que pertence à seção de Dados Específicos do encontro.

Uma vez selecionados os registros a serem enviados ao dispositivo móvel, o usuário pode finalmente disparar a requisição de importação de pacientes. Os dados enviados nessa requisição incluem os dados pessoais dos pacientes selecionados, seus dados socioeconômicos, o cuidador do paciente e o histórico de encontros. O histórico de encontros inclui todas as informações registradas pelo profissional de saúde nos encontros anteriores com o paciente em questão. A Listagem 4.5 apresenta um exemplo de dados enviados em uma requisição de importação de pacientes. Por motivos didáticos, o exemplo contém o registro de apenas um paciente, e esse por sua vez contendo apenas um encontro em seu histórico de encontros. 
$1<$ sincronizacao $>$

$<$ session $>1</$ session $>$

$<$ pacientes $>$

$<$ paciente $>$

$<$ ident $>$

$<$ Q1 $>2</$ Q1 $>$

$\langle\mathrm{NOME}>$ Jos é da Silva $</$ NOME $>$

$<$ DATANASC $>1970-07-19</$ DATANASC $>$

$<$ SEXO $>1</$ SEXO $>$

$<\mathrm{MAE}>$ Maria das Graças $</ \mathrm{MAE}>$

$<$ TELREC $>2229999</$ TELREC $>$

$<$ RECADOS $>$ J o r $\mathrm{e}<</$ RECADOS $>$

$<$ CODRUA $>588</$ CODRUA $>$

$<$ COMPL $>$ ap $123</$ COMPL $>$

$\triangle$ NUMFRO $>43<$ /NUMERO $>$

DATACONS > $1900-01-01</$ DATACONS $>$

$</$ ident $>$

$<$ cadastro $>$

$<$ MUN_NASC $>$ São Paulo $</$ MUN_NASC $>$

$<\mathrm{PAI}>$ João da Silva $</ \mathrm{PAI}>$

$<$ Q1 $>2</$ Q1 $>$

$<$ PAIS $>$ brasileir $</$ PAIS $>$

$<$ RG $>12345678</$ RG $>$

$<$ ORGAO $>$ SSP - Secretaria de Sugurança Publica $</$ ORGAO

$<$ UFRG $>$ SP $<$ /UFRG $>$

$<$ DATARG $>2011-11-11</$ DATARG $>$

$<$ CERTTIPO $>$ RG $</$ CERTTIPO $>$

$\langle$ DATACERT $>2011-11-11</$ DATACERT $>$

$<$ LER $>$ tr u e $</$ LER $>$

$\langle$ FREQUENTA $>$ f a 1 s e $</$ FREQUENTA $>$

$<$ ESCOLA $>1</$ ESCOLA $>$

$<$ ANOS_ESCOLARIDADE $>5</$ ANOS_ESCOLARIDADE $>$

$<$ ENTRADA $>>$

$\langle$ RENDA $/>$

$\langle$ TEMPO_MORA $>10</$ TEMPO_MORA $>$

$<$ TIPOMORADIA $>$ Casa / A partamento $</$ TIPOMORADIA $>$

$<$ OCUP>Ajustador mecânico, em geral</OCUP>

$<$ RELIGIAO>Católica Apostólica Romana</RELIGIAO $>$

$<$ DATAAPLI $/>$

$\triangle \mathrm{RGCOMP} />$

$<$ BRASIL $/>$

$</$ cadastro $>$

$<$ cadastroCuidador $>$

$\langle$ NOME $>$ Joaquim da Silva $</$ NOME $>$

$<$ ESCOLARIDADE $>1</$ ESCOLARIDADE $>$

$<$ ANOS_ESCOLARIDADE $>8</$ ANOS_ESCOLARIDADE $\rangle$

$<$ VINCULO $>$ ir mã $0</$ VINCULO $>$

$<$ OCUPACAO $>$ Aç o u gu e ir o </OCUPACAO >

$<$ PERIDODESPENDIDO $/>$

$<\mathrm{RENDA} />$

$<$ DIFICULDADES $/>$

$<\mathrm{APOIO} />$

$<\mathrm{Q} 1>2</ \mathrm{Q} 1>$

$</$ cadastroCuidador $>$

$<$ encontrosDomiciliares $>$

$<$ encontroDomiciliar $>$

$<$ profissionalMedico $>$ false $</$ profissionalMedico $>$

$<$ profissionalEnfermagem $>$ false $</$ profissionalEnfermagem $>$

$<$ profissionalEnfermeira $>$ false $</$ profissionalEnfermeira $>$

$<$ profissionalFisioterapia $>$ false $</$ profissionalFisioterapia $>$

$<$ profissionalOutro $>$ false $</$ profissionalOutro $>$ 


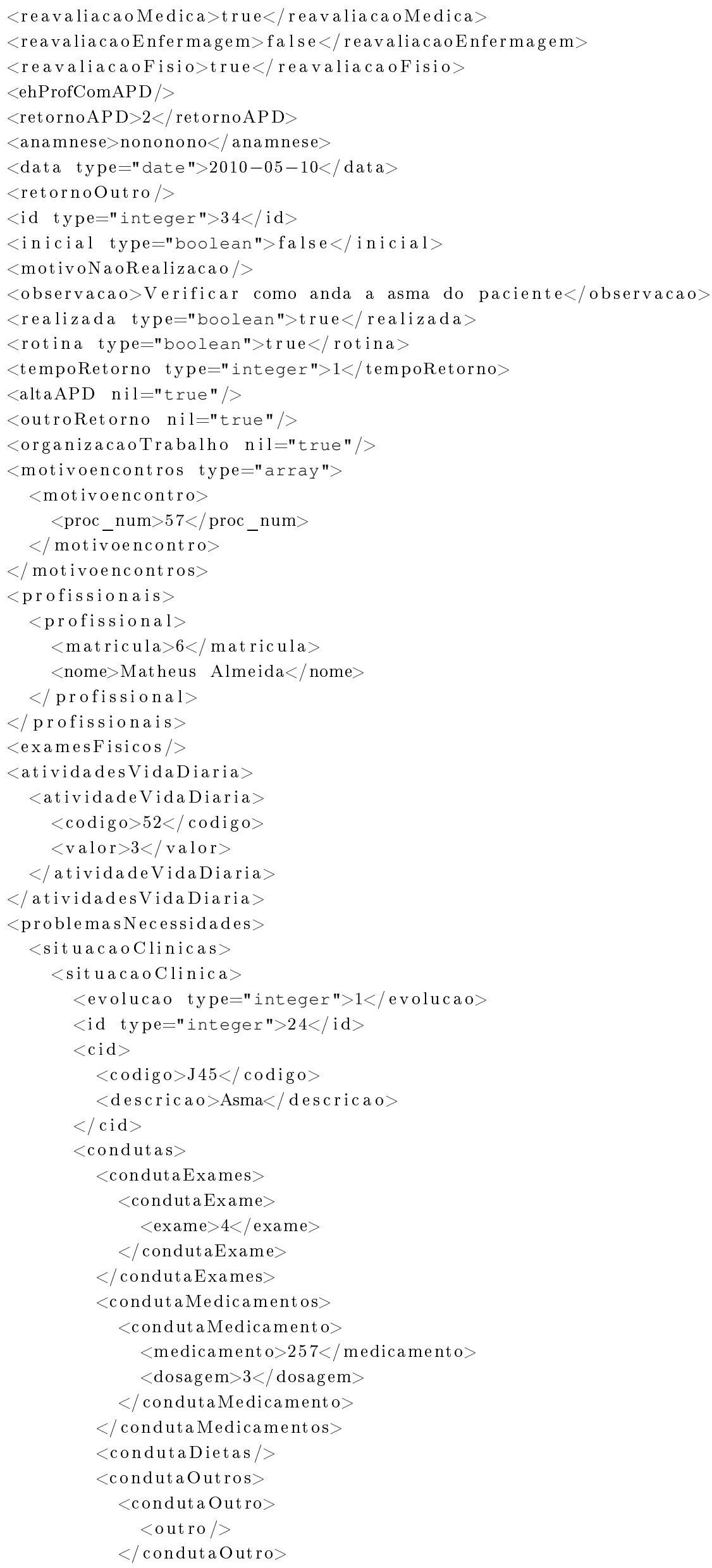


124

125

126

127

128

129

130

131

132

133

134

135

136

137

138

139

140

141

142

143

144

145

146

147

148

149

150

151

152

153

154

155

156

157

158

$159</$ sincronizacao $>$

$</$ paciente $>$

$</$ pacientes $>$
$</$ condutaOutros $>$

$</$ condutas $>$

$</$ situacaoClinica $>$

$</$ situacaoClinicas $>$

$<$ cuidadoAtividades $>$

$<$ cuidadoAtividade $>$

$<$ evolucao type="integer" $>1</$ evolucao $>$

$<$ id type $=$ "integer" $>2</$ id $>$

$<$ caracterizaca $0>10</$ caracterizaca $o>$

$<$ necessidadeOrientacao $>$ false $</$ necessidadeOrientacao $>$

$<$ orientacao $/>$

$<$ tipoCuidado $>$

$<$ descricao $>$ Mobilidade $</$ descricao $>$

$<$ id type="integer" $>5</$ id $>$

$</$ tipoCuidado $>$

$</$ cuidado Atividade $>$

$</$ cuidado Atividades $>$

$<$ vidaCotidianas $>$

$<$ vidaCotidiana $>$

$<$ evolucao type="integer" $>1</$ evolucao $>$

$<$ id type $=$ "integer" $>996332879</$ id $>$

$<$ situacao type $=$ "integer $">0</$ situacao $>$

$<$ necessidadeDiscussao $>$ false $</$ necessidadeDiscussao $>$

$<$ descricaoDiscussao $/>$

$<$ tipoVidaCotidiana $>$

$<$ id $>1</$ id $>$

$<$ descricao $>$ Autonomia $</$ descrica $o>$

$</$ tipoVidaCotidiana $>$

$</$ vidaCotidiana $>$

$</$ vidaCotidianas $>$

$</$ problemasNecessidades $>$

$</$ encontroDomiciliar $>$

$</$ encontrosDomiciliares $>$

Listagem 4.5: Exemplo de XML com o registro de um paciente 


\subsubsection{Propagação de atualizações}

A propagação das atualizações realizadas pelo dispositivo móvel é disparada quando o usuário utilizando o Borboleta ativa a operação "Exportar Pacientes". Nesse momento o Borboleta envia uma requisição ao SAGUISaúde contendo os registros dos pacientes que estão armazenados no dispositivo móvel. O formato dos dados é o mesmo da requisição de separação, ou seja, um XML correspondente ao modelo de dados utilizado pelo Borboleta (ver Listagem 4.5).

A requisição de propação é atendida pelo módulo de sincronização. A primeira coisa que o módulo de sincronização deve fazer é aplicar a transformação de dados para que o XML passe do modelo do Borboleta para o modelo de dados do SAGUISaúde. Essa tarefa é realizada utilizando a biblioteca ruby-xslt ${ }^{11}$. Essa biblioteca fornece uma interface de programação que recebe como entradas o XML original e as regras de transformação no formato XSLT, gerando como saída o XML transformado de acordo com as regras fornecidas. As regras XSLT utilizadas pelo módulo de sincronização podem ser vistas no Apêndice B.

O passo seguinte diz respeito à identificação e resolução de conflitos. Essa tarefa é realizada pelo arcabouço que foi desenvolvido e é descrito no Capítulo 3. O módulo de sincronização precisa apenas informar o identificador da transação móvel e os dados contendo as atualizações do dispositivo móvel. Em decorrência da baixa frequência de ocorrência de conflitos e do uso de versionamento que permite auditar e retificar resoluções de conflitos, um algoritmo simples de resolução de conflitos pode ser utilizado sem que haja perda de informação ou detrimento da usabilidade do sistema. Assim, utilizou-se a função de resolução de conflitos padrão do arcabouço, que implementa um algoritmo de resolução de conflitos por ordenação, sendo a data da requisição de integração utilizada como critério de ordenação.

\footnotetext{
${ }^{11}$ http://raa.ruby-lang.org/project/ruby-xslt
} 


\section{Capítulo 5}

\section{Conclusões}

A reconciliação de transações é um dos principais desafios no desenvolvimento de aplicações para dispositivos móveis. Os mecanismos existem para reconciliação de transações não fornecem a flexibilidade necessária ao desenvolvimento de aplicações móveis modernas. Foram elencados seis requisitos considerados necessários a um modelo de reconciliação de transações para atender às demandas das aplicações móveis. Os requisitos elencados foram: (i) disponibilidade; (ii) suporte a transações interativas; (iii) suporte à resolução manual de conflitos; (iv) ferramentas adequadas para apoio à resolução manual de conflitos; (v) possibilidade de auditoria e retificação de resoluções de conflitos; (vi) possibilidade de uso da semântica de conflitos na resolução de conflitos consecutivos. O Capítulo 1 apresenta maiores detalhes a respeito de cada um desses requisitos e a justificativa de serem necessários ao desenvolvimento de aplicações móveis.

Para atender aos requisitos elencados, foi desenvolvido um modelo transacional, descrito no Capítulo 3, que provê a infraestrutura necessária por meio do uso de metadados e versionamento de dados. Nesse modelo, uma transação móvel é iniciada quando o dispositivo realiza uma requisição de replicação de dados. Esse processo é denominado processo de separação. A partir daí o dispositivo móvel pode realizar atualizações em sua cópia local dos dados e, posteriormente, solicitar a integração de suas atualizações. A requisição de integração dispara o processo de integração, que é responsável por identificar e resolver os possíveis conflitos e gerar novos metadados. São os metadados gerados durante os processos de separação e integração, incluindo o versionamento de dados, que permitirão atender os requisitos de flexibilidade que foram elencados.

Para validar o modelo proposto, foi desenvolvido um arcabouço para reconciliação de transações que implementa o modelo descrito no Capítulo 3. Esse arcabouço foi utilizado na implementação de um estudo de caso para integração dos sistemas SAGUISaúde e Borboleta. O Capítulo 4 possui uma descrição dos sistemas SAGUISaúde e Borboleta e descreve os detalhes da implementação da integração desses sistemas utilizando o arcabouço desenvolvido.

Durante a implementação da integração dos sistemas SAGUISaúde e Borboleta, surgiu um desafio adicional em decorrência da heterogeneidade dos modelos de dados desses dois sistemas. Para solucionar esse problema, implementou-se um mecanismo de transformação de dados. Esse mecanismo possibilitou a integração dos sistemas SAGUISaúde e Borboleta sem a necessidade de impor um modelo de dados único, o que reduz o acoplamento entre os sistemas e provê independência das tecnologias utilizadas. Os detalhes desse mecanismo de transformação de dados são apresentados também no Capítulo 4.

Diante do que foi descrito nos Capítulos 3 e 4, pode-se concluir que o modelo transacional 
proposto atende aos 6 requisitos de flexibilidade elencados e discutidos no Capítulo 1, permitindo, assim, o desenvolvimento de aplicações móveis que possuem exigências de disponibilidade e operações desconectadas. 


\section{Apêndice A}

\section{Esquema de dados do SAGUISaúde}

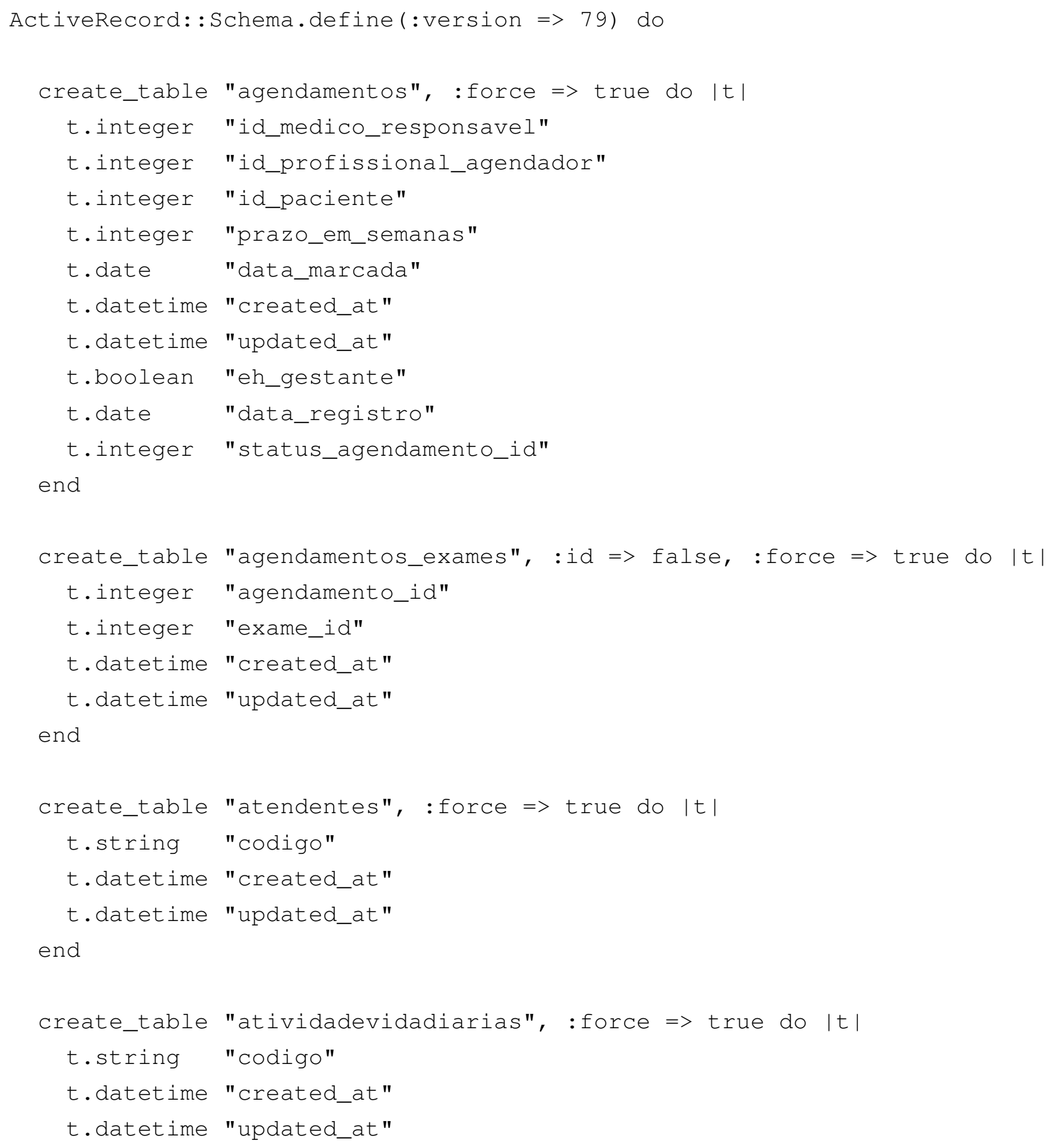


end

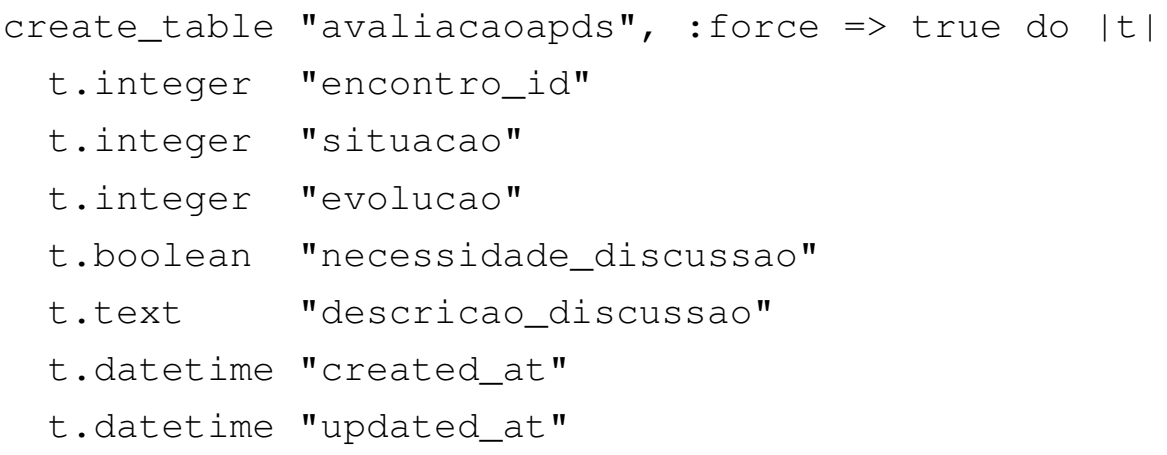




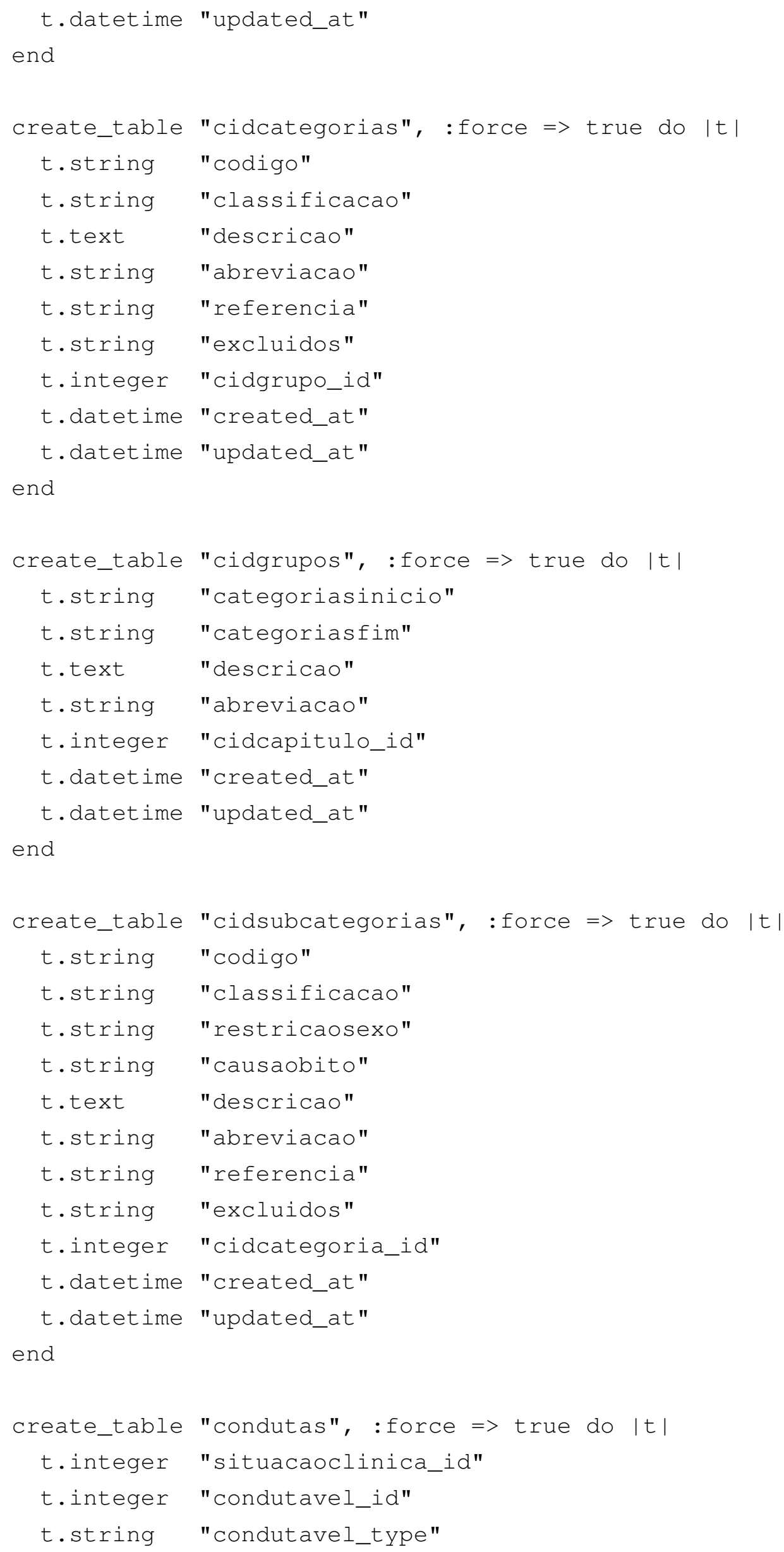




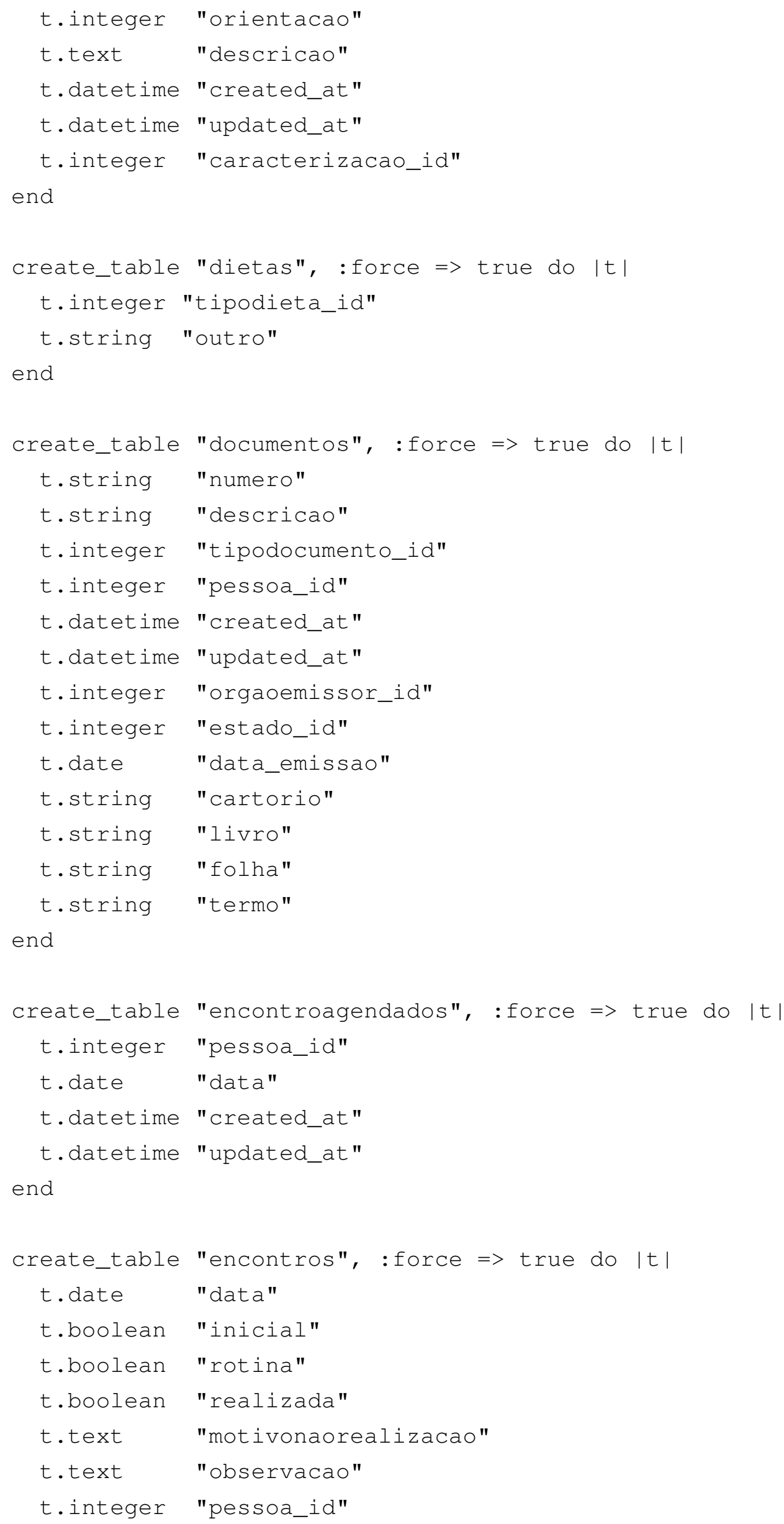




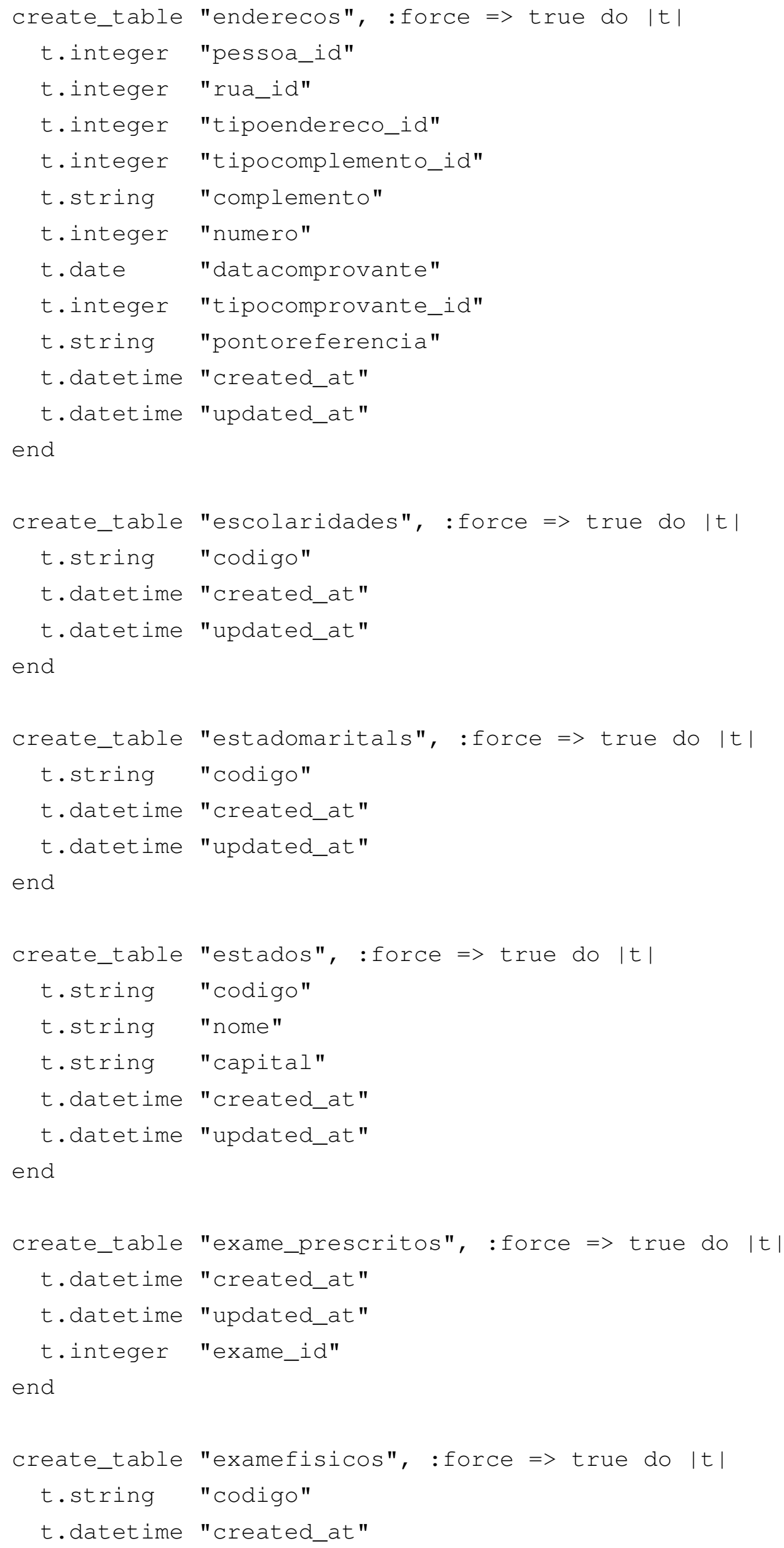



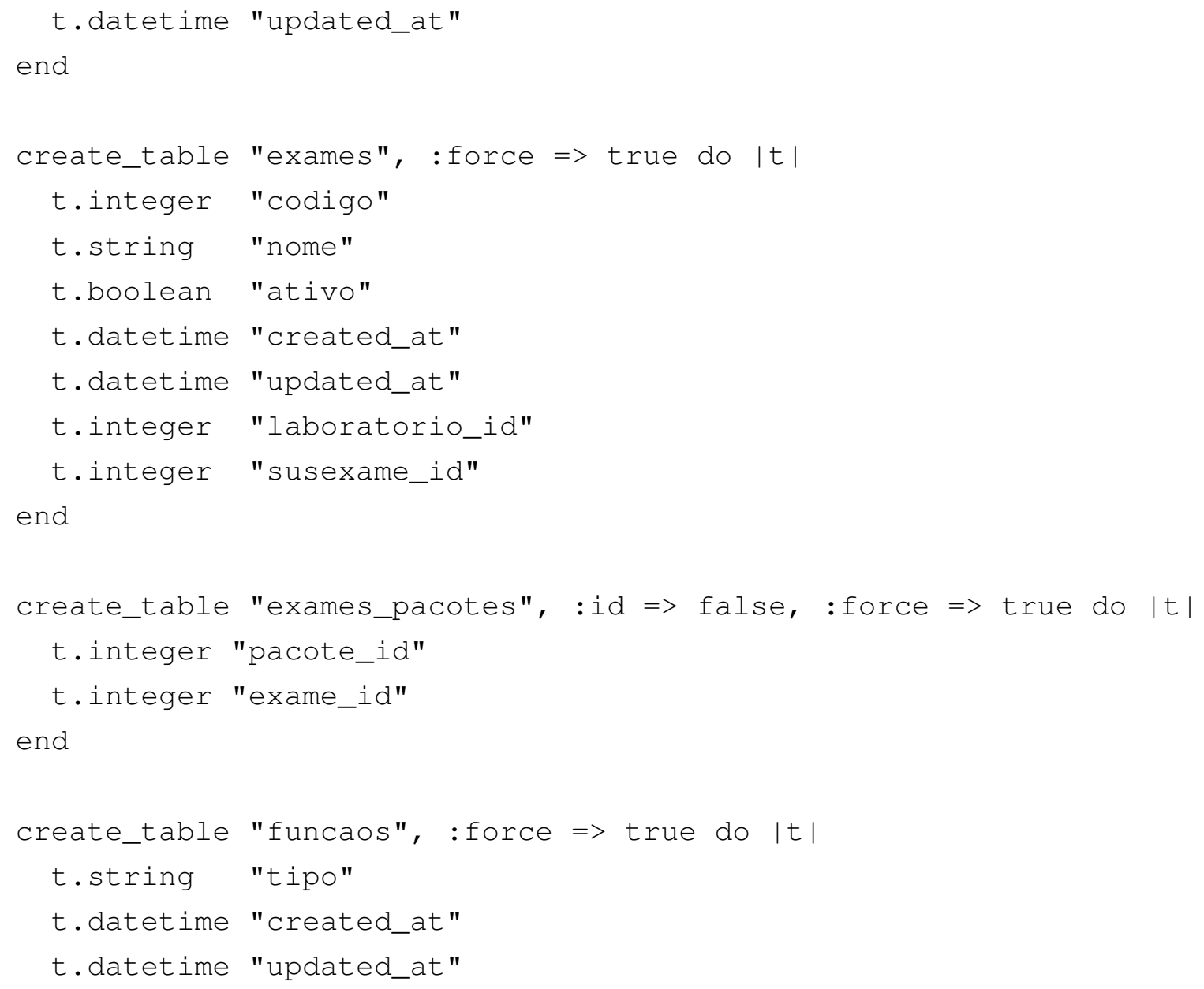
end
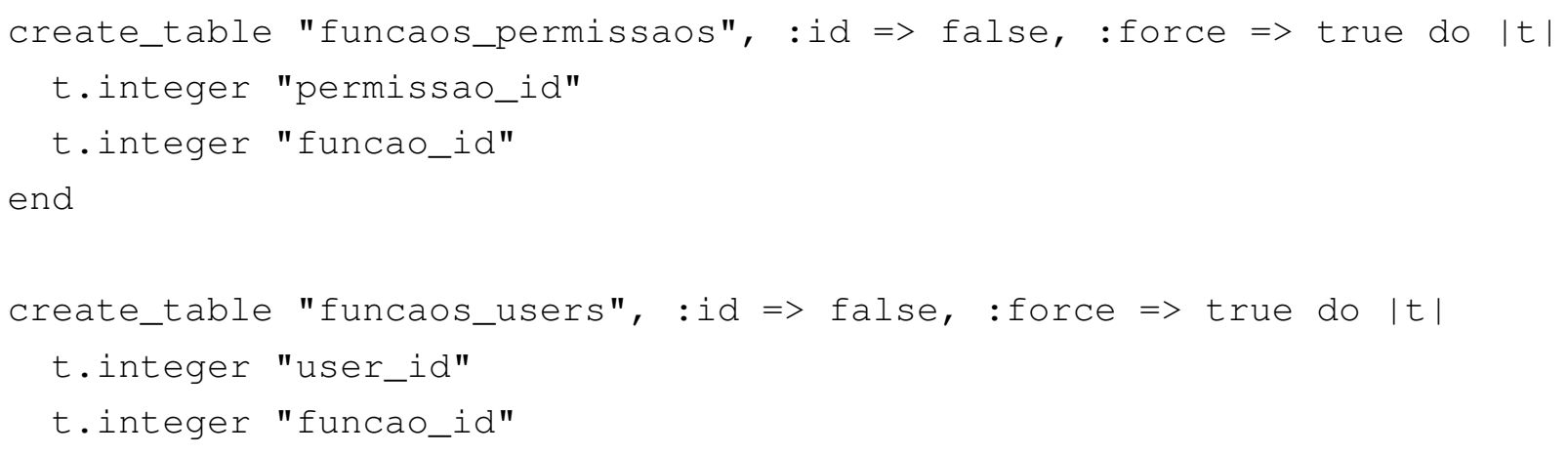
end

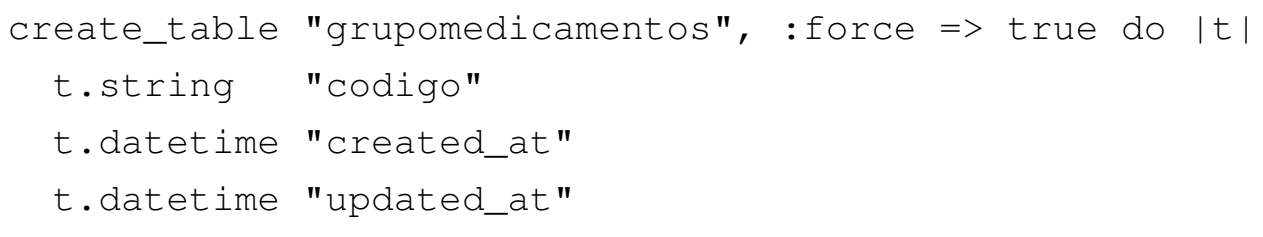
end

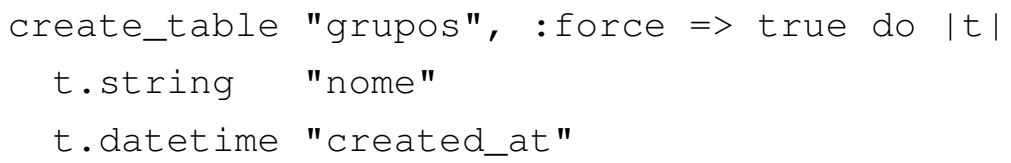




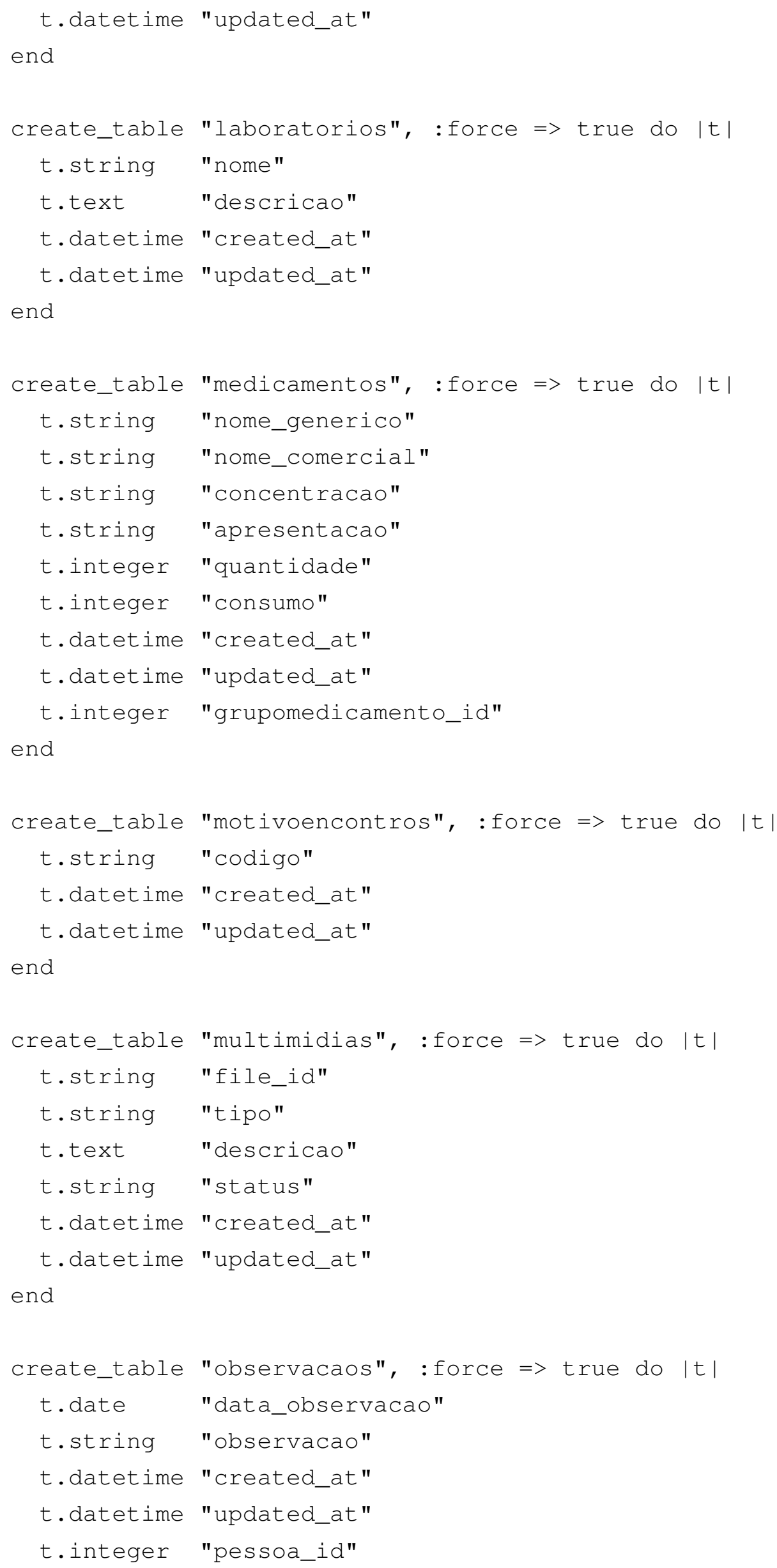




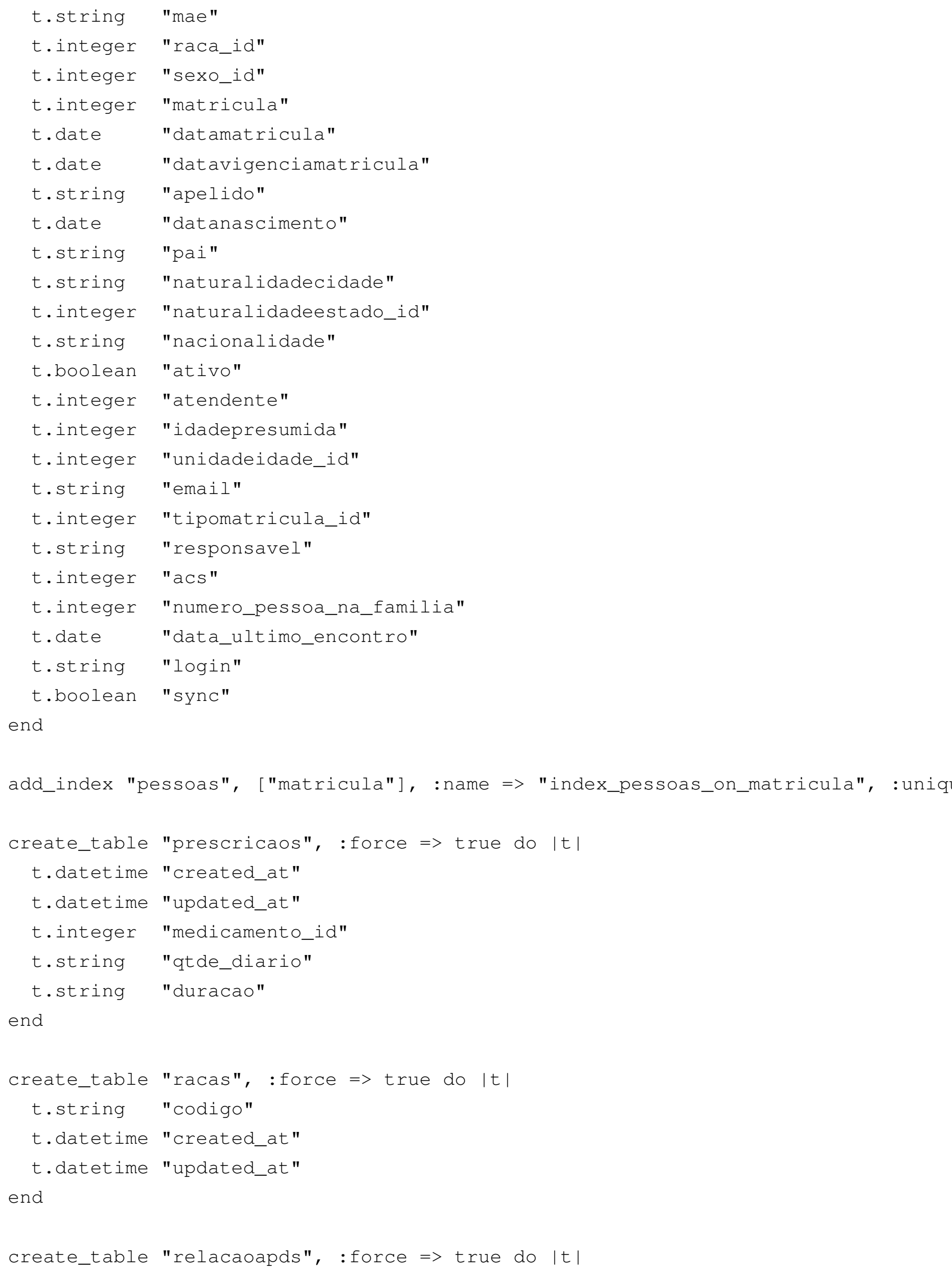




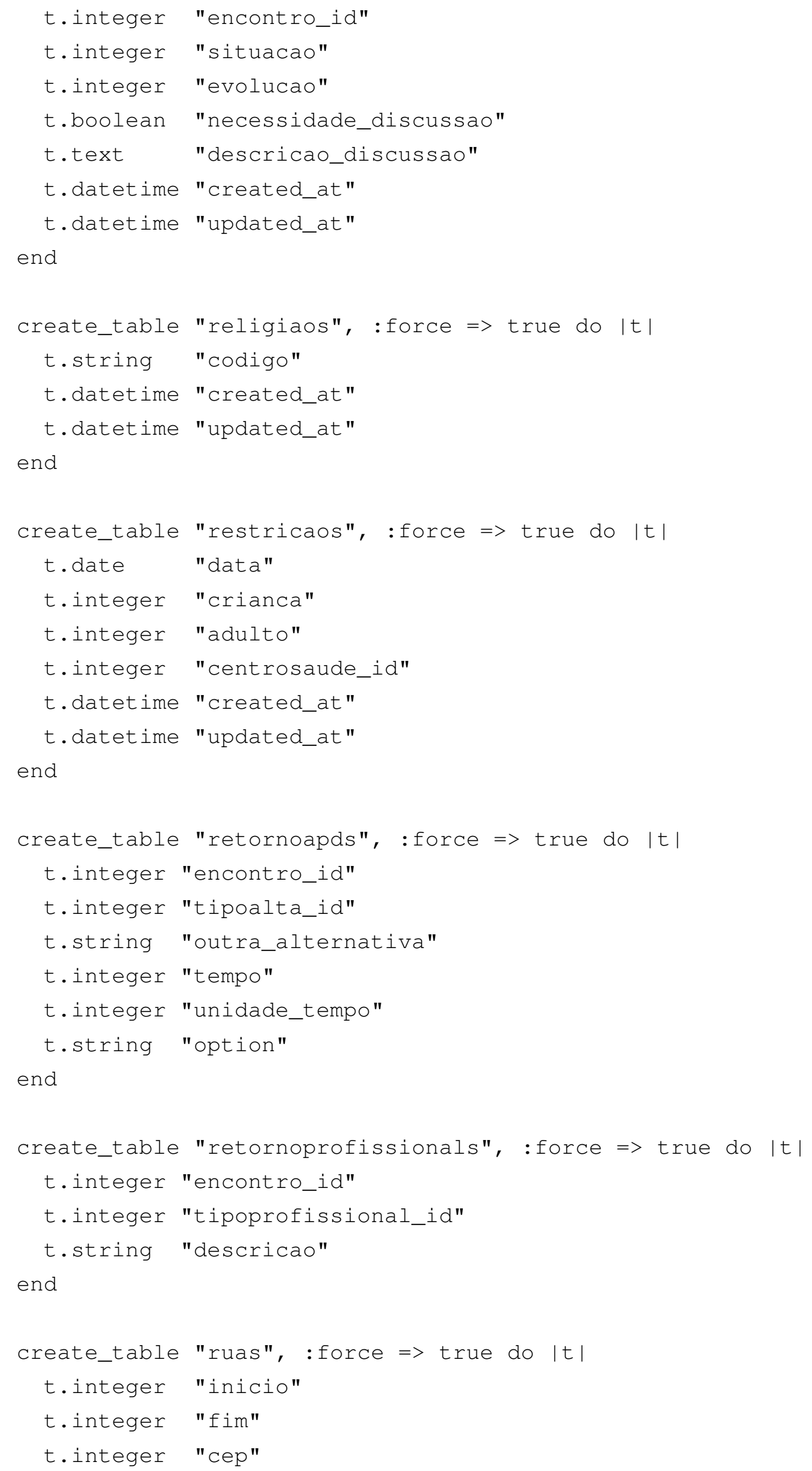




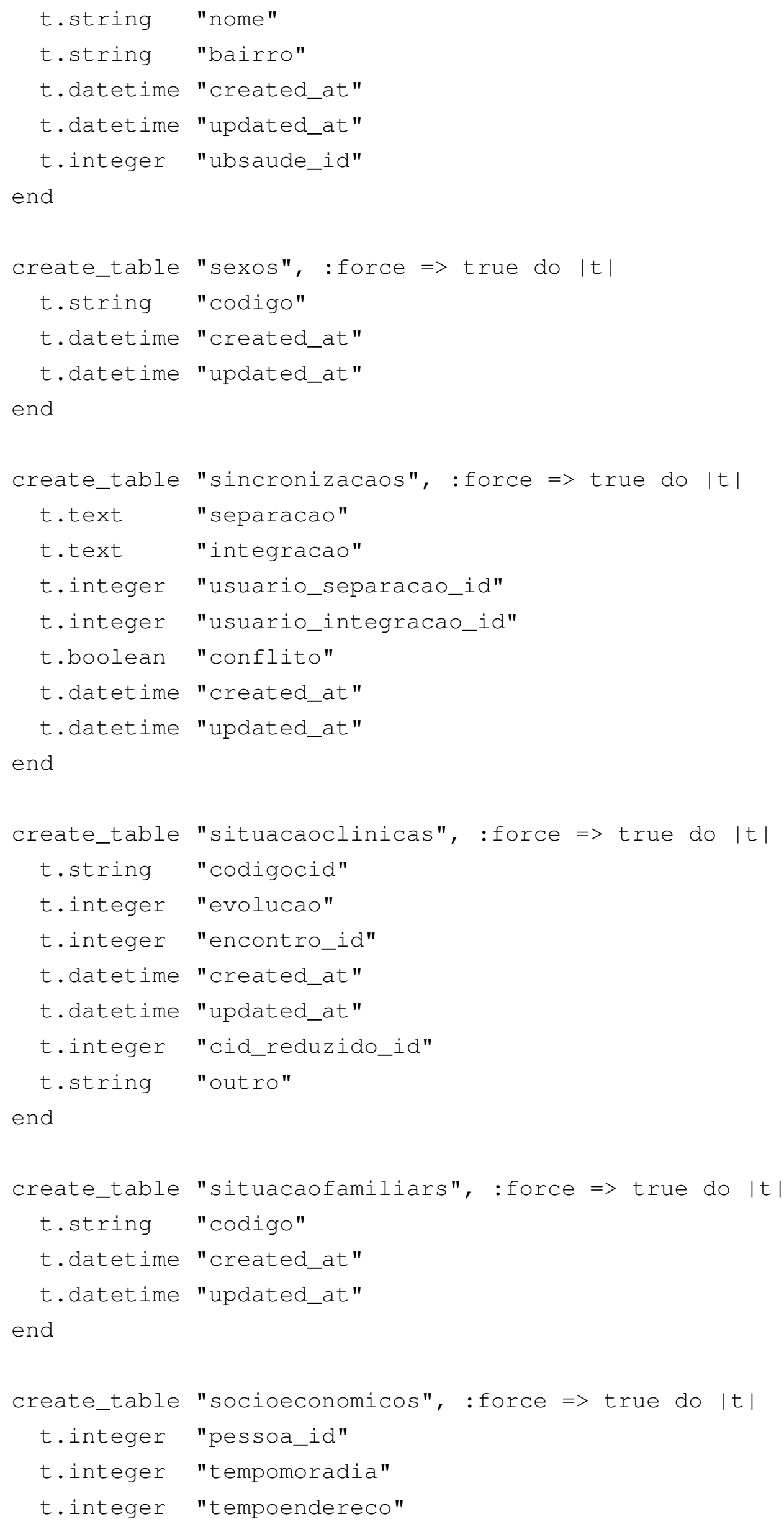




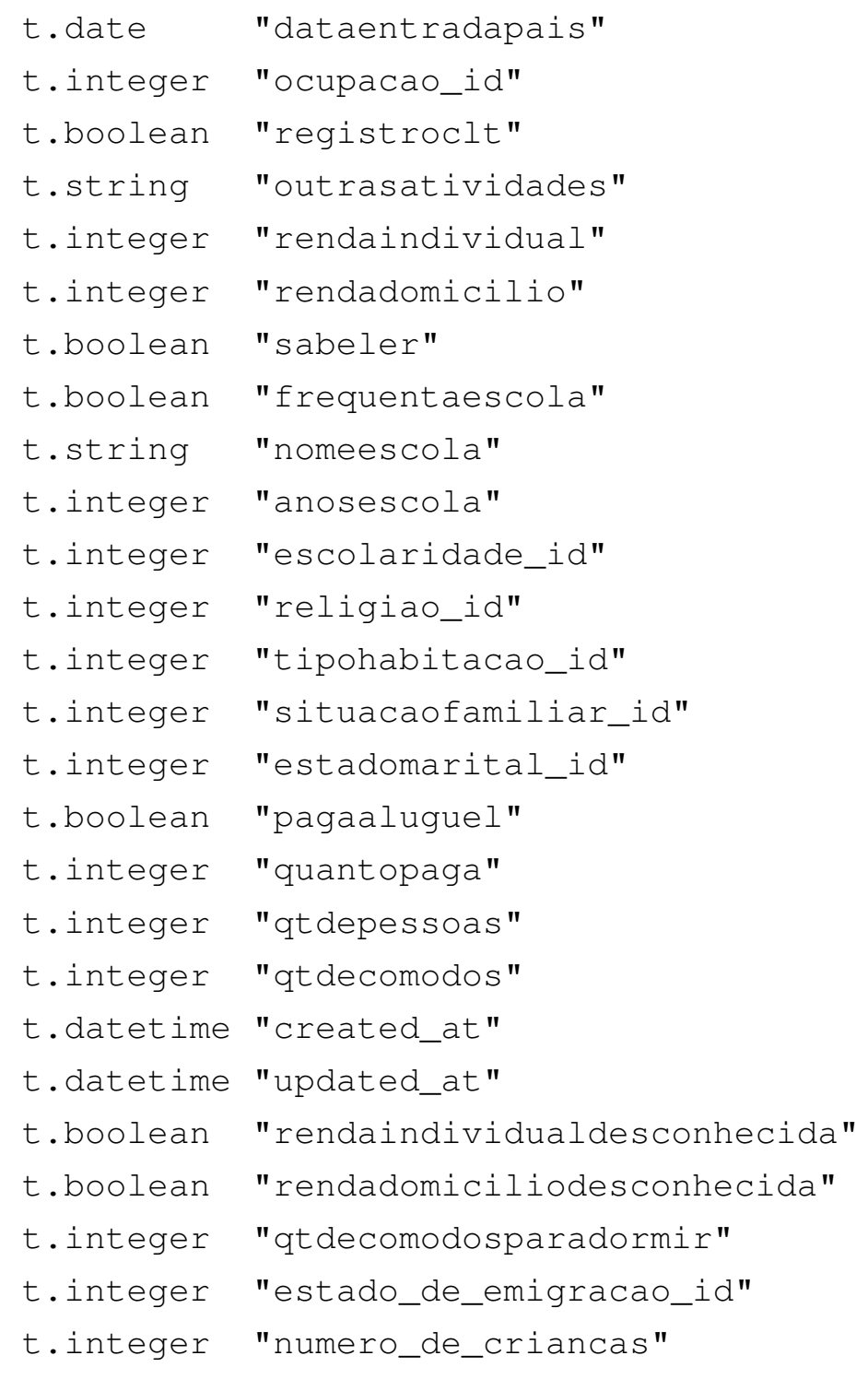
end

create_table "status_agendamentos", :force => true do |t | t.string "descricao" end

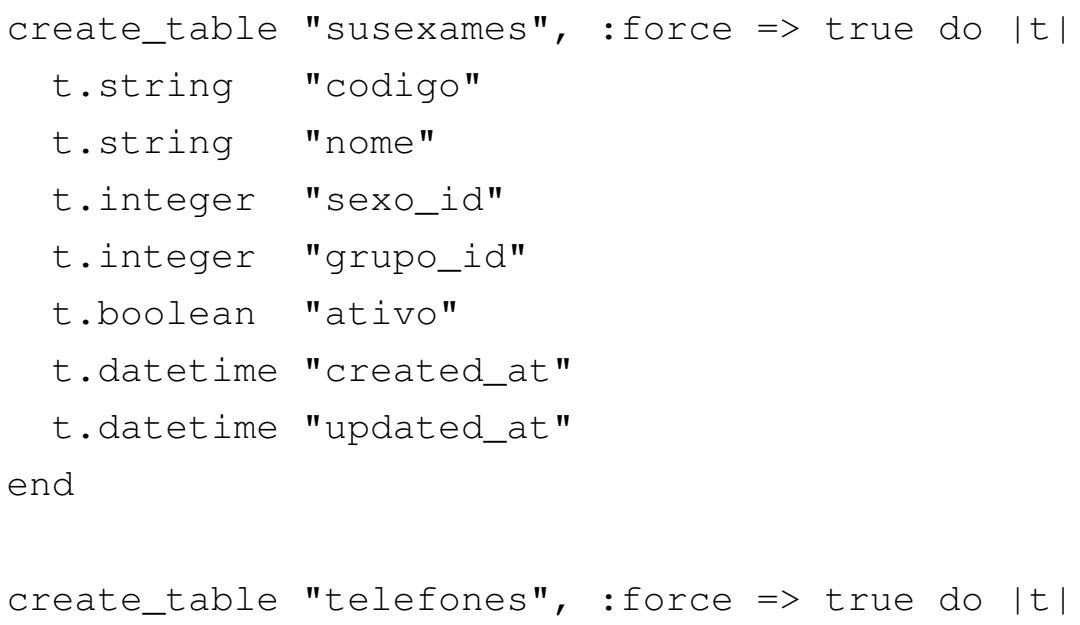




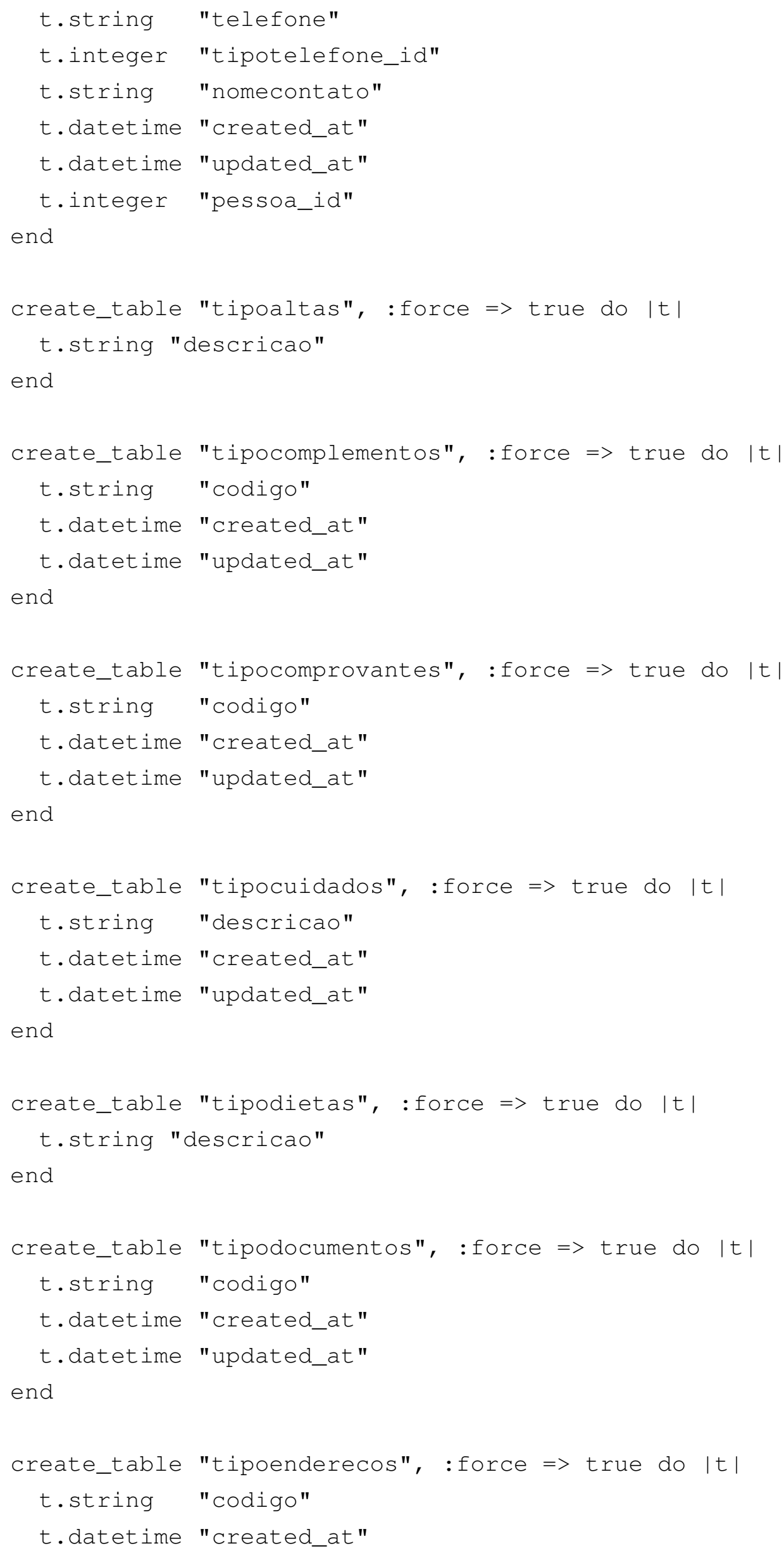




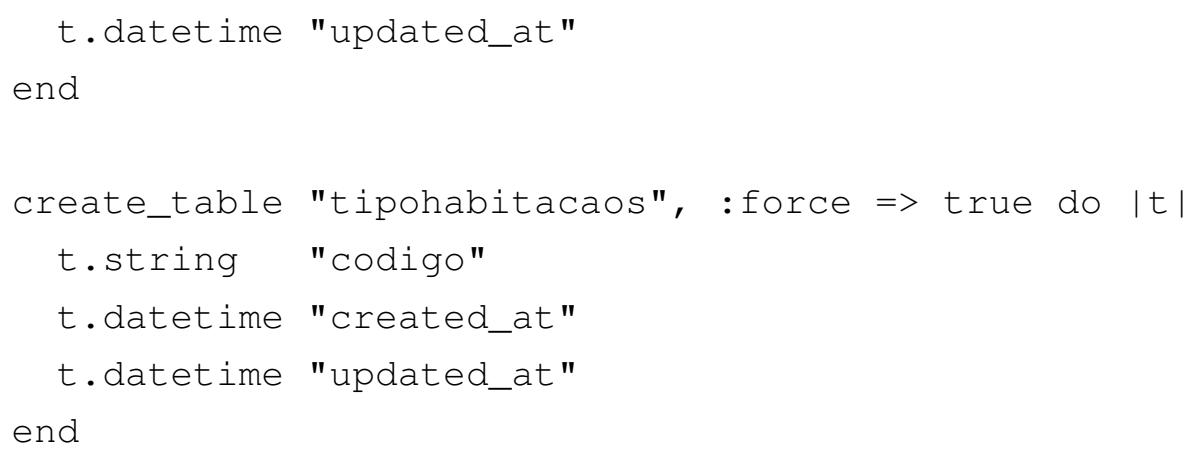




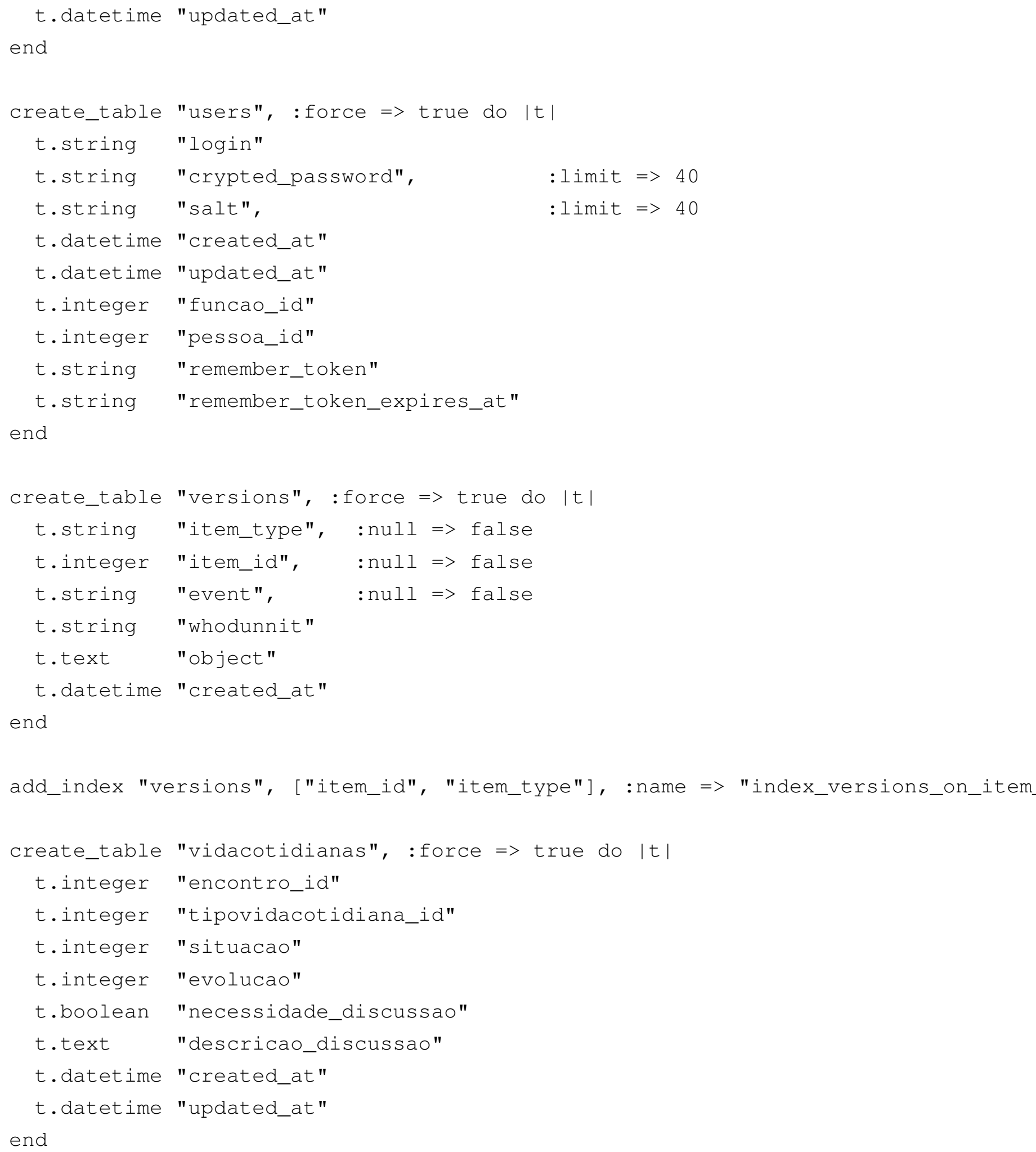


APÊNDICE A 


\section{Apêndice B}

\section{Regras de transformação XSLT}

\section{B.1 Regras de transformação do modelo do SAGUISaúde para o modelo do Borboleta}

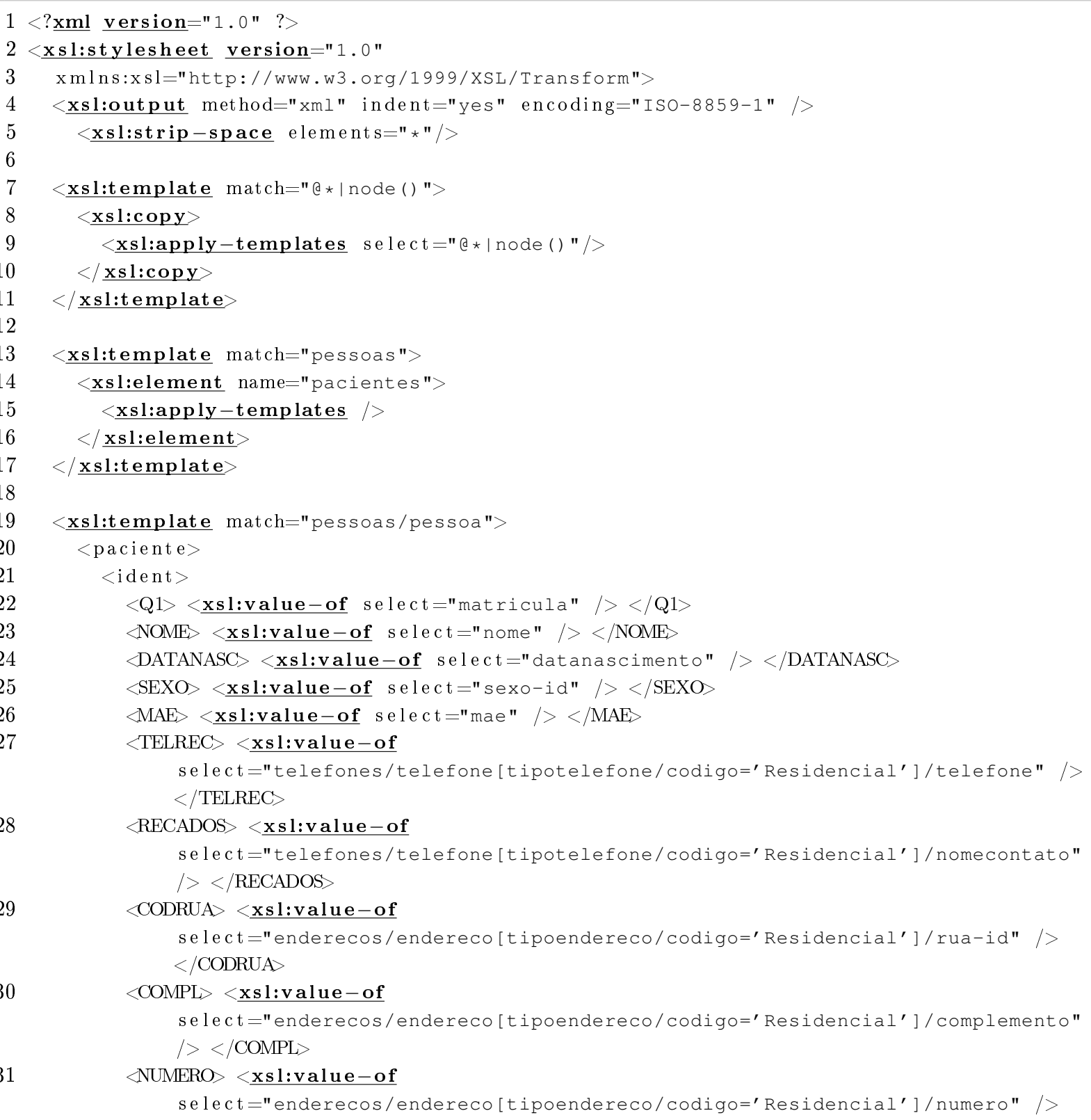


$<$ NUMERO $>$

$<$ DATACONS $>1900-01-01</$ DATACONS $>$

$</$ ident $>$

$<$ cadastro $>$

$<$ MUN_NASC $>$ xsl:value - of select="naturalidadecidade" $/>/$ MUN_NASC $>$

$<$ PAI $<$ xslivalue - of select="pai" $/></$ PAI $>$

$<$ Q1 $>$ xsl:value - of select="matricula" $/></$ Q1 $>$

$\langle$ PAIS $><\underline{\text { xsl:value }- \text { of }}$ select="nacionalidade" $/></$ PAIS $>$

$\langle\mathrm{RG}\rangle\langle\underline{\text { xsl:value }- \text { of }}$

select="documentos/documento [tipodocumento/codigo=' $\mathrm{RG}^{\prime}$ ] / numero" $/ \chi / \mathrm{RG}>$

$<$ ORGAO <xsl:value-of select="documentos/documento/orgaoemissor/nome" $1>$ ORGAO

$\langle$ UFRG $><\underline{\text { xsl:value }- \text { of }}$ select="documentos/documento [tipodocumento/codigo='RG'] / estado/codigo" $1 \times /$ UFRG $>$

$\langle$ DATARG $><\underline{\text { xsl:value }- \text { of }}$ select="documentos/documento [tipodocumento/codigo='RG'] / data-emissao" $1 \times /$ DATARG $>$

$<$ CERTTIPO $\times$ xsl:value - of select="documentos/documento/tipodocumento/codigo" / $</$ CERTTIPO $>$

$<$ DATACERT $>\underline{\text { xsl:value }- \text { of }}$ select="documentos $/$ documento/data-emissao" $1 \times /$ DATACERT $>$

$\langle$ LER $\times \underline{\text { xsl:value }- \text { of }}$ select="socioeconomicos/socioeconomico/sabeler"/ $</$ LER $>$ $\langle$ FREQUENTA $><$ xsl:value-of select="socioeconomicos/socioeconomico/frequentaescola"/ $></$ FREQUENTA $>$ $\langle$ ESCOLA $><\underline{\text { xsl:value }- \text { of }}$ select="socioeconomicos/socioeconomico/escola" / $></$ ESCOLA $>$

$<$ ANOS_ESCOLARIDADE $><\underline{\text { xsl:value }- \text { of }}$ select="socioeconomicos/socioeconomico/anosescola"/ $/$ /ANOS_ESCOLARIDADE $>$ $\langle$ ENTRADA $><\underline{\text { xsl:value }- \text { of }}$ select="socioeconomicos/socioeconomico/dataentradapais" / $</$ ENTRADA $>$ $<$ RENDA $<\underline{\text { xsl:value }- \text { of }}$ select="socioeconomicos/socioeconomico/rendaindividual"/ $></$ RENDA $>$ $\langle$ TEMPO_MORA $><$ xsl:value - of select="socioeconomicos/socioeconomico/tempoendereco"/ $/$ TEMPO_MORA $>$

$<$ TIPOMORADIA $\propto \underline{\text { xsl:value }- \text { of }}$ select="socioeconomicos/socioeconomico/tipohabitacao/codigo"/ $></$ TIPOMORADIA $>$ $<$ OCUP $><\underline{\text { xsl:value }- \text { of }}$ select="socioeconomicos/socioeconomico/ocupacao/codigo"/ $></$ OCUP $<$ RELIGIAO $\times \underline{\text { xsl:value }- \text { of }}$ select="socioeconomicos/socioeconomico/religiao/codigo"/ $></$ RELIGIAO $>$

$<$ DATAAPLI $</$ DATAAPLI $>$

$<$ RGCOMP $><$ RGCOMP $>$

$<$ BRASIL $></$ BRASIL $>$

$</$ cadastro $>$

$<$ cadastroCuidador $>$

$\langle\mathrm{NOME}\rangle\langle\underline{\text { xslivalue }- \text { of }}$ select="cuidador $/$ nome" $/></ \mathrm{NOME}\rangle$

$\langle$ ESCOLARIDADE $><$ xsl:value-of select="cuidador/escola" / $></$ ESCOLARIDADE $>$

$<$ ANOS_ESCOLARIDADE $>$ xslivalue-of select="cuidador/anosescola" / > $<$ ANOS_ESCOLARIDADE $>$

$\langle$ VINCULO $>$ xsl:value - of select="cuidador/vinculo" $/></$ VINCULO $>$

$<$ OCUPACAO> <xl:value-of select="cuidador/ocupacao/codigo"/></OCUPACAO $<$ PERIDODESPENDIDO $><$ xsl:value - of select="cuidador/peridodespendido" $/>$ $</$ PERIDODESPENDIDO $>$

$\langle$ RENDA $><\underline{\text { xsl:value }- \text { of }}$ select="cuidador/rendaindividual" $/></$ RENDA $>$

$<$ DIFICULDADES $><$ xslivalue-of select="cuidador/dificuldades" $/></$ DIFICULDADES $>$ $<$ APOIO $><$ xsl:value - of select="cuidador/apoio"/ $></$ APOIO $>$ 


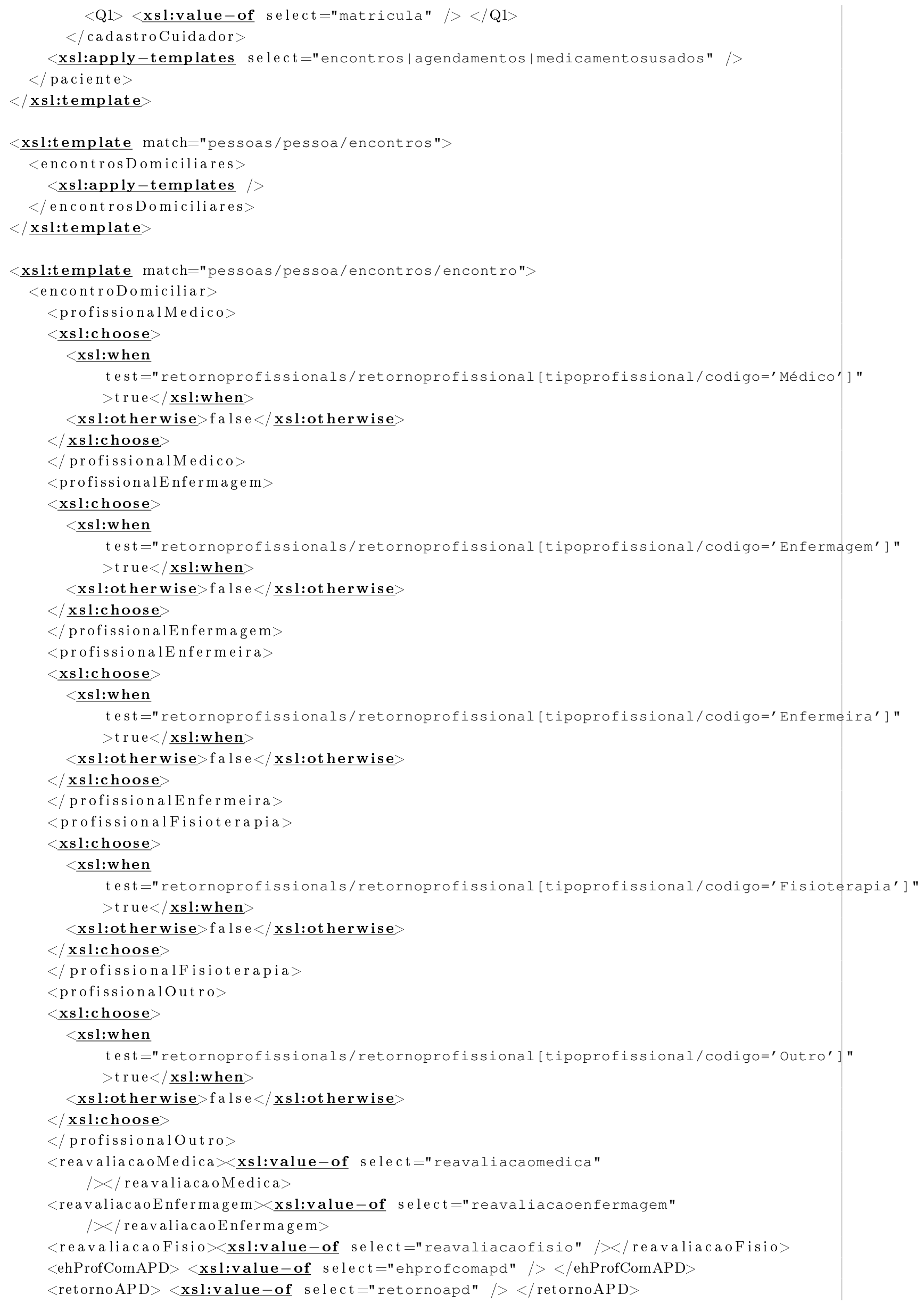




\section{$<$ xsl:apply-templates}

select="data | inicial | rotina |realizada | observacao | motivoencontros | motivoencontro|encontros-a $1>$

$<$ problemasNecessidades $>$

$<$ xsl:apply-templates

select="situacaoclinicas|cuidadosatividades|vidacotidianas" $/>$

$</$ problemasNecessidades $>$

$</$ encontroDomiciliar $>$

$</$ xsl:template $>$

<xsl:template match="pessoas/pessoa/encontros/encontro/motivonaorealizacao"> $<$ motivoNaoRealizacao $>$

$<\underline{\text { xsl:apply-templates } />}$

$</$ motivoNaoRealizacao $>$

$</$ xsl:template $>$

<xsl:template match="pessoas/pessoa/encontros/encontro/descricao-retorno" $>$

$<$ retornoOutro $>$

$$
<\underline{\text { xsl:apply-templates } />}
$$

$</$ retornoOutro $>$

$<$ xsl:template $>$

<xsl:template match="pessoas/pessoa/encontros/encontro/encontros-profissionais" $>$

$<$ profissionais $>$

<xsl:apply-templates $/>$

$</$ profissionais $>$

$</ \underline{\text { xsl:template }}>$

\section{$<\underline{\text { xsl:template }}$}

match="pessoas/pessoa/encontros/encontro/encontros-profissionais/encontros-profissionai"> $<$ profissional $>$

$<$ matricula $><$ xsl:value - of select="matricula" $/>/$ matricula $>$ $<$ nome $><\underline{\text { xsl:value }- \text { of }}$ select $="$ nome" $/></$ nome $>$

$</$ profissional $>$

$<$ xsl:template $>$

$<\underline{\text { xsl:template }}$ match="pessoas/pessoa/encontros/encontro/situacaoclinicas" $>$

$<$ situacaoClinicas $>$

$<\underline{\text { xsl:apply-templates } />}$

$</$ situacaoClinicas $>$

$</$ xsl:template $>$

<xsl:template match="pessoas/pessoa/encontros/encontro/encontros-examefisicos" $>$

$<$ examesFisicos $>$

$<$ xsl:apply-templates $/>$

$</$ examesFisicos $>$

$</ \underline{\text { xsl:template }}>$

$<\underline{\text { xsl:template }}$

match="pessoas/pessoa/encontros/encontro/encontros-examefisicos/encontros-examefisico"> $<$ exameFisico $>$

$<$ id $><$ xsl:value - of select="examefisico-id" $/></$ id $>$

$\langle$ observacao $\rangle$ xsl:value-of select="valor" $\mid></$ observacao $\rangle$

$</$ exameFisico $>$

$</ \underline{\text { xsl:template }}>$

$<\underline{\text { xsl:template }}$

match="pessoas/pessoa/encontros/encontro/encontros-atividadevidadiarias"> 


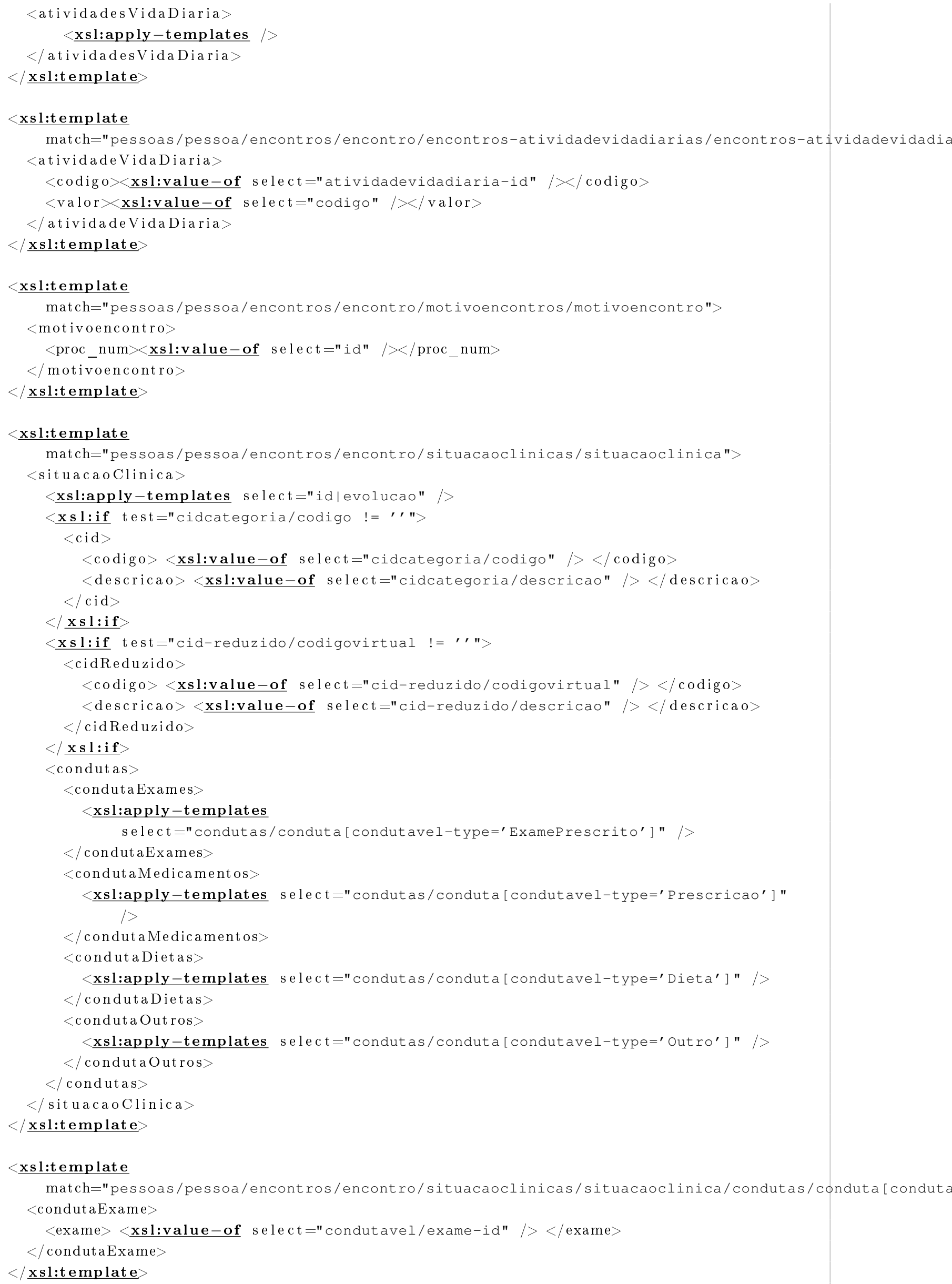


$<\underline{\text { xsl:template }}$

match="pessoas/pessoa/encontros/encontro/situacaoclinicas/situacaoclinica/condutas/conduta [cond $<$ condutaMedicamento $>$

$<$ medicamento $>\quad<$ xslavalue-of select="condutavel/medicamento-id" $/></$ medicamento $>$

$<$ dosagem $>\quad<$ xsl:value-of select="condutavel/qtde-diario" $/></$ dosagem $>$

$</$ condutaMedicamento $>$

$<$ xsl:template $>$

\section{$<\underline{\text { xsl:template }}$}

match="pessoas/pessoa/encontros/encontro/situacaoclinicas/situacaoclinica/condutas/conduta [cond $<$ condutaDieta $>$

$\langle$ dieta $><\underline{\text { xsl:value-of }}$ select="condutavel/tipodieta-id" $/>/$ dieta $>$

$</$ condutaDieta $>$

$<$ xsl:template $>$

$<\underline{\text { xsl:template }}$

match="pessoas/pessoa/encontros/encontro/situacaoclinicas/situacaoclinica/condutas/conduta [cond $<$ condutaOutro $>$

$<$ outro $><$ xsl:value-of select="condutavel/descricao" $/></$ outro $\rangle$

$</$ condutaOutro $>$

$<$ xsl:template $>$

<xsl:template match="pessoas/pessoa/encontros/encontro/vidacotidianas" $>$

$<$ vidaCotidianas $>$

$<$ xsl:apply-templates $/>$

$</$ vidaCotidianas $>$

$<$ xsl:template $>$

<xsl:template match="pessoas/pessoa/encontros/encontro/vidacotidianas/vidacotidiana">

$<$ vidaCotidiana $>$

$<\underline{\text { xslapply-templates }}$ select="id|evolucao|situacao" $/>$

$\langle$ necessidadeDiscussao $><$ xsl:value-of select="necessidade-discussao" $/>$ $</$ necessidadeDiscussao $>$

$\langle$ descricaoDiscussao $><\underline{\text { xsl:value-of }}$ select="descricao-discussao" $/>$ $</$ descricaoDiscussao $>$

$<$ tipoVidaCotidiana $>$

$<$ id $><\underline{\text { xsl:value-of }}$ select="tipovidacotidiana/id" $/></$ id $>$

$\langle$ descricao $><\underline{\text { xsl:value-of }}$ select="tipovidacotidiana/codigo" $/></$ descricao $>$

$</$ tipoVidaCotidiana $>$

$</$ vidaCotidiana $>$

$<$ xsl:template $>$

<xsl:template match="pessoas/pessoa/encontros/encontro/cuidadosatividades">

$<$ cuidadoAtividades $>$

$<\underline{\text { xsl:apply-templates } />}$

$</$ cuidadoAtividades $>$

$<$ xsl:template $\rangle$

\section{$<\underline{\text { xsl:template }}$}

match="pessoas/pessoa/encontros/encontro/cuidadosatividades/cuidadosatividade" $>$ $<$ cuidadoAtividade $>$

$<\underline{\text { xsl:apply-templates }}$ select="id|evolucao" $/>$

$<$ caracterizacao $><\underline{\text { xsl:value-of }}$ select="caracterizacao-id" $/></$ caracterizacao $>$

$<$ necessidadeOrientacao $>$

$<$ xsl:choose $>$

$\langle\underline{\text { xsl:when }}$ test $=$ "orientacao $=0$ " $>$ false $</ \underline{\mathbf{x s l}: \mathbf{w h e n}}>$

$<\underline{\text { xsl:when }}$ test $="$ orientacao $=1 ">\operatorname{true}</ \underline{\text { xsl:when }}>$

$<$ xsl:choose $\rangle$

$</$ necessidadeOrientacao $>$

$\langle$ orientacao $><$ xsl:value-of select="descricao" $/\rangle\langle$ orientacao $\rangle$

$<$ tipoCuidado $>$ 
$<$ xsl:apply-templates select="tipocuidado/id/tipocuidado/descricao"/>

$</$ tipoCuidado $>$

$</$ cuidado Atividade $>$

$<$ xsl:template $>$

$\underline{\text { xsl:stylesheet }}$

Listagem B.1: Regras de transformação do modelo do SAGUISaúde para o modelo do Borboleta

\section{B.2 Regras de transformação do modelo do Borboleta para o mo- delo do SAGUISaúde}

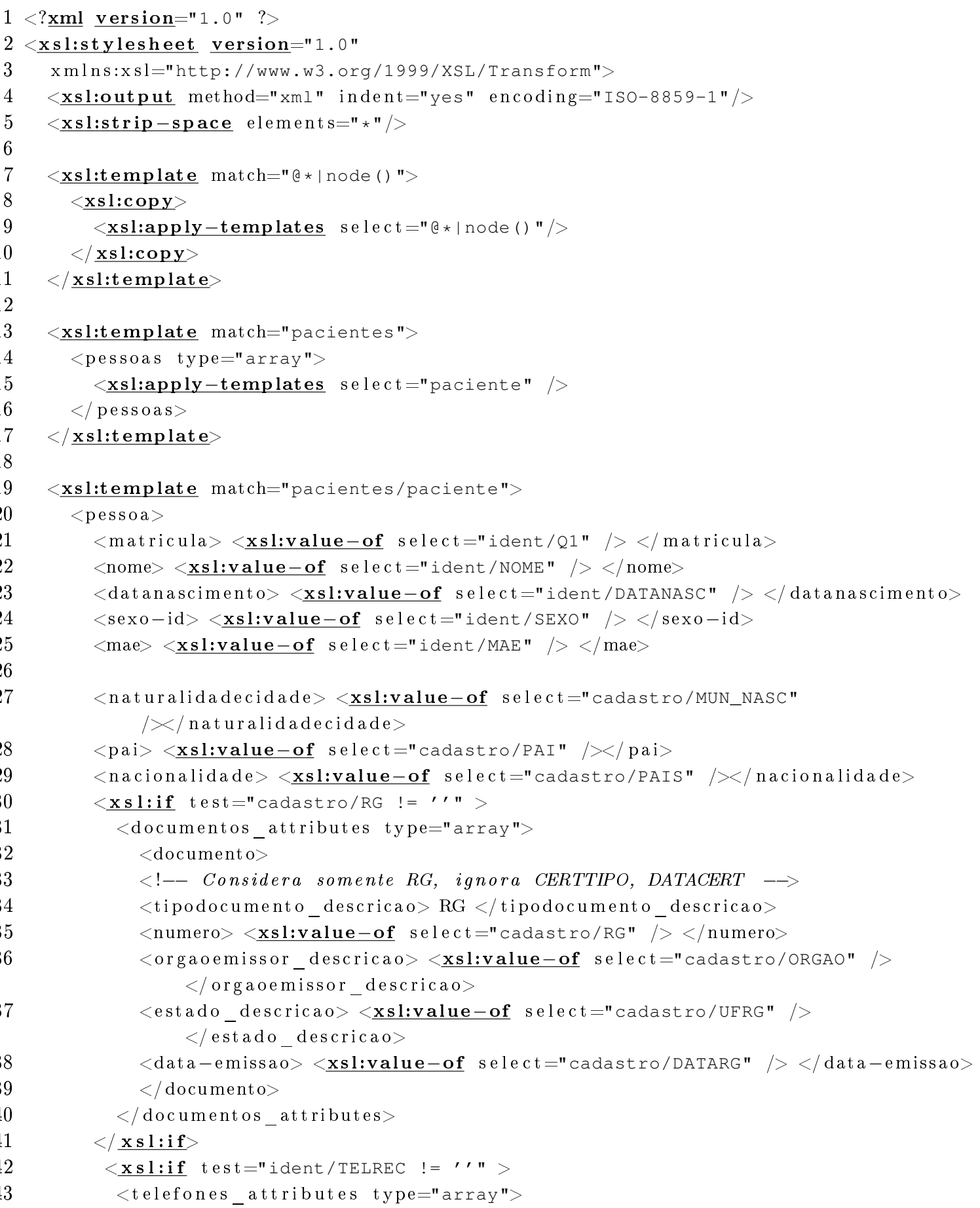




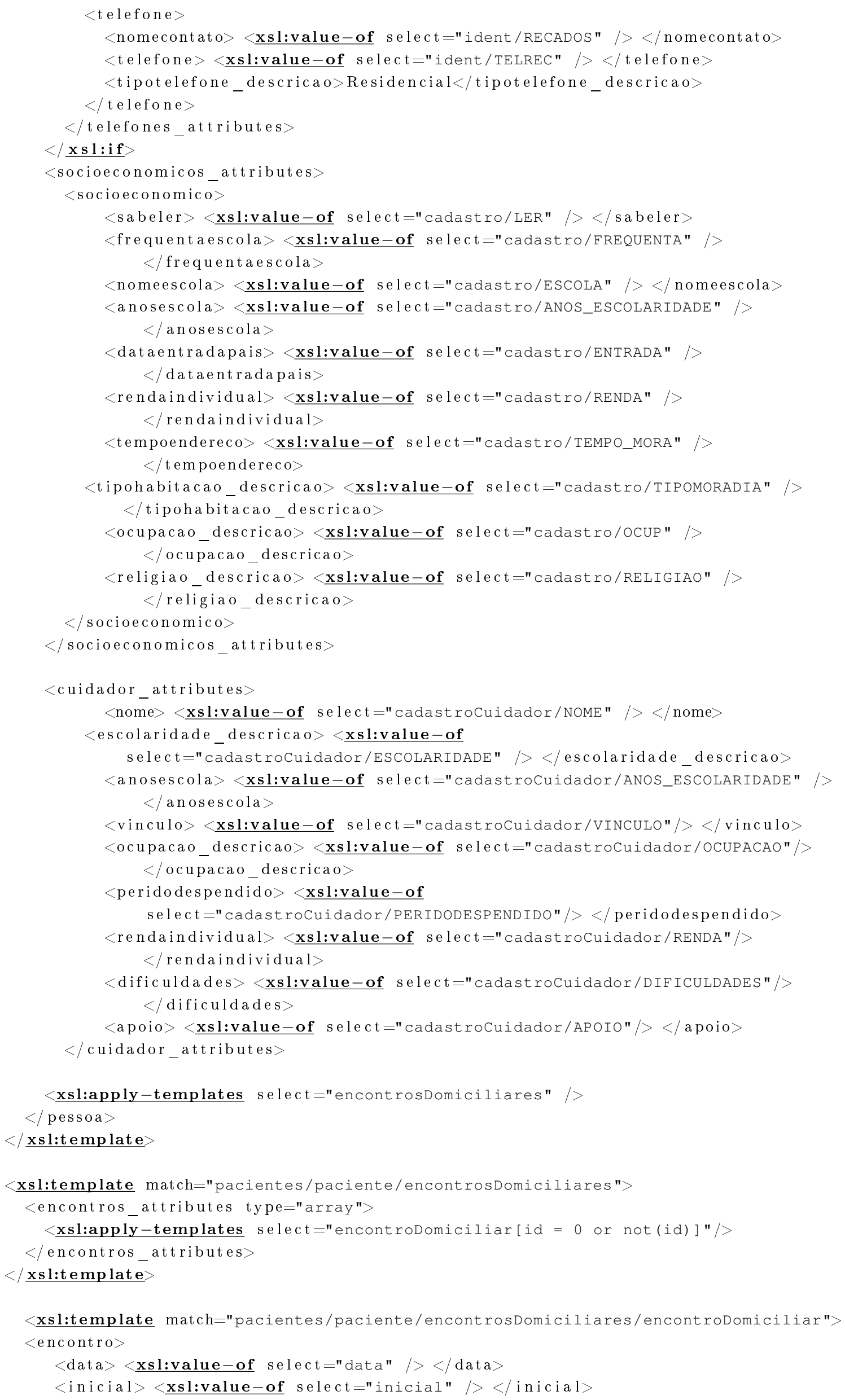




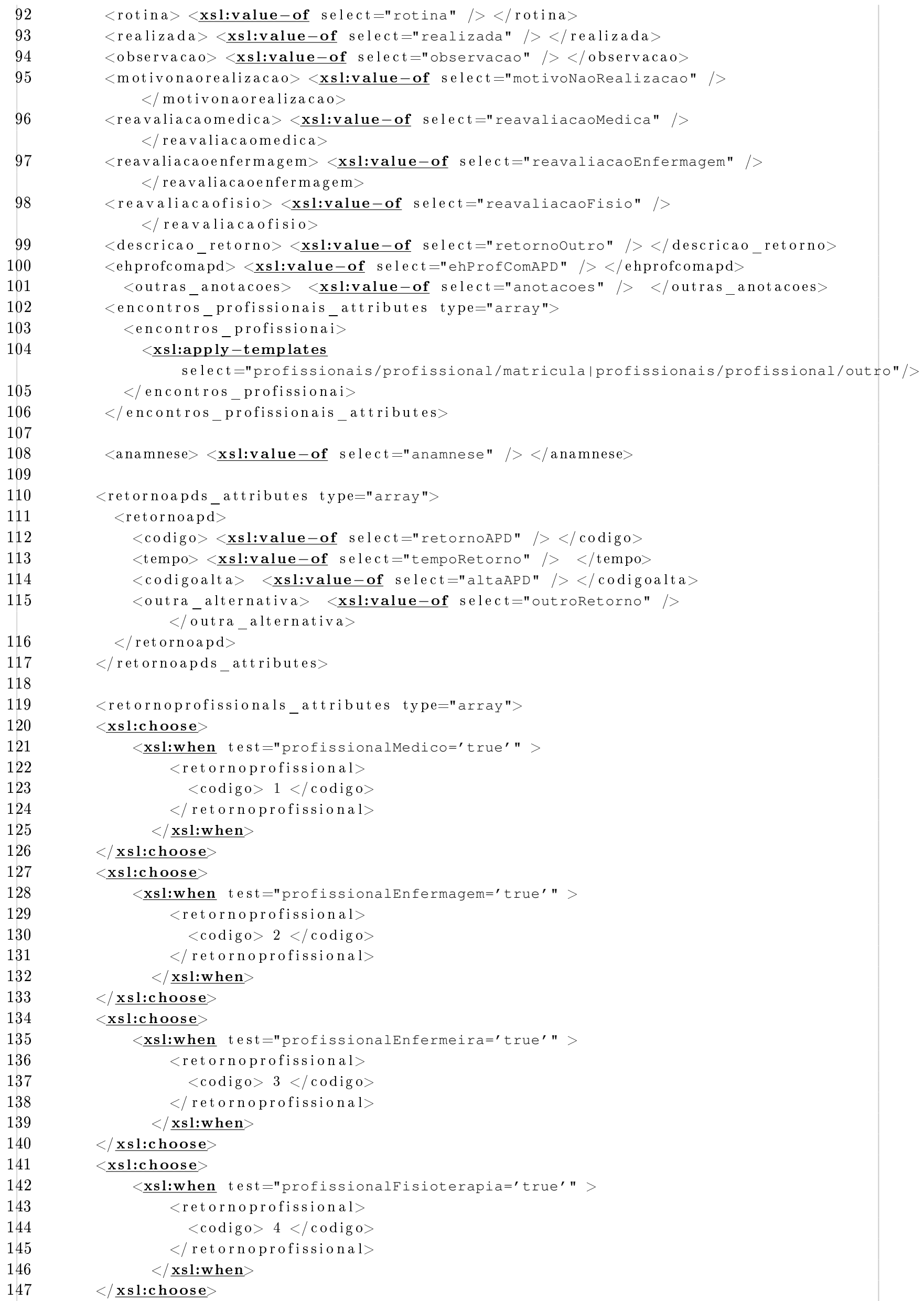


match="pacientes/paciente/encontrosDomiciliares/encontroDomiciliar/motivoencontros/motivoencont $<$ encontros - motivoencontro $>$

$<$ motivoencontro-id $><\underline{\text { xsl:value }- \text { of }}$ select="proc_num" $/ \chi /$ motivoencontro-id $>$

$</$ encontros - motivoencontro $>$

$<$ xsl:template $>$

\section{$<\underline{\text { xsl:template }}$}

match="pacientes/paciente/encontrosDomiciliares/encontroDomiciliar/problemasNecessidades">

$<$ xslapply-templates select="cuidadoAtividades|vidaCotidianas|situacaoclinicas" / >

$</ \underline{\text { xsl:template }}\rangle$

\section{$<\underline{\text { xsl:template }}$}

match="pacientes/paciente/encontrosDomiciliares/encontroDomiciliar/problemasNecessidades/vidaCo $<$ vidacotidianas attributes type="array">

$<$ xsl:apply-templates select="vidaCotidiana" />

$</$ vidacotidianas_attributes $>$

$\langle$ xsl:template $\rangle$

\section{$<\underline{\text { xsl:template }}$}

match="pacientes/paciente/encontrosDomiciliares/encontroDomiciliar/problemasNecessidades/vidaCo $<$ vidacotidiana $>$

$<\underline{\text { xsl:apply-templates }}$ select="evolucao|situacao" $/>$

$\langle$ necessidade - discussa 0$\rangle \underline{\text { xsl:value-of }}$ select="necessidadeDiscussao" $1></$ necessidade - discussao $>$

$\langle$ descricao-discussao $><$ xsl:value-of select="descricaoDiscussao" $1></$ descricao - discussao $>$

$<$ tipovidacotidiana-id $<\underline{\text { xsl:value-of }}$ select="tipoVidaCotidiana/id" $\mid></$ tipovidacotidiana - id $>$

$</$ vidacotidiana $>$

$<$ xsl:template $>$ 
$<\underline{\text { xsl:template }}$

match="pacientes/paciente/encontrosDomiciliares/encontroDomiciliar/problemasNecessidades/situacaoc $<$ situacaoclinicas_attributes type="array" $>$

<xl:apply-templates select="situacaoclinica" $/>$

$</$ situacaoclinicas_attributes $>$

$</ \underline{\text { xsl:template }}>$

\section{xsl:template}

match="pacientes/paciente/encontrosDomiciliares/encontroDomiciliar/problemasNecessidades/situacaoc

$<$ situacaoclinica $>$

<xsl:apply-templates select="evolucaolcondutas" />

$<\underline{\text { xslifif }}$ test="cid/codigo $!=", "><\operatorname{codigo}><\underline{\text { xsl:value}- \text { of }}$ select="cid/codigo" $/>$ $</ \operatorname{codig} 0 \times / \underline{\mathbf{x s} 1: \mathbf{i f}>}$

$<\underline{\text { xsl:if }}$ test="cidReduzido/codigo $!=$ " " " $><$ cidreduzido $><\underline{\text { xsl:value }- \text { of }}$ select="cidReduzido/codigo" / > </cidreduzido $</ \underline{\text { xsl:if }}>$

$</$ situacaoclinica $>$

$<$ xsl:template $>$

\section{$<\underline{\text { xsl:template }}$}

match="pacientes/paciente/encontrosDomiciliares/encontroDomiciliar/problemasNecessidades/situacaoc $<$ condutas_attributes type="array" $>$

$<\underline{\text { xsl:apply-templates }}$ select $=" \star / \star " />$

$</$ condutas_attributes $>$

$</ \underline{\text { xsl:template }}\rangle$

\section{$<\underline{\text { xsl:template }}$}

match="pacientes/paciente/encontrosDomiciliares/encontroDomiciliar/problemasNecessidades/situacaoc $<$ conduta $>$

$<$ exame $>$ xsl:value - of select $=$ "exame" $/><$ exame $>$

$</$ conduta $>$

$</ \underline{\text { xsl:template }}>$

\section{$<\underline{\text { xsl:template }}$}

match="pacientes/paciente/encontrosDomiciliares/encontroDomiciliar/problemasNecessidades/situacaoc $<$ conduta $>$

$<$ prescricao $><$ xsl:value - of select="medicamento" $/></$ prescricao $>$

$<$ prescricao $><\underline{\text { xsl:value }- \text { of }}$ select="dosagem" $/></$ prescricao $>$

$</$ conduta $>$

$</ \underline{x s l: t e m p l a t e}\rangle$

$<\underline{\text { xsl:template }}$

match="pacientes/paciente/encontrosDomiciliares/encontroDomiciliar/problemasNecessidades/situacaoc $<$ conduta $>$

$\langle$ dieta $><$ xsl:value-of select="dieta" $/></$ diet $>$

$</$ conduta $>$

$<$ xsl:template $>$

\section{<xsl:template}

match="pacientes/paciente/encontrosDomiciliares/encontroDomiciliar/problemasNecessidades/situacaoc $<$ conduta $>$

$<$ outro $><\underline{\text { xsl:value }- \text { of }}$ select="outros" $/ \propto /$ outro $>$

$</$ conduta $>$

$</ \underline{\text { xsl:template }}>$

\section{<xsl:template}

match="pacientes/paciente/encontrosDomiciliares/encontroDomiciliar/problemasNecessidades/cuidadoAt $<$ cuidadosatividades_attributes type="array" $>$

$<\underline{\text { xsl:apply-templates }}$ select="cuidadoAtividade" $/>$

$</$ cuidadosatividades_attributes $>$

$</ \underline{\text { xsl:template }}>$ 
$292</ \underline{\text { xsl:stylesheet }}>$

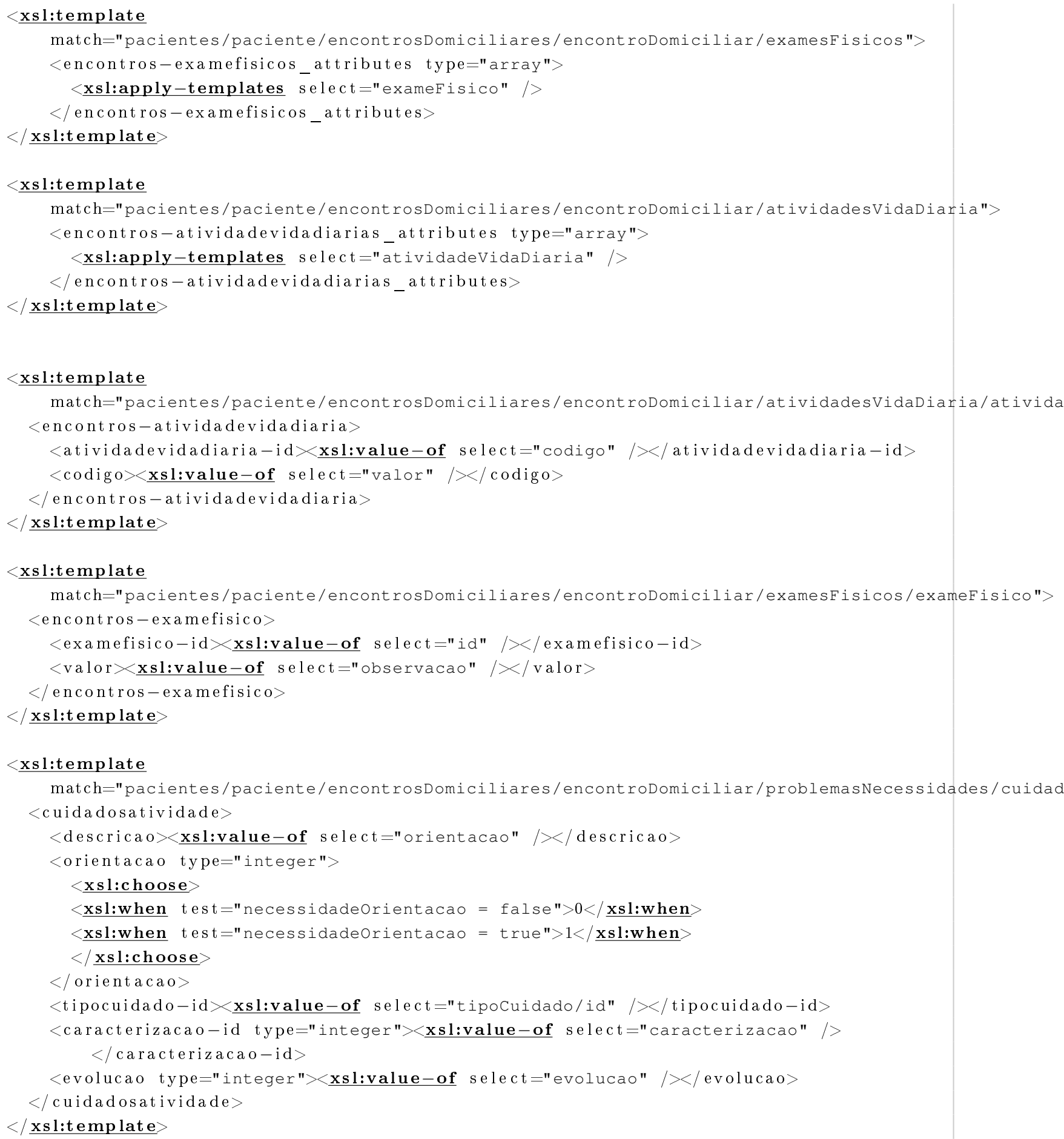

\section{$<\underline{\text { xsl:template }}$}

match="pacientes/paciente/encontrosDomiciliares/encontroDomiciliar/atividadesVidaDiaria"> $<$ encontros - atividadevidadiarias_attributes type="array">

Listagem B.2: Regras de transformação do modelo do Borboleta para o modelo do SAGUISaúde 


\section{Referências Bibliográficas}

[ACK93] Yigal Arens, Chin Y. Chee, e Craig A. Knoblock. Retrieving and integrating data from multiple information sources. International Journal of Intelligent and Cooperative Information Systems, páginas 127-158, 1993. 15

[AT89] A.E. Abbadi e S. Toueg. Maintaining availability in partitioned replicated databases. ACM Transactions on Database Systems (TODS), 14(2):264-290, 1989. 16

[BANA06] L. C. Bastos, J. H. M. Almeida, K. A. Neves, e V. F. Amaral. PEGO: Prontuário eletrônico de ginecologia e obstetrícia. Em Congresso Brasileiro de Informática em Saúde, páginas 1412-1416, 2006. 1

$\left[\mathrm{BBG}^{+} 95\right]$ H. Berenson, P. Bernstein, J. Gray, J. Melton, E. O’Neil, e P. O’Neil. A critique of ansi sql isolation levels. ACM SIGMOD Record, 24(2):1-10, 1995. 16

[Bee98] George W. Beeler. HL 7 Version 3 - An object-oriented methodology for collaborative standards development. International Journal of Medical Informatics, 48(1):151-161, 1998. 36

[BEG $\left.{ }^{+} 03\right]$ David W. Bates, Mark Ebell, Edward Gotlieb, John Zapp, e H.C. Mullins. A proposal for electronic medical records in U.S. primary care. Journal of the American Medical Informatics Association, 10(1):1-10, Jan 2003. 29

[BH07] Thomas Beale e Sam. Heard. An ontology-based model of clinical information. Medinfo 200\%: Proceedings of the 12th World Congress on Health (Medical) Informatics, páginas 760-764, 2007. 36

[BL07] Gorka Benguria e Xabier Larrucea. Data model transformation for supporting interoperability. International IEEE Conference on Commercial-off-the-Shelf-Based Software Systems, páginas 172-181, fevereiro 2007. 14, 15, 17

[BN09] P.A. Bernstein e E. Newcomer. Principles of transaction processing. Morgan Kaufmann, 2009. 10

[Che06] Nicholas Chen. Convention over configuration. http://softwareengineering.vazexqi.com/ files/pattern.html, 2006. (Acesso em 23 jan. 2012). 24

[CKK08] Rafael Correia, Fabio Kon, e Rubens Kon. Borboleta: A mobile telehealth system for primary homecare. Em 23rd Annual ACM Symposium on Applied Computing, páginas 1343-1347, Mar 16-20 2008. 30

[Cla99] James Clark. XSL transformations (XSLT) version 1.0. Relatório técnico, W3C, 1999. 39

[Cor11] Rafael José Peres Correia. Borboleta: Um sistema de telessaúde para auxílio à atenção primária domiciliar. Dissertação de Mestrado, Universidade de São Paulo, 2011. 32 
$\left[\mathrm{DCK}^{+} 08\right]$ Helves Domingues, Rafael José Peres Correia, Fabio Kon, João Eduardo Ferreira, e Rubens Kon. Análise e modelagem conceitual de um sistema de prontuário eletrônico para centros de saúde. Em XXVIII Congresso da SBC - WIM - Workshop de Informática Médica, páginas 31-40, Julho 12-18 2008. 29

[DPS $\left.{ }^{+} 94\right]$ A. Demers, K. Petersen, M. Spreitzer, D. Terry, M. Theimer, e B. Welch. The Bayou architecture: support for data sharing among mobile users. Em Workshop on Mobile Computing Systems and Applications, páginas 2-7, 1994. 10

[FF00] João Eduardo Ferreira e Marcelo Finger. Controle de concorrência e distribuição de dados: a teoria clássica, suas limitações e extensões modernas. XII Escola de Computação, páginas 73-83, Julio 2000. 9, 14

[Fie00] Roy Thomas Fielding. Architectural Styles and the Design of Network-based Software Architectures. Tese de Doutorado, University of California, 2000. 38

[Gif79] D.K. Gifford. Weighted voting for replicated data. Em Proceedings of the seventh ACM symposium on Operating systems principles, páginas 150-162. ACM, 1979. 15

[Her86] M. Herlihy. A quorum-consensus replication method for abstract data types. ACM Transactions on Computer Systems (TOCS), 4(1):32-53, 1986. 16

[KS95] Puneet Kumar e Mahadev Satyanarayanan. Flexible and safe resolution of file conflicts. Em Proceedings of the USENIX 1995 Technical Conference, páginas 95-106, 1995. 14

[LBMS06] David Lomet, Roger Barga, Mohamed F. Mokbel, e German Shegalov. Transaction time support inside a database engine. Proceedings of the 22nd International Conference on Data Engineering, páginas 35-46, 2006. 12

$\left[\mathrm{MKT}^{+} 04\right]$ Alexandre Murakami, Luiz O M Kobayashi, Umberto Tachinardi, Marco A Gutierrez, Sérgio S. Furuie, e Fábio Antero Pires. Acesso a informações médicas através do uso de sistemas de computação móvel. Em Congresso Brasileiro de Informática em Saúde, páginas $1-6,2004.1,17$

[Pâr86] J.F. Pâris. Voting with witnesses: A consistency scheme for replicated files. Em Proceedings of the 6th International Conference on Distributed Computing Systems, páginas 606-612, 1986. 16

[PB99] S.H. Phatak e BR Badrinath. Multiversion reconciliation for mobile databases. Em $i c d e$, página 582. Published by the IEEE Computer Society, 1999. 16

[Raj07] Ravi Rajamani. Oracle total recall/flashback data archive. An Oracle White Paper, Junho 2007. 12

[Sat02] M. Satyanarayanan. The evolution of coda. ACM Transactions on Computer Systems (TOCS), 20(2):85-124, 2002. 16

[SKS06] A. Silberschatz, H.F. Korth, e S. Sudarshan. Sistema de banco de dados. $5^{a}$ Edição, 2006. 9

[SL90] Amit P. Sheth e James A. Larson. Federated database systems for managing distributed, heterogeneous, and autonomous databases. ACM Computing Surveys, 22(3):183-236, 1990. 17

[SS05] Yasushi Saito e Marc Shapiro. Optimistic replication. ACM Computing Surveys, 37(1):42-81, 2005. 9, 10, 14, 35

[Suj01] W Sujansky. Heterogeneous database integration in biomedicine. Journal of Biomedical Informatics, 34(4):285-298, agosto 2001. 14, 17 
[TFB97] C. Traina, J. E. Ferreira, e M. Biajiz. Use of a semantically grained database system for distribution and control within design environments. Euro-Par'97 Parallel Processing, páginas 1130-1134, 1997. 10, 36 